University of Louisville

ThinkIR: The University of Louisville's Institutional Repository

\title{
Help-seeking behaviors of South African women after sexual offence victimization : the lived experience.
}

Sheila Young Steinbrenner

University of Louisville

Follow this and additional works at: https://ir.library.louisville.edu/etd

Part of the Nursing Commons

\section{Recommended Citation}

Steinbrenner, Sheila Young, "Help-seeking behaviors of South African women after sexual offence victimization : the lived experience." (2014). Electronic Theses and Dissertations. Paper 1378.

https://doi.org/10.18297/etd/1378

This Doctoral Dissertation is brought to you for free and open access by ThinkIR: The University of Louisville's Institutional Repository. It has been accepted for inclusion in Electronic Theses and Dissertations by an authorized administrator of ThinkIR: The University of Louisville's Institutional Repository. This title appears here courtesy of the author, who has retained all other copyrights. For more information, please contact thinkir@louisville.edu. 
HELP-SEEKING BEHAVIORS OF SOUTH AFRICAN WOMEN AFTER SEXUAL OFFENCE VICTIMIZATION: THE LIVED EXPERIENCE

\author{
By \\ Sheila Young Steinbrenner \\ B.S.N., University of Louisville 2007

\begin{abstract}
A Dissertation
Submitted to the Faculty of the

School of Nursing of the University of Louisville

in Partial Fulfillment of the Requirements

for the Degree of
\end{abstract} \\ Doctor of Philosophy \\ School of Nursing \\ University of Louisville \\ Louisville, Kentucky
}

August 2014 
(C) Copyright 2014 by Sheila Young Steinbrenner

All rights reserved 

HELP-SEEKING BEHAVIORS OF SOUTH AFRICAN WOMEN AFTER SEXUAL OFFENCE VICTIMIZATION: THE LIVED EXPERIENCE

\author{
By \\ Sheila Young Steinbrenner \\ B.S.N., University of Louisville, 2014
}

A Dissertation Approved on

May 28, 2014

by the following Dissertation Committee:

Celeste Shawler, PhD, PMHCNS-BC

Dissertation Director

Vicki Hines Martin, PhD, CNS, RN, FAAN

Sandra Ferreira, MSW, PhD

Whitney Nash, PhD, MSN, ANP-BC 


\section{DEDICATION}

This dissertation is dedicated to my father James Randall Young and my mother Sarah Anita Young. I miss you both every day. Thank you for giving me life and allowing me to live it as I chose. To my brothers Tony and Randall, I am one very lucky sister. To my sister Teresa, I miss your brilliant mind. To my wonderful daughter Sarah, I know it hasn't been easy, but thank you. 


\section{ACKNOWLEDGEMENTS}

I want to first thank the women who participated in my study. I continue to be so thankful to have had the privilege to meet each of you, and I remain humbled in the trust you had in me, my work, and the willingness to share your experiences.

I want to next thank my dissertation chair, Dr. Celeste Shawler. With your excellent mentoring I have accomplished a long time goal. I appreciate your encouragement and support so much. I can never thank you enough for your kindness and caring concern as my journey took me through an extremely difficult period in my life. You respected my need to take time out to care for my father during his illness and you were right there ready to get me back on track after his death. I will always hold the greatest appreciation for all you have done for me. Thank you so much Celeste.

I want to next thank Dr. Sandra Ferreira. Who would have ever thought a cognate course and a beautiful necklace would lead to this. I doubt I will ever be able to fully express my appreciation for everything you have done for me over past four years, but I will continue to try. From the summer of interviews in the library over berries and juice, opening your home to me, being there for me as I worked through the many complexities of conducting research in a country and culture not of my own, challenging me to question so many things, the wonderful discussions over a glass or two of St. Anna's, and being there for me when I fell down and helping me get right back up again. Thank you so much Sandra. 
I want to thank the other members of my committee, Dr. Vicki Hines-Martin and Dr. Whitney Nash. You both brought unique and extremely important knowledge and perspective to my work. Your kindness and support will always be so greatly appreciated. Thank you Vicki and Whitney.

I want to thank Stephanie Pretorius for her deep concern regarding my work, and insisting on doing all that she could to make sure it came to fruition. Your kind heart, your intelligence, your insight, and your willingness to fight the system will always be a very strong force as you continue your important work. Thank you Stephanie. As I thank Stephanie, I must also thank the Serobe Crisis Centre Board of Directors for contributing their support, trusting I would do what I sat out to accomplish. Thank you all so much.

I want to thank Dr. Adri Krieger for being so kind with her time, and sharing her insight and knowledge. And, thanks to Dr. Marianne Marais-Kotze for her time and knowledge. The passion you both have for your work is inspiring. Thank you Dr. Adri and Dr. Marianne. I want to extend a thank you to all the others in South Africa who have been so gracious with their time and so open to share all they could to help make sure this research was conducted.

Last, I want to thank Lisa Carter-Harris, Heather Hardin, Glenda Adams, and XiaoRong Wang. You each hold a very special place in my heart. I don't know what I would do without my sisters. Your friendship, support, encouragement, and love during this challenging process of doctoral studies has meant the world to me. 


\title{
ABSTRACT \\ HELP-SEEKING BEHAVIORS OF SOUTH AFRICAN WOMEN AFTER SEXUAL OFFENCE VICTIMIZATION: THE LIVED EXPERIENCE
}

\author{
Sheila Young Steinbrenner
}

May 28, 2014

There is little known about South African women's help-seeking behavior after sexual offence victimization. South Africa is estimated to have the highest rate of rape and sexual assault globally. However, only one in six women seek health services post victimization. The importance of medical and mental health care following victimization has been clearly established. Therefore understanding more about South African women's help-seeking after victimization is profoundly important.

The purpose of this study was to explore the lived experience of help-seeking behaviors of South African women after sexual offence victimization. Hermeneutic phenomenology as applied by van Manen provided the philosophical underpinnings, and van Manen's methodological approach to conducting hermeneutic phenomenology was used. The theoretical framework for the study was Bronfenbrenner's ecological systems theory. Eleven semi-structured interviews with six participants were conducted. Data sources also included two books and a manuscript. Thematic data analysis was done according to van Manen. Analysis also included the four existentials of lived space, lived body, lived time and lived other. 
Four essential themes emerged: decision making, silence, critical junctures in mental health, and moving forward. Decision making is influenced by the perceived severity of the violence, sociocultural expectations, and, perceptions of and experiences with service providers. Silence is an accepted and often expected reaction to rape, and is described as never talking about sexual offence victimization. Silence may be in the form of a secret. Shame, self-blame, and cultural norms compel silence. Critical junctures in mental health are described as women's experiences of psychological distress at any point in time after sexual offence victimization. These junctures may lead to worsening psychological distress or become a catalyst for seeking help. Moving forward is described as a woman's experiences after victimization as she moves toward and into healing. It is imperative for service providers to treat victims of sexual offences with respect and dignity. All services including medical care, mental health counseling, social services, as well as police services, must be available to assure the best outcomes. However, mental health services are considered most helpful in moving forward into healing after sexual offence victimization. 


\section{TABLE OF CONTENTS}

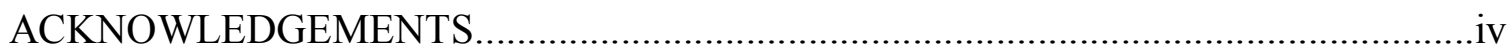

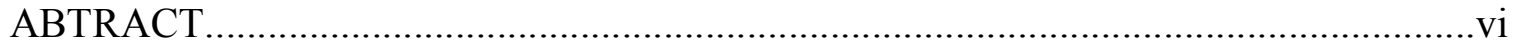

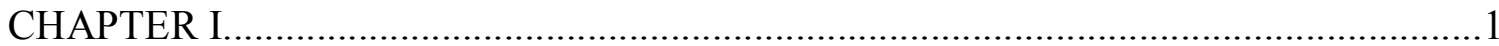

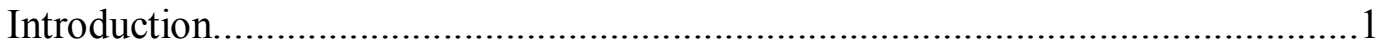

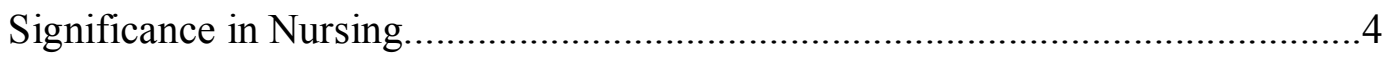

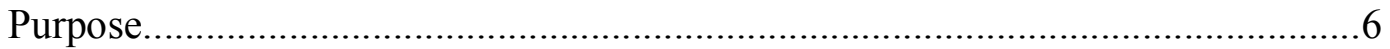

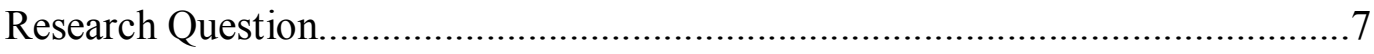

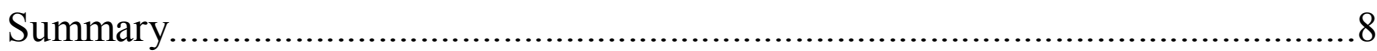

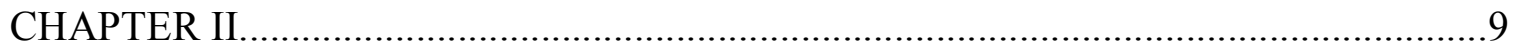

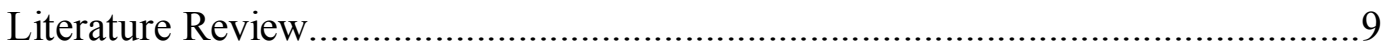

Sexual Offences in South Africa...........................................................9

South African Women Help-Seeking after a Sexual Offense Victimization

Care Systems for Victims of Sexual Offences...................................................17

Medical Services for Victims of Sexual Offences..................................18

Social Services within Thuthuzela Care Centres....................................21

Social Services and Nongovernmental Organizations............................21

Nongovernmental Organizations...........................................22

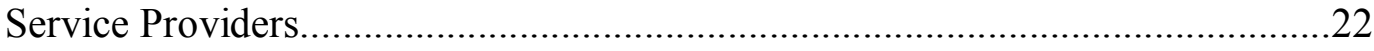

South African Police Service.............................................................23

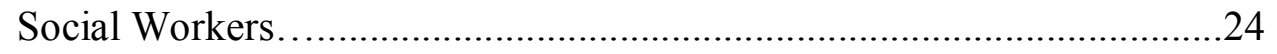

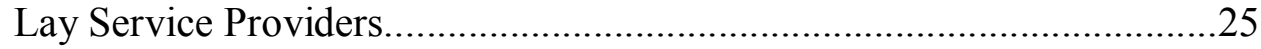

Nurses......................................................................................26

Bronfenbrenner's Ecological Systems Theory................................................30

Bronfenbrenner's Ecological Systems Theory and Hermeneutic Phenomenology

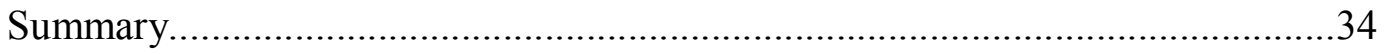

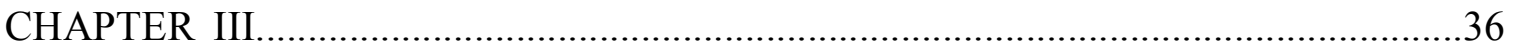


Method

Hermeneutic Phenomenology as an Approach to Human Science Research

Overview of the Philosophy of Hermeneutics........................................37

Overview of the Philosophy of Phenomenology.....................................39

The Research Methodology of Phenomenology......................................4

Hermeneutic Phenomenology as Applied by van Manen..........................4 4

Van Manen's Six Research Activities Guiding Hermeneutic

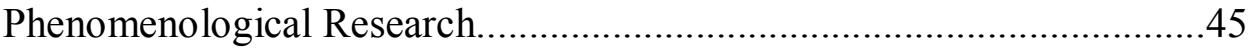

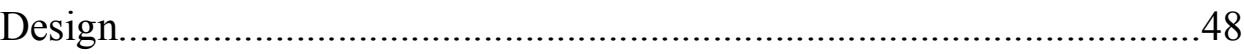

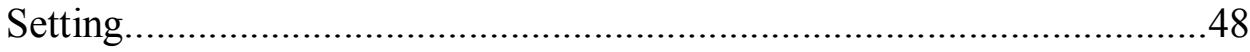

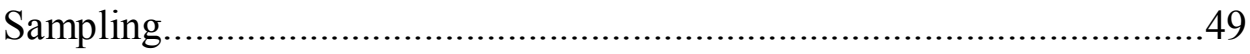

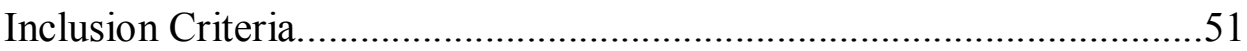

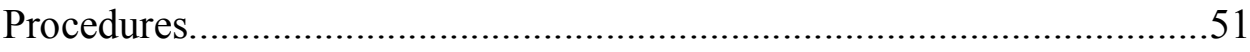

Recruitment Procedures........................................................51

Data Collection Procedures..........................................................53

Human Subjects Protection Procedures.......................................54

Ethical Treatment of Human Subjects..................................................55

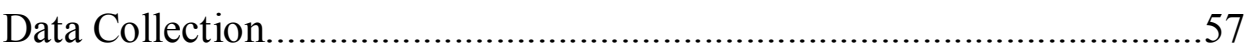

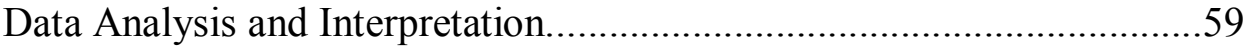

Trustworthiness.........................................................................60

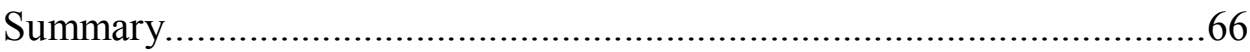

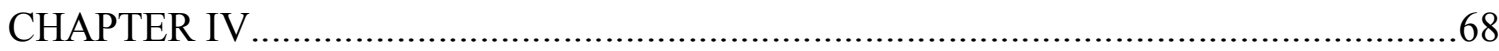

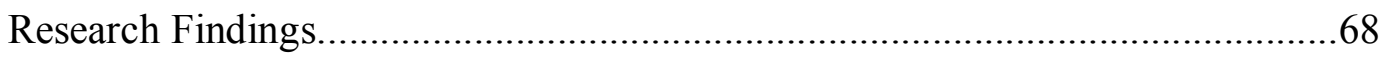

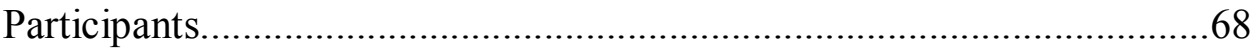

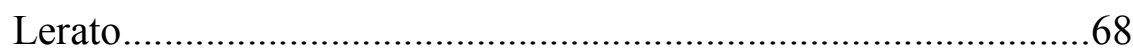

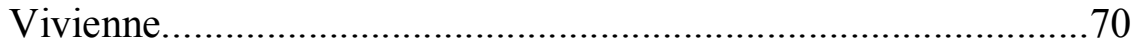

Bontle............................................................................... 71

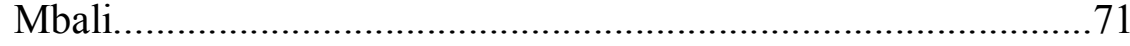

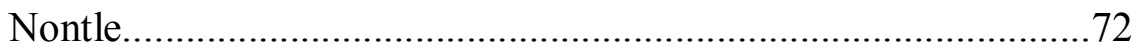

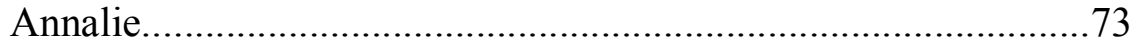

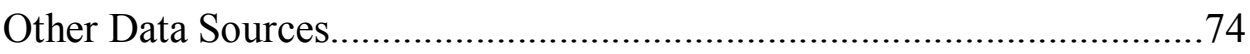

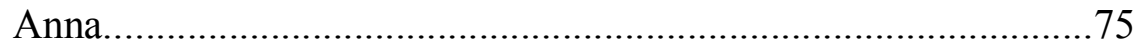

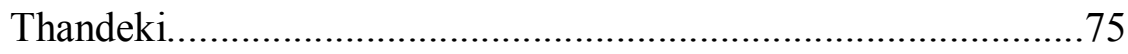

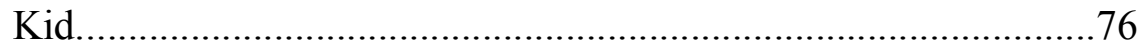

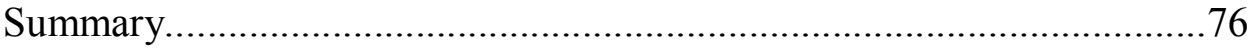

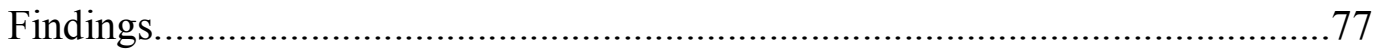

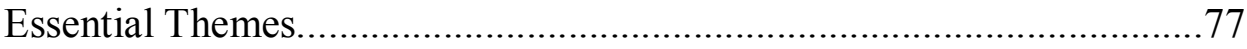




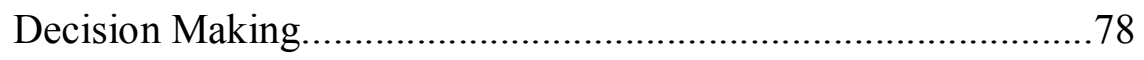

Perceived Severity of Violence.........................................79

Perceived Sociocultural Expectations...................................80

Perceptions of Appropriate Service Provider......................83

Decision Making Influenced by Experience.........................85

Complex Decision Making Events.....................................90

Silence .................................................................................

Not Talking About Victimization.........................................92

Silence in the Form of Secrets...........................................93

When a Shared Secret is Used as a Weapon.......................94

Shame and Self-Blame as Seeds of Silence.........................95

Silence as a Cultural Expectation.......................................96

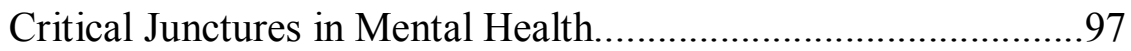

Breaking Down...............................................................98

The Power of Counseling..................................................100

Moving Forward..................................................................102

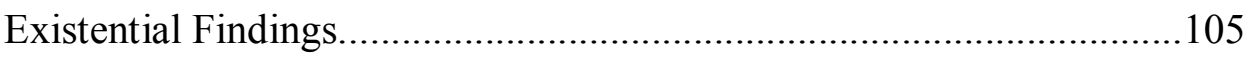

Lived Space

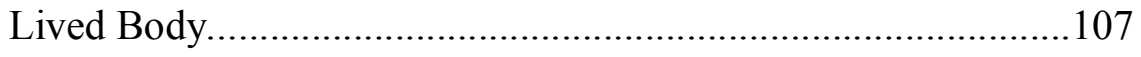

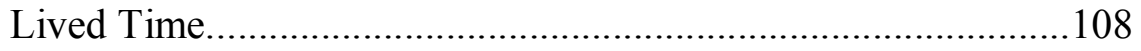

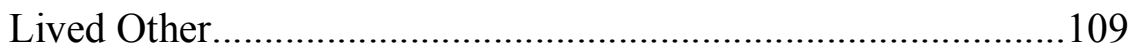

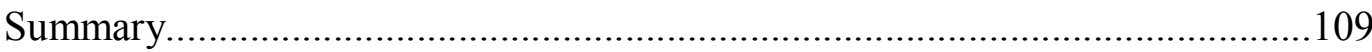

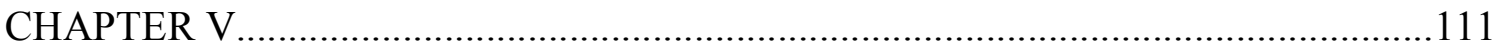

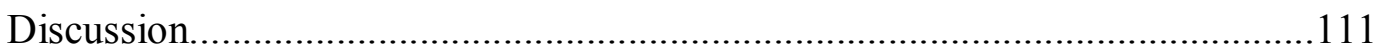

Discussion of Research Findings........................................................112

Decision Making.......................................................................112

Perception of the Severity of Violence.............................113

Perceived Sociocultural Expectations.................................113

Perception of Appropriate Service Providers....................114

Decision Making Influenced by Experience....................117

Silence.

Not Talking About Victimization....................................119

Silence in the Form of Secrets...........................................120

Shame and Self-Blame as Seeds to Silence.......................121

Silence as a Sociocultural Expectation...............................122

Critical Junctures in Mental Health............................................123

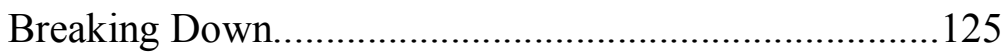

The Power of Counseling...................................................126 


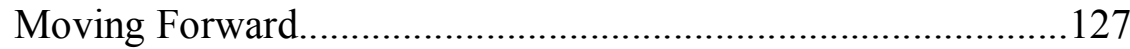

Findings in the Context of Bronfenbrenner's Ecological Systems..........129

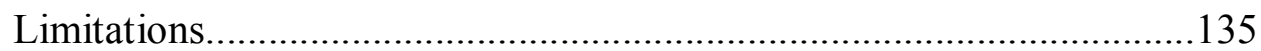

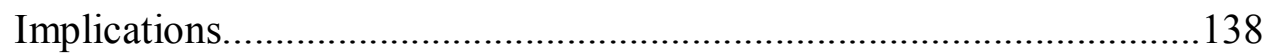

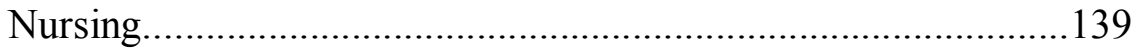

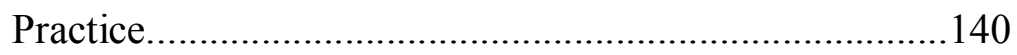

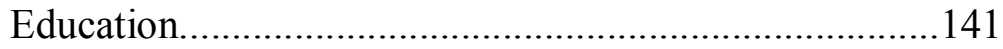

Policy................................................................142

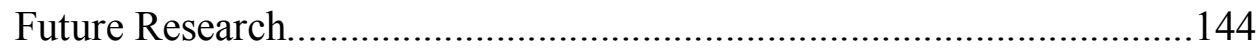

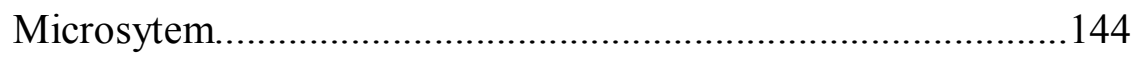

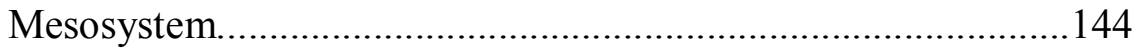

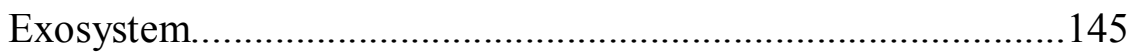

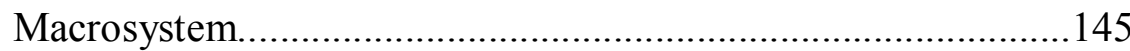

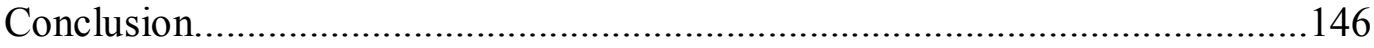

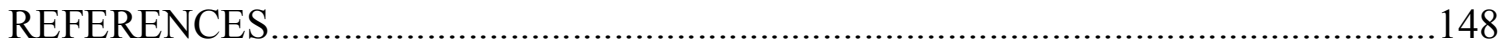

APPENDECIS

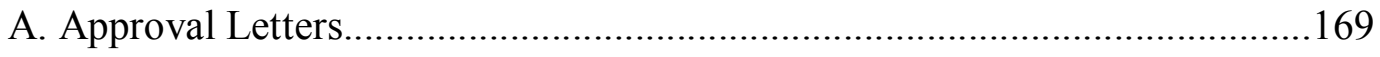

B. Letters of Support and Consent................................................................177

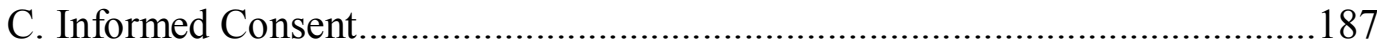

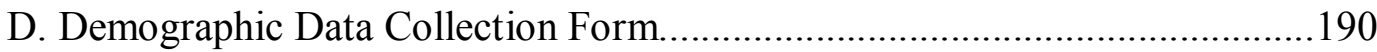

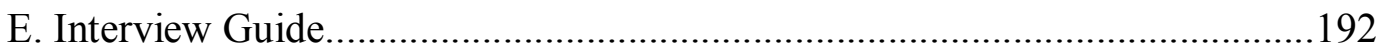

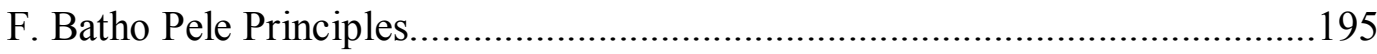

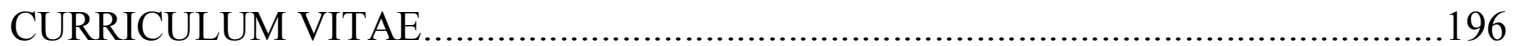




\section{CHAPTER I}

\section{INTRODUCTION}

There is little known about South African women's help-seeking behavior after sexual offence victimization. In South Africa help-seeking in response to sexual offence victimization takes a variety of forms which include but are not exclusive to the following: seeking help from family members or friends; reporting the victimization to the police; seeking medical care; or seeking help from social services. In a country that is estimated to have the highest rate of rape and sexual assault in the world (Cox, Andrade, Lungelow, Schloetelburg, \& Rode, 2007; Martin, 2002) help-seeking after sexual offence victimization takes on profound importance.

According to Martin (2002) rapes among South African women occur at a rate of 300 per 1000 . Determining the exact number of rapes or sexual assaults is impossible. This is partly due to the low level of reporting sexual victimizations to the police (Jewkes \& Abrahams, 2002; Mullick, Teffo-Menziwa, Williams, \& Jina, 2010). A study conducted in South Africa by Jewkes and Abrahams (2002) found only one in nine women reported being raped to the police. Between the years 2012 to 2013, there were 66,387 sexual offences reported to the South African Police Services (SAPS; SAPS, 2013). If only one in nine rapes is reported to the police, an occurrence of 531,096 rapes is potentially a more accurate estimation of the number of rapes that occurred between 2010 and 2011. Researchers agree the reported number of rapes and sexual assaults under represent the actual number committed (Abrahams, Martin, \& Vetten, 2003; Christofides, 
Muirhead, Jewkes, Penn-Kekana, \& Conco, 2005; Hirschowitz, Worku, \& Orkin, 2000; Jewkes, Dunkle, Nduna, \& Shai, 2010; Vetten, Le, Leisegang, \& Haken, 2010). Along with low reporting rates to the police, there is the low rate of South African women who seek health related services after rape (Abrahams, \& Jewkes, 2010; Christofides et al., 2005). Jewkes and Abrahams (2002) reported only one in six women sought health services post victimization.

There are myriad factors that may potentially impact a women's help-seeking behavior. She may not seek help because she blames herself for becoming a victim. She may blame herself due to the clothing she wore (Mullick et al., 2010; Jewkes \& Abrahams, 2002, Jewkes, Penn-Kekana, \& Rose-Junius, 2005), or, she may blame herself because of a particular behavior she exhibited (Mullick et al., 2010; Jewkes \& Abrahams, 2002, Jewkes et al., 2005). Or, there may be sociocultural implications to her not seeking help (Parkes et al., 2013; Shalhoub-Kevorkian, 1999). The woman's interpretation of victimization and her response will be contingent on her life experiences and her perceptions of victimization in the context of her life experiences. Some women may not define their experience as a sexual assault or rape. The experience may be interpreted as punishment (Jewkes et al., 2005; Kim \& Motsei, 2002). Others may interpret seeking help as a catalyst that will perpetuate more violence (Jewkes et al., 2005; Kim \& Motsei, 2002).

Other factors that may impact a women's help-seeking behaviors after victimization may be associated with a woman's ability to access care because her geographic location or her economic status. In rural areas women may not have the transportation required to travel a long distance to receive care. If public transportation is 
available, utilization of the transportation may be cost prohibitive, or present a risk to the woman's personal safety. Risks to personal safety particularly exists if she is traveling at night (Abrahams, \& Jewkes, 2010; Rohrs, 2011; Steinbrenner, 2011).

The South Africa government has enacted laws to "ensure the provision of adequate and effective protection to victims of sexual offences" (National Instructions, 2008, p. 1). In 2007, the government of South Africa amended criminal law related to sexual offences broadening the scope of the application of sexual offences criminal law, and enhancing the government's ability to prosecute offenders. In the past, common law had considered the crime of rape only possible if the act was committed by a male who had vaginally penetrated a woman with his penis (Law Reform Examiner, 2008). Rape is now defined by the criminal law Sexual Offences and Related Matters Amendment Act, No. 32 of 2007 (SOA2007), as an act that may be committed by a male or a female and sexual penetration has taken place without consent. In the past, according to common law most other sexually deviant acts including sexual assault were under the umbrella of indecent assault (Law Reform Examiner, 2008). Sexual assault according to SOA2007 is now defined as;

(1) A person ("A") who unlawfully and intentionally sexual violates a complainant ("B"), without the consent of B, is guilty of the offence of sexual assault. (2) A person ("A") who unlawfully and intentionally inspires the belief in a complainant ("B") that B will be sexually violated is guilty of the offence of sexual assault. (SOA, 2007, chapter 2, § 5)

With the enactment of the criminal law SOA2007, also referred to as the Sexual Offences Act of 2007 (Rohrs, 2011), common law was repealed and statutory laws related to sexual crimes were introduced. The purpose of the SOA2007 was to centralize all aspects of law related to sexual offenses to a single statute (SOA, 2007). 
Now under SOA2007 both rape and sexual assault are defined as sexual offences. Therefore in this study, the researcher has used the term sexual offences to describe both rape and sexual assault, and to maintain congruency with SOA2007. The terms rape or sexual assault have been used in this study to as accurately as possible reflect the word usage of researchers when reporting their study findings, or to mirror study participants word usage. Additionally, the South African spelling of offence was used throughout the study to reflect cultural context and the spelling of offence as it appears in South African criminal law and policy. Also, to maintain continuity and congruency with South African criminal law and policy related to sexual offences the term victim was used. The term victim is utilized throughout South African legal documents and policy concerning persons who have experienced harm "through acts or omissions that are in violation of criminal law" (Webster, 2008, p. 27).

\section{Significance to Nursing}

South African researchers report women 29 years of age and younger experience the highest rates of sexual offences victimization (Belo \& Pather, 2008; Changwa \& Pather, 2008; Dunkle et al., 2004; Francis \& Baird, 2000; Lammers, Martin, Andrews, \& Seedat, 2010; Meel, 2008; Vetten \& Haffee, 2005) and one in four South African girls become victims of sexual offences before they reach the age of 16 years (Cox et al., 2007; Lammers et al., 2010; Meel, 2008). However, South African women of all ages are victims of sexual offences (Jewkes, Sikweyiya, Morrell \& Dunkle, 2009). In a review of patient records at a large urban South African hospital, Lammers, Martin, Andrews, and Seedat (2010) reported the youngest victim of rape was a newborn and the "eldest 78 years old" (p. 362). 
Historically, services provided to South African women after being victimized by a sexual offence have been fraught with difficulties. For example, there has been secondary victimization reported as a result of insensitive behaviors toward victims by each of the various post victimization service providers (e.g., medical services, police services, and social services) (Human Rights Watch, 1997; Rohrs, 2011, Steinbrenner, 2011). Other difficulties include a long history of the lack of properly trained medical professionals competent in the care of victims of sexual offences (Christofides et al., 2003; Human Rights Watch, 1997; Rohrs, 2011). Because secondary victimization by the criminal justice system was a serious concern, wording regarding the protection from secondary victimization was included in the SOA2007 (Chapter 1, § 2, p. 11). According to the Objects of the act, the law is to protect complainants from "secondary victimization and trauma by establishing a co-operative response between all government departments (SOA, 2007, Chapter 1, § 2, p. 11). Therefore the development of a better understanding of the South African woman's lived experience of help-seeking behaviors after sexual offence victimization is critical to building an understanding of factors that may influence women's help-seeking and add insight into the low use rate of post victimization services. In the context of health care, a woman's current and future health and wellbeing may be seriously jeopardized without the delivery of appropriate care. Without postassault health care a woman is at high risk for unwanted pregnancy, sexually transmitted infections including HIV (Heise, Ellsberg, \& Gottmoeller, 2002), and at high risk of experiencing mental health issues (Campbell, Dworkin, \& Cabral, 2009; Ullman \& Filipas, 2001). Research findings have clearly established the importance of the provision of medical and mental health services as necessary for the victim's future health and 
wellbeing following sexual offence victimization (Abrahams \& Jewkes, 2010;

Christofides et al., 2005; Mullick et al., 2010; Sullivan \& Bybee, 1999; Ullman \& Filipas, 2001). With adequate and appropriate post victimization care negative consequences may be lessened or eliminated.

The goal of this study was to understand the experience of the women themselves who sought help after the experience of a sexual offence. This study has expanded the awareness of help-seeking from the women's perspective. The knowledge developed in this study along with further research will provide needed information to medical, mental health, social services, and police service providers to better adapt their services to address the help-seeking needs of South African women. Findings from this study provide important knowledge to South African policy makers who greatly affect the options a woman has in her help-seeking process.

Additionally, study findings provide international funding organizations with needed insight into where to direct funding to yield the greatest benefit to the women of South Africa who have experienced sexual offence victimization. These findings may assist in clarifying the need for oversight to ensure recipients of international funding are held accountable for the funded services. Study findings also provide important information to organizations such as nongovernmental organizations (NGO) and grassroots organizations regarding how they may direct some of their services to best serve clients.

\section{Purpose}

The purpose of this study was to explore the lived experience of help-seeking behaviors of South African women after sexual offence victimization. There is little 
understanding of women's experiences as they seek help after victimization, and what influences their help-seeking process. Therefore, hermeneutic phenomenology as applied by van Manen has provided the philosophical underpinnings, and van Manen's (1990) methodological approach to conducting hermeneutic phenomenological has been used. Findings from a pilot study concerning South African service providers for victims of sexual offences revealed a need to develop a better understanding of the help-seeking experiences of South African women after sexual offence victimization (Steinbrenner, 2011). As the researcher interviewed providers of various services, they reflected on their experiences while helping their clients who sought care. Providers mentioned numerous difficulties they and their clients faced while in the process of help-seeking. One example of difficulties described by providers was that of a provider witnessing her client being subjected to secondary victimization while receiving nursing care. A second example was a provider discussing being unable to access care for her clients after 4:00 P.M. on weekdays, during nights, or on weekends at a care center specifically tasked with the care of victims of sexual offence victimization. Therefore as a result of the providers expressing their numerous concerns with services and service provision, the researcher determined it was important to better understand South African women's experiences as they sought help.

\section{Research Question}

The research question guiding this study was what is the lived experience of help-seeking behaviors of South African women after sexual offence victimization. To address the research question, a qualitative research method was used. Qualitative methods use a holistic research approach, and the method supports the notion there are 
different truths for different people (Munhall, 2012). Each person's truth is a culmination of their lived experiences, perceptions, and contexts. Therefore the qualitative approach is a situated approach (Munhall, 2012).

\section{Summary}

It is estimated South African women experience one of the highest rates globally of sexual offences, including rape and sexual assault (Cox et al., 2007; Martin, 2002). The importance of medical and mental health care provision following sexual offence victimization has been clearly established as necessary for the women's future health and wellbeing (Abrahams \& Jewkes, 2010; Christofides et al., 2005; Mullick et al., 2010; Ullman \& Filipas, 2001). Without adequate and appropriate post-victimization care a woman is at high risk for negative consequences such as unwanted pregnancy, the transmission of sexual transmitted infections including HIV, or issues related to mental health. With adequate and appropriate post victimization care these negative consequences have the potential to be mitigated or eliminated.

In light of the importance of medical and mental health care in contrast with low rates of service usage, it is critical to gain insight into what influences a woman's perceptions and experiences when she makes her decision to seek help. Additionally, it is important to understand women's processes of help-seeking. Through the development of knowledge related to women's experiences of help-seeking after sexual offence victimization, an opportunity emerges to better understand service needs from the women's perspective, and to support the potential improvement in usage rates of medical and mental health services by South African women. 


\section{CHAPTER II}

\section{LITERATURE REVIEW}

\section{Sexual Offences in South Africa}

South African girls and women of all ages are victimized by sexual offences (Jewkes et al., 2009), and in many instances the assailant is known to the victim. Known assailants may range from being a friend or acquaintance of the victim to being a member of the victim's family (Abrahams \& Jewkes, 2010; Changwa \& Pather, 2008; Francis \& Baird, 2000; Lammers et al., 2010). Stranger rapes also occur in high numbers (Francis \& Baird, 2000; Killian, Suliman, Fakier, \& Seedat, 2007; Swart, Gilchrist, Butchard, Seedat, \& Martin, 2000; Vetten et al., 2008; Vetten \& Haffee, 2005). However, Vetten et al. (2008) found adults were more likely than children to be raped by strangers. Vetten and Haffee (2005) reported gang rapes were most often committed by strangers.

Sexual offences occur in many different locations. Many sexual assaults in South Africa are reported to take place in victims' homes (Changwa \& Pather, 2008; Steinbrenner, 2011; Swart et al., 2000, Vetten et al., 2008). Additionally, there are a large number of assaults reported to occur in assailant's homes (Changwa \& Pather, 2008; Steinbrenner, 2011; Swart et al., 2000). Sexual assaults are also reported to occur in open fields or velds, on the street, in a friend's home, at parties, or in bus or train stations (Changwa \& Pather, 2008; Steinbrenner, 2011; Vetten et al., 2008; Vetten \& Haffee, 2005). Vetten and Haffee (2005) reported that gang rapes most often occurred in open spaces such as the veld, or public parks. 
Sexual offences are reported to occur at any time of the day or week (Changwa \& Pather, 2008; Francis \& Baird, 2000; Vetten \& Haffee, 2005). However, the largest numbers of sexual offences are reported to occur on weekends (Changwa \& Pather, 2008; Killian et al., 2007; Steinbrenner, 2011; Swart et al., 2000; Vetten \& Haffee, 2005). Furthermore, on any day of the week, most rapes are reported to occur between 6 p.m. and 5 a.m. (Changwa \& Pather, 2008; Francis \& Baird, 2000; Swart et al., 2007; Vetten \& Haffee, 2005). Sexual offences occur in large numbers on the weekends and most frequently at night. Therefore, when an individual becomes a victim of a sexual offence it is imperative for medical and mental health, police, legal, and social services to be available and accessible for the provision of care to victims.

\section{South African Women Help-Seeking after a Sexual Offense Victimization}

There is little known about the South African woman's lived experience of helpseeking behavior after sexual offence victimization. Even though there is scant literature, several researchers do address various aspects of this phenomenon. Findings from several key studies will be described in this section of the literature review.

Abrahams and Jewkes (2010) explored the barriers to completion of post exposure prophylaxis (PEP) after rape, and included discussion regarding influences on help-seeking. Rohrs (2011) investigated barriers to accessing post rape healthcare in South Africa. Womersley and Maw (2009) used discourse analysis to better understand the impact of patriarchy and the environments in which the women lived, through their narrative about their rapes. Several scholars studied the provision of health care services to South African women after rape (Changwa \& Pather, 2008; Christofides et al, 2003; Christofides et al, 2005; Mullick et al, 2010). Vetten, van Jaarsveld, and Riba (2012) 
analyzed dockets from a rural area of the Gauteng Province to gain insight regarding the characteristics of rape reported to the police. Epidemiological research explicating rape and sexual coercion was conducted by Jewkes and Abrahams (2002). And, there is a study concerning the South African Police Service (SAPS), and their treatment of rape victims (Francis, 2000). Additionally, Vetten et al. (2008) investigated the attrition of rape cases through the South African justice system. This literature constitutes an important body of work regarding sexual offences and related matters, and will be described and discussed in the remainder of this section of the literature review.

Abrahams and Jewkes (2010) explored barriers to the completion of PEP after rape. The research took place in an urban area of the Western Cape and in a rural area of the Eastern Cape. Research findings revealed that one in three women completed the medication regimen. Barriers to completion of PEP included self-blame, psychological distress related to the victimization, social implications related to others learning the woman had been raped, victim blame, and issues related to medication administration. Women's perceptions of their victimization was also found to influence medication compliance. Additionally, limited knowledge of HIV was found to be a barrier. Blame greatly influenced the women's mental health wellbeing and as a result impacted their medication completion behavior. Knowledge of the PEP medications and their importance in the prevention of HIV transmission, along with positive interactions with service providers, were related to the reduction of barriers in completion of PEP. Helpseeking was influenced by victim self-blame and was also associated with silence. In the rural area of the Eastern Cape, help-seeking was found to be initiated by reporting to the village headman. However, the headman did not always provide assistance. The 
researchers provided the example of a woman being removed from her community as a result of reporting her uncle, who had sexually victimized her over a long period of time. Humiliation and blaming of the victims was a nearly insurmountable barrier for the women.

Rohrs (2011) conducted a large South African study to investigate the barriers of accessing post-rape health care. As victims discussed their experiences with the police and at health care facilities, it was found $25 \%$ of them had to wait more than an hour to be transported to medical facilities because there was no vehicle available. Additionally, police had victims provide their full statements before being transported to healthcare facilities versus the provision of a preliminary statement followed by obtaining a full statement after medical care. A process that would considerably reduce the time it takes to get a victim to the hospital and PEP started. The National Instruction (2008) repeatedly describes throughout the document the importance of the police transporting the victim as soon as possible. Victims were found to be subject to long waits between arrival to health care facilities and the forensic exam being conducted which also resulted in the delay of beginning PEP. However, victims in the Western Cape did report they were pleased with the services provided by the specialized care center for victims of sexual offences. Onehalf the study participants in all four provinces where the study was conducted (e.g., Limpopo, Gauteng, Eastern Cape, and Western Cape) reported waiting less than a half hour. However, there were participants in the Eastern Cape that had to wait as long as eight hours for their forensic exam. And, as a result delayed the initiation of PEP. As a component of the study qualitative data (Rohrs, 2011) from 39 victims was obtained in the Western Cape. The data collected addressed the victims' experiences at the healthcare 
facilities they attended. Of the 39 survivors, a majority went to a specialized rape clinic for their care, and most reported they were pleased with the services provided by the specialized care center for victims of sexual offences. Reasons given for being pleased with service were victims being treated with respect and people were friendly.

Using feminist discourse analysis Womersley and Maw (2009) conducted a study to develop understanding regarding the impact of patriarchy and the oppressive context of the environments where many women live. They conducted their study in a low-income area of Cape Town in the Western Cape. Their participants had all been victims of sexual offences within the 72 hours preceding their interviews. Through the use of discourse analysis they learned the women's perceptions of their experiences were impacted by patriarchal discourse. The pressure of patriarchy on the women reaffirmed the power imbalance inherent in patriarchal social constructs.

Changwa and Pather (2008) explored the management of victim care at a district hospital in a township in the North-West Province of South Africa. They wanted to better understand the victim's experience while receiving treatment. Findings were mixed. On one hand, victims were pleased with service provided by rape crisis counselors. Conversely, victims reported they felt both nurses and doctors doubted they had been raped. Some victims were not pleased with long waits for treatment, but others felt the time they waited for treatment was fine. As a result of study findings the researchers concluded there was a need for further training of nurses and doctors regarding care provision.

A study by Christofides et al. (2005) aimed to learn about women's experiences and preferences for services after rape in South Africa, and what influenced their choice 
of services. Of the $(N=319)$ participants, 155 had experienced rape, and 160 had not experienced rape. One hundred fifty six of the women were urban dwellers and the remaining 163 were from a rural site. The researchers discovered women participating in the study placed the highest level of importance on prophylactic treatment for HIV. The next most important was the desire to have a caring and compassionate service provider who was also qualified to conduct counseling. The third most important aspect for these women was quality of service identified as receiving a thorough exam. The importance of the quality of the exam took precedence over the length of time for the exam. Thus, even if the exam took a long period of time, to the researchers' surprise, women were willing to travel longer distances to obtain the quality of care they identified as important.

Francis and Baird (2000) conducted interviews with women who had reported their rapes to the police. The researchers wanted to learn more regarding victims experiences within the context of police service provision to improve services. The interviews took place in the Western Cape. Interviews were conducted immediately following victims reporting their rape to the police and then at two and four week time intervals. Findings revealed most of the victims were 16 to 20 years of age and the majority knew the person who raped them. The researchers discovered that most women reported to the police within one to nine hours after their victimization. However, there were instances of two women who reported 24 hours after victimization. Statements were reported to last between 20 to 60 minutes. And, it was revealed victims were frequently treated unsatisfactorily by police. There was a range of waiting times reported for the police to transport victims to medical facilities. Waiting times ranged from one hour to several days 
Vetten et al. (2008) conducted an analysis of rape cases in the Gauteng Province. Findings revealed adult women were more likely to be victims of stranger rape than girls 17 years and younger. For both women 18 years and older, and adolescent girls 12 to 17 years abduction occurred in almost half of the cases. The involvement of weapons, force and threats was most likely to occur in the cases of adult women. But for both women and adolescent girls injury or death was threatened in every one in three cases. It was reported that $39.6 \%$ of the rapes of adolescent girls occurred in the perpetrator's home. And, in almost one-half of the cases the adolescent girls knew the rapists, they were neighbors, friends, or acquaintances. In the case of young girl newborns to 11 years, $31.8 \%$ were raped by a relative. In approximately one third of the cases of young newborn girls to 11 years findings revealed they were raped in their own homes. Findings also revealed young girls were most likely to be told by their perpetrator to keep the rape secret, one third of the young girls did kept the rape secret. Only half of the adult women's cases of rape led to arrests, and only one in seven went to trial. In the cases of adolescent and young girls greater than half of the cases led to arrests, and one in five went to trial. For adolescent girls convictions occurred in $7.6 \%$ of the cases and for young girls convictions occurred in one in $10.1 \%$ of the cases.

Other researchers examined service providers, organizations, and systems provide understanding of the phenomenon of victims of sexual offence. For example, Christofides et al. (2003) analyzed service provision country wide. Findings indicated there was a need for more provider training. The standardization of care services were needed due to considerable variability of available services throughout the country. It was also found provider attitudes varied, and that social workers were not involved in a large number of 
facilities. The lack of the involvement of social workers creates a large gap in the service provision of victim referrals that are essential to access needed services, especially counseling services.

Mullick, Teflo-Menziwa, Williams, and Jina (2010) examined multi-sectorial services throughout South Africa. They made many recommendations which included: improve information available concerning prevalence, incidence, and trends; operational model development for care provision; develop means to provide better information regarding services; improve training; and, develop policies and strategies for treatment delivery, nurse service provision, treatment adherence, and look at mental health care needs for victims.

Vetten, Jaarsveld, and Riba (2012) analyzed dockets from one police station in Mpumalanga, a rural area in the Gauteng Province, South Africa. The aim was to better understand the characteristics of reported rape cases. There were 317 cases of rape reported during the time frame of analysis (e.g., two years). Of those cases, 26 case dockets were missing, 34 of the cases were still open, and 10 cases were being reinvestigated. Therefore 247 dockets were analyzed, and of those reviewed it was reported that half of the survivors were less than 18 years old, and over half of the rapes were committed by strangers. A majority of the rapes occurred on the weekends, between $7 \mathrm{pm}$ and $6 \mathrm{am}$, however, adult women were more likely than girls to be raped during that time period.

Epidemiological analysis using statistical information from South African crime data was completed by South African researchers Jewkes and Abrahams (2002). Analysis of data indicated barriers to reporting were: the concern held by a victim that they will 
not be believed, fear of perpetrator retaliation, police behaviors resulting in revictimization, reporting will not result in the perpetrator being punished for their behavior, police corruption resulting in dockets being lost, and sexual coercion.

The literature reviewed in this section indicates a number of important aspects of South African women's experiences of help-seeking after victimization. Wait times were long for: victim transport to police stations, to medical facilities, to be seen by medical providers, and in receiving PEP. Psychological distress including self-blame are barriers to seeking care and can interfere with a victim's completion of PEP. The literature suggests the training of all service providers including police, nurses, and doctors should be improved in order to best meet the needs of women after victimizations. Findings from several studies revealed the high number of women and girls who are sexually victimized by someone they know including fathers, other relatives, neighbors and acquaintances. And last, patriarchal and sociocultural factors impact women's perceptions and reactions to sexual offence victimizations.

\section{Care Systems for Victims of Sexual Offences}

According to the service charter for victims of crime, published by the South African Department of Justice and Constitutional Development (n.d.) and in conjunction with other public service departments in the South African government, victims have the right to receive available assistance, including health, counseling, social, and legal services (e.g., legal services include police services, and access to the Sexual Offense's courts [SOC] and their prosecutors). Specifically and according to South African law, post-exposure prophylaxis (PEP) must be available for victims of sexual offences at designated medical facilities (Government Gazette, 2007). 


\section{Medical Services for Victims of Sexual Offences}

Government supported medical services may be accessed through the public health system, with the assistance of the South African Police Service (SAPS), with the assistance of nongovernmental agencies (NGO), or on one's own accord. Medical service provision is available through public health clinics and community health centers, Thuthuzela Care Centres (TCC), or through district, regional, or tertiary level hospitals (Mullick et al., 2010; Steinbrenner, 2011). In many cases victims of sexual offences will be referred to a TCC if there is one within the referral chain of the medical facility where a woman initially seeks care. TCCs are specialized "one-stop facilities" for victims of sexual offences. A victim can access medical and mental health services, police services, social services, and legal services at one location (TCC pamphlet, n.d., p. 2). TCCs were developed with the goal "to reduce secondary trauma for the victim, improve conviction rates and reduce the cycle time for finalizing case[s]" (TCC pamphlet, n.d., p. 2).

A woman may seek post victimization care without reporting first to the police (Mullick et al., 2010; Steinbrenner, 2011). If a victim chooses to report their victimization to the police first, the police must provide the victim with a list of health care facilities that provide sexual assault care services, specifically facilities offering post exposure prophylaxis (PEP) for HIV (Rohrs, 2011). If there is a TCC available, SAPS will refer the victim to that facility. Regardless of which facility is chosen by the victim, and according to SAPS National Instructions on Sexual Offences (National Instructions, 2008), SAPS is required to transport victims to a medical facility for care if the victim chooses to seek medical care (Rohrs, 2011). 
The National Prosecuting Authority's (NPA) Sexual Offences and Community Affairs (SOCA) unit opened its first TCC in GF Jooste Hospital outside of Cape Town in 2000 (United States Agency for International Development, 2010). Thuthuzela Care Centres were developed with the objective of centralizing and improving the provision of sexual assault services (Mullick et al., 2010). In addition to the objective of the centralization of care services, the rape investigation component of TCCs have the following objectives: "ensures prompt transportation, examination and care of victims; increases communication between prosecutor, police and victim; develop best practices for speedy and sensitive investigation of cases; ensures accurate data collection and analysis; [and provides] immediate crisis counseling for victims" (Thuthuzela Care Centre [TCC] Pamphlet, n.d., p. 4). The objectives directly related to the Sexual Offences Court (SOC) component of TCCs include: "reduce secondary victimization; improve conviction rates; and reduce the time to finalization of cases" (TCC Pamphlet, n.d., p. 4).

Thuthuzela Care Centres are structured to facilitate a close working relationship with SAPS. Individuals who experience sexual offence victimization are not required to report the event to the police to receive medical services (Department of Health Republic of South Africa [DOH], 2005). However, if the individual wants to prosecute the assailant, and learn the assailant's HIV status, then a police docket must be opened (Government Gazette, 2007).

The national management guidelines for the medical care of victims of sexual offences calls for the provision of holistic care (DOH, 2005, section 5.7). According to the DOH's national guidelines, victims are to be treated with dignity and with the assumption they are being truthful in their allegations (DOH, 2005, section 5.7). In 2005, 
DOH published the national management guidelines for sexual assault care for individuals who present within 72 hours of sexual assault. For individuals who present after 72 hours, the main variation in the care management protocol is that the victim will not receive PEP for HIV.

There is some concern about the centralization of sexual assault services. For example, Mullick et al. (2010) suggests due to centralizing services, the centers may be overwhelmed and not have the capacity to provide the services they are responsible for providing. Mullick et al. (2012) concerns counter the anticipated positive aspects of the centralization of services. Mullick et al. (2012) predicted that instead there would be longer waiting times versus the proposed reduced waiting times, and greater problems of accessibility to post victimization services versus the anticipated ease of accessibility. Vetten et al. (2010) were concerned about sources of the funding that supported the development of TCCs. Funding of TCCs to date has been largely provided by donors outside South Africa. Little funding has been provided by the South African government (Mullick et al., 2010). In fact, there is very little known about the level of funding provided by the South African government (Vetten et al., 2010). Inadequate funding, and limited understanding of actual funding by the South African government leads to the concern the TCCs will not have the financial means to continue providing services (Mullick et al., 2010). This is of particular concern if outside funders reduce current levels of financial support (Mullick et al., 2010). A shift in TCC funding was planned to occur during the 2010/2011 financial year (Shukumisa, 2011). The National Prosecuting Authority (NPA) was positioned to take on the role of funding the cost of center personnel. The NPA asserted they would only take over the funding if the TCC model 
experienced projected outcomes initially promised at the time of the adoption of the TCC model (Shukumisa, 2011).

\section{Social Services within Thuthuzela Care Centres}

Some social workers working at TCCs are provided by the Department of Social Development, others are provided by NGOs working in correlation with the Department of Social Development (S. Ferreira, personal communication, September 28, 2011;

Steinbrenner, 2011; Waterhouse, 2008). Social workers also occupy other roles within the TCCs such as site coordinators, mental health counselors, and case managers (S. Ferreira, personal communication, September 28, 2011; Steinbrenner, 2011). An objective of the TCCs is for staff to facilitate the provision of social services and referrals for social services related to the victimization of sexual offences. Often testing for HIV, and HIV pre-counseling and post-counseling, are provided by social workers working within TCCs (Steinbrenner, 2011).

\section{Social Services and Nongovernmental Organizations}

Outside the TCC system, social workers provide counseling services, and assist with the provision of services related to housing or economic needs, along with providing referrals for services (S. Ferreira, personal communication, September 28, 2011). Social workers in South Africa play a key role in providing referrals to services that are important in the care of victims (S. Ferreira, personal communication, September 28, 2011; Waterhouse, 2008). Social workers with the Department of Social Development often work with lay providers who work with NGOs to assist in victim care (Steinbrenner, 2011). 
Nongovernmental Organizations. Nongovernmental Organizations (NGOs)

provide important services to victims. Some victims rely on NGOs as a point of entry into the TCC system (Sexual Offenses and Community Affairs [SOCA], 2008). NGOs act as victim advocates, assisting in navigating the complex systems of care. Nonmedical care such as counseling is a key role of NGOs (SOCA, 2008). NGO's serving in the role of the direct provision of nonmedical care are often geographically situated in the victim's community and run by community members. Community members who have established NGOs or work for an NGO have often done so out of deep concern for victims of sexual offences, or as a result of their own experiences of sexual offences victimization (M. Van Kraayenburg, personal communication, November 23, 2011; Steinbrenner, 2011).

Services provided by NGOs caring for victims of sexual offences include assisting victims with accessing medical care or legal assistance. They may also provide long term social support by conducting victim support groups to assist in the long term healing process, or provide counseling to individuals and couples after sexual offence victimization. Other services include helping victims go through the long judicial process typically required to convict perpetrators of sexual offences (Christofides et al., 2003). Service providers in NGOs also act as community educators, for example educating communities regarding contraception or preventative measures for HIV (Steinbrenner, 2011).

\section{Service Providers}

Service providers for victims of sexual offences include the police, social workers, lay providers, and nurses. These providers may or may not be specially trained in caring for victims of sexual offences. But, each provides services important to the 
safety, and health and wellbeing of South African women who have been victimized by sexual offences.

\section{South African Police Service}

In 2008 the South African government published national instructions for SAPS regarding the processes of working with victims in an effort to enhance the quality of the provision of services to victims of sexual offences (National Instructions, 2008). The instructions are comprehensive and include information concerning how to properly care for victims of sexual offences when they report to the police. The South African Police Service provides transportation to medical services, provides victims with "details of the available services regarding the receiving of Post Exposure Prophylaxis (PEP) for possible HIV infection and for the testing of the alleged sex offender for HIV" (p. 57), assists in victims' timely acquisition of post-exposure prophylaxis (PEP), provides information regarding legal processes and victims' rights (National Instruction, 2008; Rohrs, 2011).

Research findings indicate even with the instructions to guide the SAPS care process, there are still issues related to the treatment of victims when they report sexual offences. The problems include issues with the provision of legal and PEP information, long wait times for victims before being transported to a medical care facility, as well as assistance from SAPS to access services (Rohrs, 2011; Steinbrenner, 2011). Victim's interactions with the police historically have been fraught with issues such as revictimization, victim blame, or verbal abuse (Francis \& Baird, 2000; Rohrs, 2011; Steinbrenner, 2011; Vetten et al., 2008; S. Ferreira, personal communication, November 
24, 2011). And, according to Rohrs (2011) and Vetten et al. (2008) little has changed in the SAPS treatment of victims of sexual offences.

South Africa is experiencing a countrywide personnel shortage of police officers contributing to the low number of officers available to address all police duties (Minnaar $\&$ Mistry, 2004). Additionally, there is a shortage of officers properly trained in the responsibilities of caring for victims of sexual assault (Rohrs, 2011; Steinbrenner, 2011).

\section{Social Workers}

Social workers are employed in multiple organizations and provide a variety of services for victims of sexual offences. Typically many social workers become employees of the Department of Social Development or the Department of Health. Social workers are also employed by NGOs (S. Ferreira, personal communication, September 28, 2011; Earle, 2008). A four year bachelor degree in social work is required to become a licensed social worker in South Africa (Earle, 2008; S. Ferreira, personal communication, September 28, 2011). South African social workers are most often required to manage extremely high caseloads (Earle, 2008; Steinbrenner, 2011; S. Ferreira, personal communication, September 28,2011 ) and work with very few resources (e.g., office supplies, computers, etc.; Earle, 2008; Steinbrenner, 2011; S. Ferreira, personal communication, September 28, 2011). They receive low levels of remuneration for their work leading to considerable job dissatisfaction (Earle, 2008; Steinbrenner, 2011). High levels of job dissatisfaction lead to concern for the quality of care social workers provide to victims of sexual offences (Steinbrenner, 2011). There is a shortage of social workers to provide services for victims of sexual offences. 
In the TCC system, some of the roles social workers may perform are coordinating victim access to the criminal justice system, preparing court reports for the prosecution of assailants, and testifying in SOCs on behalf of child victims (S. Ferreira, personal communication, September 28, 2011). Waterhouse (2008) reported stakeholders in the criminal justice system, along with SAPS, NPA, along with South African citizens described poor quality services provided by social workers and others in the Department of Social Development who are involved with criminal justice.

\section{Lay Service Providers}

Nonmedical care provision for victims of sexual offences is also provided by lay service providers who are often associated with nongovernmental organizations (NGOs) (S. Ferreira, September 28, 2011). Lay providers frequently work as volunteers. They may be involved with the provision of nonmedical care in the acute period immediately following sexual assault, and in the long term care of individuals who have experienced sexual assault. The roles of lay providers may include serving as the first point of contact when victims initiate their care seeking process. Additional roles include victim advocate; helping victims navigate medical care, or assisting with opening a police docket.

Some lay providers are trained by organizations to provide care for victims. An example of this is lay provider training offered by Rape Crisis Cape Town Trust. The organization provides a six week volunteer counselor training course focused on "personal growth, the medical, legal and psychological aspects of rape, and of course counselling skills" (Rape Crisis, 2014, para 3). Rape Crisis Cape Town Trust also provides facilitator training. This training prepares volunteer lay providers to conduct 
workshops and present talks to various organizations and assist in "fundraising and awareness raising events" (Rape Crisis, 2014, para. 4).

\section{Nurses}

South Africa continues to experience a nursing shortage (Pillay, 2009; Rohrs, 2011; Wildschut \& Mgqolozana, 2009). It was estimated that there would be a shortage of 20,000 nurses in 2011 (Wildschut \& Mgqolozana, 2009). In 2005, in an attempt to remedy the shortage of a variety of public sector workers, the South African Department of Labour initiated the National Skills Development Strategy II (Goga \& van der Westhuizen, 2012). The purpose of this strategy was to identify scarce skills and acknowledge the need to retain and further develop public sector workers including nurses (Goga \& van der Westhuizen, 2012). As a result the South Africa government initiated an occupational specific dispensation (OSD) scheme (Goga \& van der Westhuizen, 2012; Pillay, 2009). Per the OSD scheme particular occupations were identified to receive higher levels of remuneration (Goga \& van der Westhuizen, 2012; Pillay, 2009). Included in the scheme were specialty areas of nursing such as theatre nurses and critical care nurses.

Interestingly, forensic nurses were not included in the OSD scheme because the South African Nursing Council (SANC) will not recognize forensic nursing as a specialty nursing area (Fourie, 2011; Rohrs, 2011; Steinbrenner, 2011). Therefore forensic nurses receive no additional compensation as do other nurses in designated specialty areas who have completed additional training programs similar in length and depth of curriculum (Fourie, 2011; Rohrs, 2011; Steinbrenner, 2011). 
Training opportunities to become a forensic nurse (e.g., a nurse specifically trained to provide forensic examinations for victims of sexual assault) are extremely limited in South Africa (Rohrs, 2011; Steinbrenner, 2011). There is a two week training program focused on post rape and sexual assault forensic exams provided by the South African Department of Health that is taught intermittently in some areas of the country (Rohrs, 2011; Steinbrenner, 2011). And, there is one comprehensive diploma forensic nursing program offered through the University of the Free State School of Nursing (Fourie, 2011; Rohrs, 2011, Steinbrenner, 2011).

The diploma program curriculum "addresses four components: sexual offences; physical assault/trauma; child abuse; and family trauma", and includes the following "compulsory modules: ethos and professional practice of nursing, health and law, health care management, pharmacology, [and] HIV/AIDS" (Fourie, 2011, pp. 6-7). The program also requires completion of a clinical learning experience. To participate in the forensic nursing program one must have previously attained a bachelor of nursing science and be a registered nurse. Often nurses who participate in the program are sent by their employers in an effort to meet training quotas. A number of program graduates go on to work as forensic nurses. However, due to employer demands, too few available positions, or low levels of remuneration many do not go on to work as forensic nurses (Fourie, 2011; Rohrs, 2011; Steinbrenner, 2011).

Many scholars report that a South African nurse's work is challenging regardless of the nurse's area of expertise (Frank, 2006; Kekana, du Rand, \& van Wyk, 2007; Koekemoer \& Mostert, 2006; Nyathi \& Jooste, 2008; Rohrs, 2011; Pillay, 2009). Nursing tasks are often complicated by lack of training (Abdool \& Brysiewicz, 2009; Christofides 
et al., 2003; Christofides et al., 2005; Uys \& Naidoo, 2004; Rohrs, 2011 ), lack of resources (Klopper, Coetzee, Pretorius, \& Bester, 2012; Koekemoer \& Mostert, 2006; Pillay, 2009; Rohrs, 2011), high workload levels (Kekana et al., 2007; Koekemoer \& Mostert, 2006; Pillay 2009), lack of clarity of one's job responsibilities (Koekemoer \& Mostert, 2006), and staffing shortages (Frank, 2006; Kekana et al., 2007; Klopper et al., 2012; Koekemoer \& Mostert, 2006; Nyathi \& Jooste, 2008). All of which are associated with nurse job dissatisfaction (Kekana et al., 2007; Klopper et al., 2012; Pillay, 2009). Low levels of remuneration, a key factor of job dissatisfaction for forensic nurses, is one of the main factors continuing to lead to job dissatisfaction experienced at a high number by other South African nurses (Kekana et al., 2007; Klopper et al., 2012; Koekemoer \& Mostert, 2006; Pillay, 2009).

There is little literature available discussing the implications of the unequal remuneration between SANC defined specialty nurses versus forensic nurses. Anecdotal evidence indicates one of the implications to unequal compensation is lowered nurse morale (S. Fourie, personal communication, October 6, 2011; Steinbrenner, 2011). Low nurse morale has been identified as a factor affecting the quality of care delivered by nurses (Leiter, Harvie, \& Frizzell, 1998; Pillay, 2009).

Nurses play a key role in the delivery of healthcare in South Africa, and profoundly affect the quality of healthcare South Africans receive. There are a number of studies linking patient dissatisfaction with nursing care to the behaviors exhibited by South African nurses (Changwa \& Pather, 2008; Jewkes, Abrahams, \& Mvo, 1998; Mashego \& Peltzer, 2005; Steinbrenner, 2011; Uys \& Naidoo, 2004). South African researchers Jewkes, Abrahams, and Mvo (1998) conducted research focused on the 
behaviors of obstetric nurses. They reported patients expressed the nursing staff did not care about them and neglected to care for them. Mashego and Peltzer (2005) investigated a community's perception of the quality of care provided at primary health care facilities in a rural area of South Africa. They found participants expressed negative comments concerning the behavior of nurses. Comments included patients were treated indifferently, were neglected, and received poor medical services (Mashego \& Peltzer, 2005). Uys and Naidoo (2004) found high levels of patient dissatisfaction after administering a survey to determine the quality of nursing care in a number of South African districts. Steinbrenner (2011) also reported participants describing negative experiences such as indifference and neglect while seeking post victimization services.

Jewkes and Abrahams (2002) reported only one in every six women sought health related services after rape. For the victims of sexual offences the use of healthcare services including medical and mental health services is essential. Women who do not receive care after being victimized by a sexual offence are at a high risk for poor outcomes that have the potential to affect her health and wellbeing for the duration of her life (Heise et al., 2002; Campbell et al., 2009; Ullman \& Filipas, 2001). Therefore there is concern related to nurses low job satisfaction and patients dissatisfaction with nursing care, both of which could potentially be contributing to the low usage rates of post victimization services.

There are services and service providers available for victims of sexual offences in many areas of South Africa. However, there are myriad complex factors that influence the help-seeking behaviors of South African women. Influencing factors include but are not limited to: access to care, self-blame, interpretation of victimization, and sociocultural 
factors. To understand the victims' views of these influences, a theoretical framework that provides context for the study was selected.

\section{Bronfenbrenner's Ecological Systems Theory}

Bronfenbrenner (1979) developed the ecological systems theory which takes into consideration a person's environment and the effect it has on their development and subsequent behavior over their lifespan. This theory is grounded in the concept that a person's environment, the people, the objects, the symbols, the social and cultural systems, and economic systems within the environment dynamically interact with a person's experiences over a life time, to shape and form their behavior and development as a human (Bronfenbrenner, 1979).

Scholars have used Bronfenbrenner's theory or adaptations of his theory to analyze gender-based violence (Heise, 1998; Heise et al., 2002), psychological sequela (Neville \& Heppner, 1999), and in the analysis of the impact of mental health issues related to sexual assault (Campbell et al., 2009). In addition, researchers have used Bronfenbrenner's theory to investigate risk factors associated with intimate partner violence (Garcia-Moreno, Jansen, Ellsberg, Heise, \& Watts, 2005).

Scholars have found that ecological systems theories (Bronfenbrenner, 1979; Kelly, 2006) are effective theoretical frameworks for use in research involving the analysis of complex subjects. It is anticipated the use of Bronfenbrenner's ecological systems theory will situate the complexity of a woman's experience after sexual offence victimization within the theory's four ecological environments.

In defining his theory Bronfenbrenner (1979) emphasized the following three foundational aspects to his ecological systems theory. First, Bronfenbrenner believed 
there was a dynamic interaction between a person and their environment. Second, the interaction between a person and their environment was reciprocal. Last, it is important to consider a person's environment in a broad context. Therefore not only does a person's immediate environment impact them, but a person is also affected by a range of other, broader environments in which they live and exist (see Figure 1).

Also foundational to Bronfenbrenner's (1979) ecological systems theory is the "phenomenological conception of the environment" (p. 23). He posits the reality of one's existence is not based solely of the concrete aspects of existence; one's reality is also situated in their perceptions of their experience.

Bronfenbrenner (1979) described his concept of a person's ecological environment "as a nested arrangement of concentric structures, each contained within the next" (p. 22; see Figure 1). The innermost structure is the microsystem (Bronfenbrenner, 1979). This is the setting where the woman is located and actively participates within. The microsystem setting (Bronfenbrenner, 1979) includes her family members, friends, and all of her lived experiences. The next system structure is the mesosystem. The mesosystem is conceptualized by Bronfenbrenner (1979) as a "system of microsystems" (p. 25). It is the interrelations (e.g., linkages) between all the settings the individual actively participates in, and the interrelations formed when the individual participates in and experiences new settings. The third nested structure is the exosystem. The exosystem is constituted of settings the person does not actively participate in, "but in which events occur that affect or are affected by what happens in the setting containing the [person]" (Bronfenbrenner, 1979, p. 25). Therefore this structure includes the settings such as health care systems, or legal systems. The macrosystem is made of the patterns from the 
other systems that are unique to the culture or subculture the person exists within (Bronfenbrenner, 1994). The person's understanding of their life experience is predicated on the bases of their culture, belief systems, social constructs, and political systems in which they were raised.

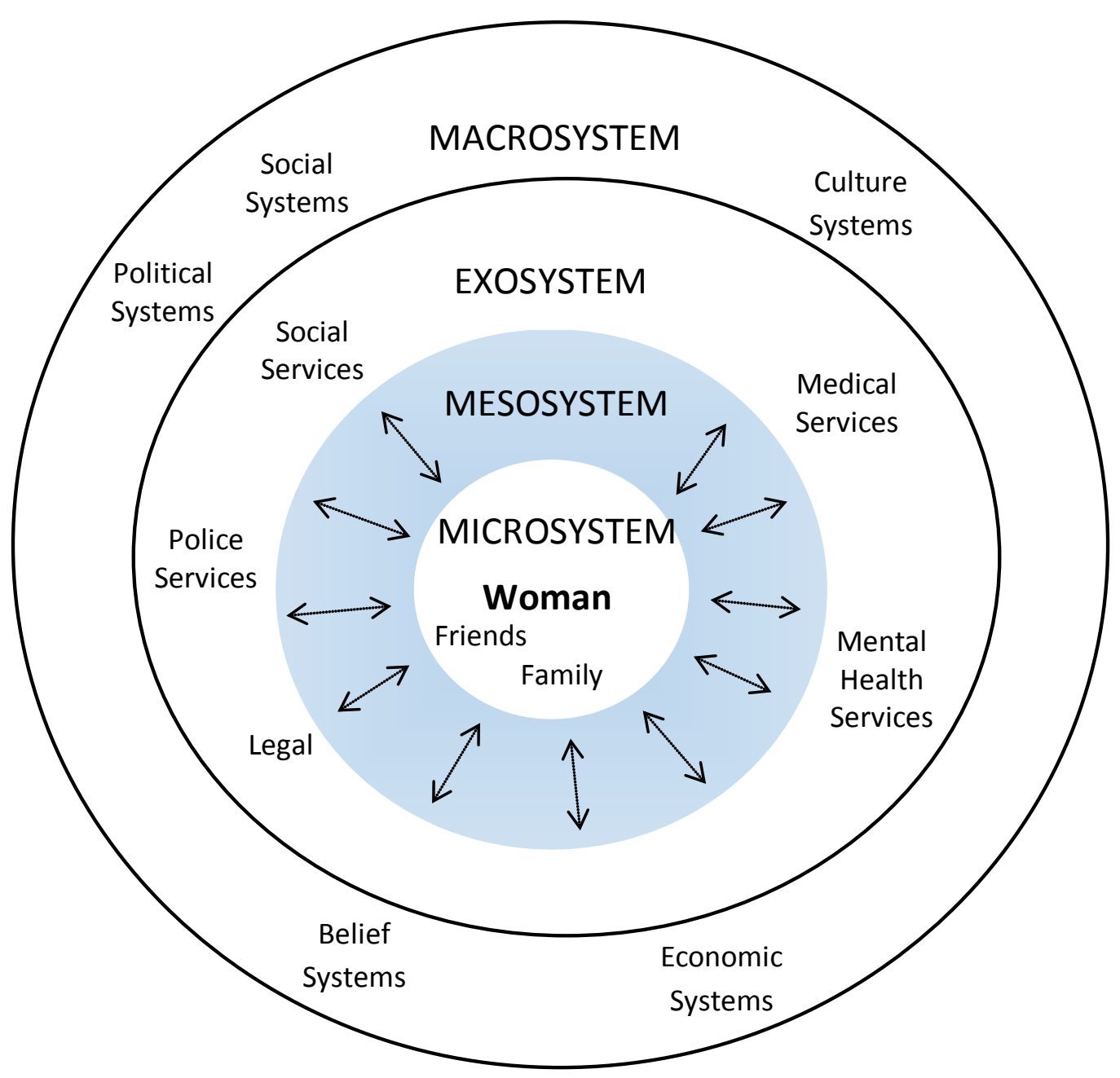

Figure 1. Bronfenbrenner's ecological theory model

\section{Bronfenbrenner's Ecological Systems Theory and Hermeneutic Phenomenology}

Bronfenbrenner's ecological systems theory and hermeneutic phenomenology have integration when one examines the concept of experience. For example, 
Bronfenbrenner (1979) stresses "a critical term" in defining ecological systems is experience (p. 22). Hermeneutic phenomenology is a research approach used to interpret lived experience and meaning given to the lived experience in the context of the phenomenon being researched (van Manen, 1990). In this study, the focus of the research was the lived experience of women who sought help after sexual offence victimization. Their lived experiences are embedded in the context of the systems in which they live. Therefore when used with hermeneutic phenomenology, Bronfenbrenner's ecological systems theory provides a structure to systematically contextualize women's lived experiences of help-seeking behaviors into ecological systems (e.g., ecological environments).

Bronfenbrenner (1979) states, "very few influences significantly affecting human behavior ... can be described solely in terms of objective physical conditions and events" (p. 22). An individual experiences their environment at a concrete level. However, it is the subjective meaning individuals give their experiences within the environment that defines the experience itself. According to Campbell et al. (2009) "the utility of an ecological [theoretical] framework is that it can suggest multiple ... [interpretations] at multiple levels of analysis" (p. 226). The subjective meanings of women's lived experiences vary according to their ecological environments.

Hermeneutic phenomenology maintains that the phenomenon being studied and a person's lived experiences (in the context of the phenomenon) is the source of research data "for purpose of analysis, description, and interpretation" (van Manen, 1990, p. 18). Hermeneutic phenomenology is the human sciences research approach focused on the interpretation of an individual's lived experience of a phenomenon and the meaning they 
give to their lived experience (van Manen, 1990). Therefore the interpretation of the meaning of a woman's lived experience of help-seeking must consider the contexts of her ecological environments.

Bronfenbrenner (1979) explains experience within the context of the theory of ecological systems is phenomenological. To fully consider the South African woman's lived experience of help-seeking the research must take into consideration the context of the woman's ecological environments. Her lived experiences are embedded in the context of her ecological environments. Accordingly hermeneutic phenomenology combined with Bronfenbrenner's ecological systems theory provided a strong theoretical foundation for the exploration of a South African woman's lived experience of help-seeking behaviors after sexual offence victimization.

\section{Summary}

Research indicates there are very high rates of sexual offences victimization in South Africa. Therefore there is a critical need for available and accessible services to meet the needs of South African victims of sexual offences. There have been strides in South Africa to establish sexual offences care provision through the TCCs. However, with so few forensic nurse training opportunities available, and the refusal by the South African Nursing Council to recognize forensic nursing as a specialty, the availability of forensic nurses is severely limited. And, due to the TCCs most often being located in hospitals in urban areas, accessibility for individuals outside the urban areas is of great concern.

There are additional concerns related to sustainability of the TCCs since the centers receive a large portion of their funding from entities other than the South African 
government. Services for victims of sexual offences are provided by community clinics, however, because of the TCC initiative, clinics are directing victims to TCCs for care. Potential future issues may emerge that are associated with the large number of victims in need of services and inadequate resources to meet the need at the TCCs, including lack of properly trained staff to provide care.

In addition to there being too few trained forensic nurses, there are too few other properly trained medical providers. And, there is a shortage of police officers who are properly trained to support their constitutionally mandated role in the care of victims of sexual offences. Additionally, because of the shortage of social workers, those currently working with victims are overwhelmed by the high number of assigned cases.

When considering the above concerns, important questions must be raised. Why are there such low usage rates of the services that are available to victims when there is such a high rate of sexual offences? Are low usage rates associated with the availability and accessibility of services? Or, are there issues related with the quality of the provision of care? What are the environmental factors impacting a woman's perceptions and lived experience as she seeks help?

The exploration of the lived experience of help-seeking behaviors of South African women after sexual offence victimization has the potential to increase knowledge and understanding regarding the low usage of services. Furthermore, this study will provide new understanding about needed resources that lead to healing after a sexual offence victimization. 


\section{CHAPTER III}

\section{METHOD}

Little is known about the lived experience of help-seeking by South African women after becoming a victim of a sexual offence. The purpose of this study was to explore the lived experience of help-seeking behaviors of South African women after being victimized by a sexual offence. A qualitative design was used to gain an in-depth understanding of the lived experience. For this study hermeneutic phenomenology as applied by van Manen (1990) provided the philosophical underpinnings, and van Manen's (1990) methodological approach to conducting research using hermeneutic phenomenology was used. The qualitative research approach of hermeneutic phenomenology (Richards \& Morse, 2007) was a method congruent with the purpose of this study.

This chapter provides an overview of the philosophies of hermeneutics and phenomenology, phenomenology as a methodology, and hermeneutic phenomenology as applied by van Manen (1990). A discussion then follows concerning van Manen's (1990) methodological approach to hermeneutic phenomenological research as it was used in this study. Last, details of the method used to conduct the study are described including: setting and sample, procedures, the protection of human subjects, data collection, data analysis, and trustworthiness. 


\section{Hermeneutic Phenomenology as an Approach to Human Sciences Research}

Hermeneutic phenomenology brings together two philosophies, philosophical hermeneutics and phenomenology (van Manen, 1990), to form a philosophical (Benner, 1985; van Manen, 1990) and methodological (Munhall, 2012; Richards \& Morse, 2007; van Manen, 1990; Wojnar \& Swanson, 2007) approach to human sciences research. Approaching human science research using hermeneutic phenomenology centers the research "point of departure in the situation" (e.g., the situation is the phenomenon under study; van Manen, 1990, p. 18). Hermeneutic phenomenology posits the phenomenon being studied and a person's lived experiences in the context of the phenomenon as the source of research data "for purpose of analysis, description, and interpretation" (van Manen, 1990, p. 18). Therefore hermeneutic phenomenology is the human science research approach focused on the interpretation of an individual's lived experience in the context of a phenomenon and the meaning they give to their lived experience (van Manen, 1990). To build more understanding of hermeneutic phenomenology it is important to examine the development of the philosophies of hermeneutics and phenomenology.

\section{Overview of the Philosophy of Hermeneutics}

Initially, hermeneutics had a long history as a method for the interpretation of religious and classical text (Benner, 1994; Grondin, 1994). One of the early philosophers, Dilthey, emphasized understanding as important to hermeneutics (Dilthey, 1976). "Understanding penetrates the observable facts of human history to reach what is not accessible to the senses and yet affects external facts and expresses itself through them" (Dilthey, 1976, p. 173). Dilthey (1976) and Grondin (1994) conceived understanding to 
be reflection that moves inward beyond the physical aspects of the human to what dwells inward According to Grondin (1994) and van Manen (1990) Dilthey also contributed to shifting the method of hermeneutics into the phenomenological (e.g., the experiential) realm through bringing focus to the concept of lived experience in hermeneutics. Van Manen (1990) and Grondin (1994) interpreted Dilthey's use of the concept of understanding presented the opportunity to "bring together the foundational notion of lived experience with the concrete work done in the humanities" (Grondin, 1994, p. 87), and thus, securing a place for hermeneutics in the human sciences. Hermeneutics as a philosophy became firmly situated through the work of Heidegger.

Heidegger's key philosophical position involved the study of ontology (e.g., being). "Phenomenology is the science of the being of beings - ontology" (Heidegger, 1953/2010, p. 35). Most important to this study is Heidegger's (1953/2010) assertion of Dasein as the ontological position of being. Dasein allows for "confront[ing] of the cardinal problem, the question of the meaning of being" (Heidegger, 1953/2010, p. 35). It is the ability a person has to ponder the question of their own existence at both a concrete level, and at an abstract level (Heidegger, 1953/2010; McConnell-Henry, Chapman, \& Francis, 2009; Rodgers, 2005). Questioning one's own existence reveals one's existence as unique and unlike any other. Likewise, van Manen (1990) refers to phenomenology as the "theory of the unique" (p. 7). Phenomenological research explores the person's experience of a phenomenon from the person's unique perspective as well as the perspective of their lived experience in their lifeworld (van Manen, 1990). Heidegger (1953/2010) and van Manen (1990) perceived the practice of hermeneutics as a process to generate understanding of being in the world. According to van Manen (1990) 
hermeneutics is the process of interpretation leading to understanding. Therefore, hermeneutic phenomenology is the process or practice of developing understanding of the lived experience through the process of interpretation.

Van Manen's (1990) approach to hermeneutics, and as the notion of understanding has been used in this study, indicates that understanding must be considered more broadly than when applied in a strictly rational scientific form. According to van Manen (1990) the "notion of understanding ... tends to be interpreted much more narrowly in the behavioral sciences than in the human sciences - an issue which is sometimes debated in terms of difference between rational understanding and empathic understanding" (p. 15). According to Rodgers (2005) "a rational view allows analysis of science on the basis of factors internal to the science rather than on contextual factors or factors external to the science" (p. 116). Therefore, in this study a broader use of understanding was imperative.

The research question guiding this study, what is the lived experience of helpseeking behaviors of South African women after sexual offence victimization required reflection on women's lived experiences. Each woman's lived experience is unique and situated in her experiential context. The intention of this study was to establish phenomenological understanding in the context of a South African woman's life. Thus, in order to build understanding of the women's lived experience it was vitally important to use research methodology oriented to examining the lived experience.

\section{Overview of the Philosophy of Phenomenology}

Some of the concepts important to the philosophy of phenomenology according to Husserl include: consciousness, essence and bracketing, First, Husserl (1931/2012) 
postulated we experience the natural world through our consciousness. Husserl (1931/2012) and van Manen (1990) assert consciousness is always intentional. We become aware of something because it intentionally enters into our consciousness (Husserl, 1931/2012; van Manen, 1990). Therefore every event that is perceived is perceived because it has entered one's awareness and thus has become available to their consciousness. Husserl (1931/2012) posited phenomenology was to seek the essence of consciousness.

Second, Husserl (1913/2012) described essence as what makes something what it is. Van Manen suggested that a phenomenon has a universal quality or qualities that are essential to the phenomenon and "can be described through a study of the structure that governs the instances or particular manifestations of the essence of that phenomenon" (van Manen, 1990, p. 10). Husserl takes the position "empirical or individual intuition can be transformed into essential insight... The object of such insight is then the corresponding pure essence" (Husserl, 1913/2012, pp. 11-12). Therefore the essence of phenomenon is the what that is unique to the phenomenon and is what makes the phenomenon what it is.

Third, Husserl (1931/2012) suggests that one can set aside or bracket one's presuppositions and thus describe or interpret phenomena without the influence of presuppositions. When undertaking the process of bracketing (e.g., phenomenological epoche) Husserl declares, “...I do not deny this 'world' ... I do not doubt that it is there . .. but I use the 'phenomenological' [epoche] which completely bars me from using any judgment that concerns spatio-temporal existence ([e.g.,] Dasein)" (Husserl, 1931/2012, p. 59). Therefore, Husserl (1931/2012) asserts to access "pure consciousness" (e.g., 
transcendental consciousness) one may use the phenomenological epoche (e.g., bracketing; p. 63).

\section{The Research Methodology of Phenomenology}

Phenomenology is a research approach used to facilitate the understanding of the lived experience related to a particular phenomenon (Richards \& Morse, 2007; van Manen, 1990). In other words, it is the study of the life world in the context of the phenomenon being investigated (van Manen, 1990). According to Richards and Morse (2007) there are two assumptions associated with phenomenology. The first assumption is perceptions are developed through the lived experience of a person, and it is a person's lived experience that generates their understanding of the world. The second assumption is "human existence is meaningful and of interest in the sense that we are always conscious of something ... [existence is] being in the world ... and [people] are understandable only in their context” (Richards \& Morse, 2007, p. 50). A person's perception and understanding of their experiences is a synthesis of multiple interrelated factors unique to each individual. Each person's lived experience (e.g. their phenomenological experience) is informed by their unique life experiences which are an aggregate of the cultural, social, and family influences, in addition to myriad other factors. As a result, each person's perceptions, interpretations, and the meaning they give to their life experiences are situated in their own unique subjective contexts (Munhall, 2012).

\section{Hermeneutic Phenomenology as Applied by van Manen}

Van Manen's (1990) application of hermeneutic phenomenology to the research of lived experience includes the philosophical notions from both descriptive and 
hermeneutic or interpretive phenomenology. For example, van Manen (1990) used the term descriptive which is most often associated with Husserlian phenomenology.

However, he clarifies that he uses descriptive interchangeably to include both notions of descriptive phenomenology (e.g. Husserlian phenomenology) and hermeneutic phenomenology. The result, according to van Manen (1990) "is a human science research approach, showing a semiotic employment of the methods of phenomenology and hermeneutics". Therefore when hermeneutics and phenomenology are taken together to form a methodological approach to research there is the capability to address unique and situated lived experiences.

There are some phenomenological notions van Manen (1990) has applied that fall clearly into either the descriptive phenomenological or hermeneutic phenomenological categories, they are: bracketing, consciousness, and essence.

First, is an example of van Manen's adoption of Heidegger's position regarding bracketing. Heidegger (1953/2010) opposed Husserl's notion of bracketing or phenomenological reduction. Heidegger's position was that presuppositions could not be set aside. He maintained being in the world is knowing the world (Heidegger, 1953/2010). Later, van Manen (1990) took a position similar to that of Heidegger. He asserted "it is better to make explicit our understandings, beliefs, biases, assumptions, presuppositions, and theories" (p. 47). According to van Manen (1990) if one attempts to bracket away what they know of the phenomenon of interest there is a risk of the knowledge emerging in the interpretive process and affecting the findings of the inquiry. By making explicit the researcher's knowledge related to the phenomenon, greater clarity of the themes constituting the essence of the lived experience is gained. 
Second, consciousness as applied by van Manen (1990) is more parallel to Husserl (1931/2012) and the descriptive phenomenology application of consciousness than that of hermeneutical phenomenology. Van Manen (1990) states "anything that presents itself to consciousness is potentially of interest to phenomenology, whether the object is real or imagined, empirically measurable or subjectively felt” (p. 9). Van Manen's (1990) approach involves exploring a person's consciousness in search of insight regarding their perceptions and interpretations of the phenomenon under study. This approach provides the person's situated knowledge of the phenomenon as it is given meaning through their lived experience.

Third, the notion of essence which has long been part of philosophical thought is present in both hermeneutic and descriptive phenomenology. Van Manen's (1990) approach to hermeneutic phenomenology includes seeking the essence of phenomenon. Husserl discussed essence as the what or whatness of something (Husserl, 1913/2012; Moran \& Cohen, 2012). Essence for Husserl is not what is physically present but describes a definition of what is conceivable (Husserl, 1913/2012). Essence for Heidegger according to Dahlstrom's (2013) interpretation of Heidegger's concept of essence is "for essence—verbally understood—is indeed only the way something is, how it is ... the ground of inner possibility of what is initially and in general taken as familiar" (p.67). Essence according to van Manen (1990) "is that what [that] makes a thing what it is (and without which it would not be what it is); that what makes a thing what it is rather its being or becoming something else" (p. 177). The researcher aimed to understand the essences of the phenomenon, as well as the structures that constitute those essences of the phenomenon that make it what it is according to van Manen (1990). To 
understand the essences of phenomenon, they can "only be intuited or grasped through a study of the particulars or instances as they are encountered in lived experience" (van Manen, 1990, p. 10).

Van Manen (1990) was influenced early in his work by the "interpretive or hermeneutic" German tradition of "the Dilthey-Nohl School" and also by the Utrecht School of Dutch origin which was "more descriptive or phenomenological" (van Manen, 1990, p. ix). The varied influences are evident in his approach to conducting research utilizing hermeneutic phenomenology. He has included concepts of Husserlian phenomenology, Heideggerian hermeneutic phenomenology, along with concepts from Merleau-Ponty (1945/2012), Gadamer (1975/2011), and Sarte (1956). Van Manen's (1990) motive for development of his approach has been the desire to assure inclusion of the lifeworld versus "armchair philosophizing or abstract theorizing" (p. ix). van Manen's (2007) approach to hermeneutic phenomenology as a research method may be best explained in his discussion regarding the Utrecht School, "they shied away from technical philosophical issues and they openly admitted that they were primarily interested in phenomenology as a practical reflective method" (p. 23). Therefore van Manen devised a practical approach to the method of conducting research using hermeneutic phenomenology.

The catalyst for van Manen to develop his methodological approach to conducting hermeneutic phenomenological research was a result of his observation that there was little direction about how to methodologically apply phenomenology to research of the lived experience. Thus, van Manen (1990) developed "six methodological themes" to 
assist researchers in devising and guiding their approach to conducting hermeneutic phenomenological research (p. 30).

\section{Van Manen's Six Research Activities Guiding Hermeneutic Phenomenological \\ Research}

Van Manen's (1990) six methodological themes to assist and guide hermeneutic phenomenological research include research activities he posits interact dynamically during the research process. The research activities guiding van Manen's methodological approach include:

1. Turning to a phenomenon which seriously interests us and commits us to the world,

2. Investigating experience as we live it rather than as we conceptualize it,

3. Reflecting on the essential themes which characterize the phenomenon,

4. Describing the phenomenon through the art of writing and rewriting,

5. Maintaining a strong and oriented. . relation to the phenomenon,

6. Balancing the research context by considering parts and the whole (pp. 30$31)$.

The first of van Manen's (1990) research activities includes two components, the first component is "turning to a phenomenon which seriously interests us and commits us to the world" (p. 30). The second component of the first research activity involves the process of reflexivity.

The first component involves the initial act of deciding which phenomenon to investigate. The impetus to conduct the current research concerning the help-seeking experiences of women in South Africa after sexual offence victimization was strongly 
associated with the research findings from a pilot ethnographic study to develop a comprehensive understanding of sexual assault services and service providers in the Free State Province of South Africa (Steinbrenner, 2011). Research findings indicated there was a lack of provider training, problems with accessibility and availability of services, and a low or a lack of funding for sexual offence victim services (Steinbrenner, 2011). Thus, the following research question emerged: What is the lived experience of helpseeking behaviors of South African women after they experience the victimization of a sexual offence?

The second component of the first research activity is the process of reflexivity which involves the process of explicating "preunderstandings ... suppositions, [and] assumptions" (van Manen, 1990, p. 46). This process required the researcher to use reflexivity to reveal her own personal beliefs and concepts concerning the phenomenon being studied. It is important for an investigator to reckon with their personal beliefs, preunderstandings, suppositions, and any other concepts that may emerge and cloud understanding. As the researcher conducted thematic analysis of the study data, she also consistently used the process of reflexivity to identify interpretations that may have been affected by the researcher's personal understandings of the phenomenon.

Van Manen's (1990) second research activity is the process of gathering experiential data. This process includes gathering data through interviewing participants, and from a variety of other resources, that may include observation, poetry, literature, or art (van Manen, 1990). In addition, van Manen (1990) suggests gathering data associated with terms and idiomatic phrases used in association to the phenomenon under study. He asserts both emerge from the lived experience and have the potential to provide 
interpretive importance associated with the phenomenon. The researcher conducted interviews with study participants. Additionally, data was collected from three South African literature sources related to the lived experience of South African women seeking help after sexual offence victimization.

Van Manen's (1990) third research process involves the analysis of study data. This involves "phenomenological reflection" which is the process of thematic analysis (van Manen, 1990, p. 77). Van Manen provides direction for conducting thematic analysis to assist in the effort of producing in-depth meaningful data analysis. This study's data underwent thematic analysis as described by van Manen, and discussed below.

The fourth research activity is the art of writing and rewriting, and is the process of creating the phenomenological text. Van Manen (1990) asserts, the "purpose [of this activity] stands in service of the fundamental commitment that animates the research question" (p. 112). Through writing and rewriting interpretations of experience, meaning emerges. Therefore considerable effort was made by the researcher to write and rewrite interpretations in an effort to draw out the essence of the meaning of the South African woman's lived experience of help-seeking behavior after victimization by rape or other sexual offence.

Van Manen's (1990) fifth research activity is a process of remaining strongly oriented to the research question being studied. This process must be maintained throughout the research endeavor so the research outcome does not represent a "settl[ing] for superficialities and falsities" (van Manen, 1990, p. 33). Therefore the researcher persevered to maintain an intense focus on the current study's research question, thus 
preventing other factors not associated with the lived experiences of help-seeking after victimization of a sexual offence from blending into the themes as they emerged.

The sixth and last research activity van Manen (1990) suggested was the constant process of assessing the whole body of the emerging research text to assure all elements of the context are presented. Van Manen emphasized the importance of not letting the study design drive the results of the research. The researcher persisted in the assessment of the emerging research text as a whole to assure the context was maintained and thoroughly represented.

\section{Design}

The qualitative method of hermeneutic phenomenology was used to address the research question of what is the lived experience of help-seeking behavior of South African women after sexual offence victimization. The study was conducted over a three month period of time in the country of South Africa. The research was guided by van Manen's (1990) six methodological themes as well as van Manen`s approach to dealing with researcher presuppositions. Therefore the researcher consistently attempted to acknowledge and "make explicit ... understandings, beliefs, biases, assumptions, presuppositions, and theories"(van Manen, 1990, p. 47) while in the process of identifying the themes that most authentically represented the lived experience of helpseeking after experiencing sexual offences victimization.

\section{Setting}

There were two types of research settings. One research setting was a university setting in a mid-sized city. The second type of research setting included NGOs located in 
the community of the same city. The researcher utilized two different types of research settings to assure there would be accessibility to an adequate sample of participants.

\section{Sampling}

Purposive sampling, specifically criterion sampling (Creswell, 2007; Patton, 2002) was used in this study. When determining the sampling strategy for qualitative research Patton (2002) suggests the use of purposeful sampling. Patton (2002) asserts "the logic and power of purposeful sampling lie in selecting information-rich cases for study ... studying information-rich cases yields insights and in-depth understanding rather than empirical generalizations" (p. 230). Morse (1991) asserts the sample must be selected to assure the sample is "knowledgeable about the topic and experts by virtue of their involvement in specific life events and/or associations" (p. 132). Therefore criterion sampling, a type of purposive sampling (Patton, 2002) was chosen due to its appropriateness for sample recruitment in this current study. Criterion sampling (Creswell, 2007; Patton, 2002) is a recommended approach to sampling when researching the lived experience of a phenomenon. When conducting phenomenological research it is necessary that all the participants have experienced the phenomenon understudy. In the current study the criterion that guided the sampling was women had to have experienced sexual offence victimization and sought help at any point after being victimized.

Morse (1991) contends the appropriateness of a sample is determined by "informant characteristics" and "by the type of information needed by the researcher" (p. 135). Therefore the service providers involved in the pilot study and one additional service provider from a local university were contacted and asked if they would assist with identifying potential candidates from their past or present clients. At the time of the 
study all the service providers were assisting victims of violence, including victims of sexual offences. Therefore the service providers were ideal to assist with the criterion sampling due to their daily work with victims of sexual offences. Additionally, working with the service providers facilitated accessibility to an adequate number of potential participants.

Sample size in qualitative research is typically far smaller than that of quantitative research (Sandelowski, 1995). According to Sandelowski (1995), "sample size is ultimately a matter of judgment and experience in evaluating the quality of the information collected against the uses to which it will be put. .." (p. 183). According to Sandelowski (1995) sample size is determined by achieving saturation. Saturation is achieved when information provided by participants begins to repeat and no longer results in the emergence of new themes (Patton, 2002; Sandelowski, 1995)

According to Benner (1994) the sample size of a phenomenological study may change during the research period. The sample size should be contingent on the researcher's interview plan (e.g., single or multiple interviews with participants) and the quantity of the text (Benner, 1994). Benner further maintains it is the "quality of the text and the way the lines of inquiry are reshaped by the participants" that also determine the sample size (Benner, 1994, p. 107). Parse (1990) suggests a sample size of two to ten for phenomenologic studies "in that the quality of redundancy is sought" (p.10). The redundancy Parse (1990) speaks of is the notion of saturation described by Sandelowski (1995). Morse (1991) posits the researcher must be aware of the full extent of the data that has been collected throughout the course of study to address adequacy of study data. According to Sandelowski (1995) sample size may be increased until saturation of data is 
met, and new themes no longer emerge. For the current study it was estimated that a sample size of five to 10 women would be recruited, ultimately six participants were recruited. The researcher's awareness of the data that was collected facilitated identifying when saturation had been achieved, and therefore no need to increase the sample size. Saturation was achieved with the sixth study participant.

Three additional sources of data were used for the purpose of triangulation. These sources of data included two books and one manuscript. All three sources were by South African authors and meet the criterion of women who had sought help after sexual offense victimization (Lotter, 2005; Muholi, 2004; Umlilo, 2002).

\section{Inclusion Criteria}

The study sample included South African women, 18 years of age and older, who resided in the country of South Africa, and had sought help after experiencing sexual offence victimization. Study participants had to be conversant in English, and agree to participate in at least three interviews. They also had to agree the interviews could be recorded. The occurrence of the sexual offence victimization may have been at any point during the lifetime of the participant.

\section{Procedures}

Recruitment Procedures. Study participant recruitment was conducted in two ways and both employed criterion sampling. The first approach to recruitment was asking the care providers who participated in the pilot study to assist in identifying potential participants for the study according to the established criterion.

Before the care providers discussed the study with any potential participants the researcher met with each of the providers to explain the study. During the meeting the 
researcher discussed the details of the study and the care provider's recruitment role. The discussion included the purpose of the study, why their assistance was important to the study, and the ethical considerations of the study. Considerable effort and emphasis was placed on the discussion of the ethical considerations of the study. The ethical standards of respect for persons, beneficence, and justice were discussed with each care provider to assure they understood how the standards applied to the ethical conduct of research, and how they were to be upheld during the course of the study. Particular emphasis was made regarding the ethical standard of respect for persons in relation to informed consent, and why informed consent had to take place before a person could participate in the study. Additionally, voluntary participation, and, participant privacy and confidentiality were emphasized, and why each was essential when conducting ethical research.

To assure that beneficence was upheld the researcher emphasized that participants would not directly benefit from participating in the study, however, the study findings could potentially benefit society. To minimize the risk of potential psychological distress associated with participating in the study, the care providers who assisted with the recruitment of participants were asked to be prepared to provide additional assistance to any participant who they had identified from their client base and was in need of services as a result of psychological distress. Because each of the care providers who assisted with participant recruitment worked to provide care for victims of sexual offences on a daily basis, they were well suited to provide additional counseling if needed. However, during the course of the study there was no additional counseling needed.

To assure justice was maintained, the researcher discussed with care providers the importance of the fair selection of study participants. The researcher emphasized when 
potential participants were identified it should not be based on "social, racial, sexual, economic, or cultural biases institutionalized in society" (University of Louisville Investigators Guide, 2011, p. 13).

The second approach to recruitment was gaining the assistance of the local university's social worker. She had not participated in the researcher's pilot study. Her role as a social worker included providing counseling to victims of sexual offences. The exact same procedures were used to ensure understanding of the study. And, the ethical standards respect, beneficence, and justice were thoroughly explained.

Data Collection Procedures. Prior to participating in any interviews the participant provided written consent that they voluntarily participated in the study. The first data collected were demographics. See Appendix D. Next, a series of up to three interviews were conducted with each participant. The participants were asked open ended questions related to their lived experience of help-seeking after sexual offence victimization. Questions were directed to elucidate the meaning participants attributed to their lived experience. See Appendix E for the interview guide. Participant interviews were recorded and transcribed verbatim to assure the retention of the authenticity and richness of the data collected. All interviews were conducted in English by the researcher. Each participant received R100 for each interview they completed. At the time the study was conducted R100 was approximately $\$ 11.00$ US dollars. The procedure for the payment of study participants followed University of Louisville (2011) protocol for payment in international research. According to pay rates published by Nursing Services of South Africa (2012) the participant payment of R100 was approximately equal to two hours of pay for a registered nurse working in a government hospital ward. 
A second participant payment comparison done was according to the Department of Labour Republic of South Africa's (n.d.) published guidelines for domestic workers' wages for the yearly period of 2012 through 2013 . The payment of R100 was equal to approximately 12 hours of a domestic worker's wages.

Human Subjects Protection Procedures. The researcher obtained Institutional Review Board (IRB) approval from the University of Louisville's (Uof L) Social/Behavioral/Educational IRB. The Faculty of Humanities of the South African university also provided ethical clearance to conduct research. Research activities that took place on the university campus followed the human subject's protection guidelines as required by that university as well as Uof L. Research activities that took place at the community research sites (i.e., the NGOs) followed human subject protection guidelines as required by the Uof L IRB, and human subject's protection oversight required by the NGOs (e.g., confidentiality).

The researcher initiated the informed consent process by stating to the potential participant that participation in the study was completely voluntary. The researcher then explained voluntary informed consent. Next, potential participants were provided with a paper copy of the informed consent. The researcher then read each section of the informed consent to the potential participant. At the completion of each section the participant was asked if they had any questions concerning that section of the informed consent. The researcher then asked the participant to describe the meaning of that particular section that was read. If the researcher perceived a participant did not fully understand the section, the researcher read the section's information again to assure the participant had clarity of understanding. The process was repeated until the researcher 
was confident the participant clearly understood the information. This process continued throughout each section of the informed consent. Upon completion of this process the potential participant was then asked if they had questions concerning any aspect of the informed consent, or about participating in the study. If they had no questions they were then provided the opportunity to sign the informed consent. No potential participants declined to participate in the studied upon completion of the informed consent discussion. Upon signing the informed consent a copy of the signed form was made and given to the participant for their records. Throughout their participation in the study the participant was reminded their participation was completely voluntary and the information they provided would be kept confidential.

\section{Ethical Treatment of Human Subjects}

All efforts were made to conduct an ethically sound and respectful study. The guidelines used for the ethical conduct of research involving human subjects were those as indicated in the University of Louisville's Investigators guide (2011), and supported by the foundational documents, the Nuremberg Code and the Belmont report. Upon receiving IRB approval from the researcher's university the researcher provided the South African university with documentation identifying the researcher's home university IRB approval. The researcher then applied for, and received ethical clearance from the South African university.

Two key documents provided components of the ethical foundation for conducting the study. The two documents were the Nuremberg Code (1949) and the Belmont report (Belmont Report, 1979; University of Louisville, 2011). Because the study was a social/behavioral study involving no experiments the Nuremburg Code 
directed voluntary consent be provided to any human subject participating in research. The remaining ethical guidelines were provided by the Belmont report.

Of particular importance to research being overseen by the researcher's IRB were the ethical principles described by the Belmont Report (1979); they are respect for persons, beneficence, and justice (Belmont Report, 1979; University of Louisville, 2011). Respect for persons is the right of the individual to make their own choice of whether to participate in a study or not (University of Louisville, 2011). Beneficence is the principle to do no harm to human subjects participating in research, and to maximize benefits and minimize risk that may be associated with research (University of Louisville, 2011). Justice is the principle of assuring participants have equal access to participate in the research, in addition to sharing equally the burden of research (University of Louisville, 2011).

Respect for persons guaranteed the prospective participant the right to voluntary participation in the study. To reduce threats to human subjects who participated in the proposed study, voluntary informed consent was obtained according to the Nuremberg Code (1949). Voluntary informed consent indicated the potential study participant clearly understood that their participation in the study was voluntary, which was emphasized throughout the recruitment process. Once an individual decided to participate, the individual was reminded that at any time they could remove themselves from the study without fear of retribution

The principle of beneficence was consistently employed during the course of the study (Belmont Report, 1979; University of Louisville, 2011). There was some psychological risk in the study associated with the participant's discussion of their 
experience after a traumatic event. If a participant became distressed as a result of discussing her experience the researcher had arranged for the care provider who had identified the participant to provide any further needed care.

Further efforts to maintain the principle of beneficence included all information provided by participants being kept confidential and was shared only as needed with individuals directly involved in the study (e.g., researcher, researcher's South African mentor, researcher's dissertation committee). All participant consents were kept in a locked cabinet in the researcher's mentor's office on the campus of the South African university. All study data collected through interviews with participants was stored on a password protected computer.

The principle of justice directed the compensation for the study participants. Each of the women in the study was compensated with R100 for each interview in which they participated. Each participant was equally compensated. If a participant chose to withdraw from the study during the process of an interview the participant would still receive compensation for their participation in the current study. No participants chose to withdraw from the study.

\section{Data Collection}

Data collection was conducted using several different sources. When using the methodological approach of hermeneutic phenomenology, van Manen (1990) suggests study data may be found in a variety of sources including interviews, art, theatre, or literature. Thus, one source of data collection was a series of in-depth interviews conducted with South African women concerning their lived experience of help-seeking after victimization by sexual offence. It is common practice in phenomenological 
research to conduct a series of interviews with each participant (Benner, 1994; Bergum, 1991; Creswell, 2007). According to Bergum (1991) and Creswell (2007) conducting a series of interviews with each participant will facilitate the process of clarification. Specifically, Benner (1994) suggests carrying out a series of interviews with a participant allows the researcher to more thoroughly understand meanings the participant apply to their experiences. Using the technique of multiple interviews allowed for probes to be developed and used to seek a deeper, more insightful understanding of the essence of the participant's lived experience.

Interviews were conducted in English. In 1994, eleven official languages were declared in South Africa, thus language usage varies considerably throughout the different provinces of South Africa. However, many South Africans commonly speak English (S. Ferreira, personal communication, July 19, 2011). Education throughout South Africa is largely conducted using the English language (S. Ferreira, personal communication, July 19, 2011). During the pilot study, the researcher observed many South Africans in the recruitment sites spoke English.

When conducting phenomenological research (Creswell, 2007; Richards \& Morse, 2007; van Manen, 1990) other data sources may be used. Data sources may include art, theatre, poetry, or literature. For this study, data was gathered from three South African publications (e.g., 2 books and 1 manuscript). All sources were chosen for their congruency with the criterion used for sampling. This was done by choosing sources in which the subjects of the sources were women who had experienced sexual offence victimization and sought help at any point after being victimized. This assured the other data sources aligned with the purpose of the study and would therefore contribute to 
gaining understanding of the lived experience of sexual offence victimization. The sources were limited to the language of English.

\section{Data Analysis and Interpretation}

Data analysis and data collection took place simultaneously. At the completion of each interview the researcher transcribed the audio recorded interview. NVivo data management software version 10 (QSR International, 2013) was used to aid the processes of managing data and data analysis. Data sources other than interviews (e.g., two books and manuscript) were digitally imported into the NVivo software, and underwent the same process of analysis as did the interviews.

Thematic data analysis was conducted according to van Manen (1990). First, thematic statements were identified. To identify thematic statements van Manen (1990) suggested using one of the following options; reading and reflecting on the text as a whole, identifying statements or phrases that are significant, or reading textual data sentence by sentence. The researcher chose the approach of identifying significant statements (i.e., thematic statements) in each interview. Once identified, thematic statements were grouped according to the salient point of each statement. Grouped thematic statements from each interview and from the other data sources were then brought together across all data, and regrouped so that groupings were inclusive of the full data set. The grouped thematic statements were then again grouped in accordance to emerging themes. Once themes were established, the process of identifying the meaning (e.g., essence) of each theme took place. This was done by reading and rereading themes, and reflecting on themes. Themes and their meanings were compare throughout all study data to better understand the established themes and meaning in the context of whole data 
set. The last step in the process of van Manen's thematic analysis was to then to synthesize essential themes and their meanings across the full data set.

Once the essential themes and their meanings across the full data set were finalized, the themes and their meanings underwent a final stage of analysis guided by van Manen's (1990) four existentials of lived space, lived body, lived time, and lived other (p. 101). This final step in analysis added additional understanding concerning a woman's existential lived experience of help seeking after sexual offences victimization. The existential lived space refers to the space a person occupies at an abstract level, van Manen refers to it as "felt space" (p. 102). The lived body "refers to the phenomenological fact that we are always bodily in the world" (p. 103). This existential has the potential to take on considerable significance in understanding a woman's helpseeking experience after sexual victimization. Lived time "is subjective time as opposed to clock time" (p. 104). Lived time is the experience of time in the context of the lived experience. The last of van Manen's (1990) four existentials is the lived other. The lived other concerns "the lived relation we maintain with others in the interpersonal space that we share with them" (p. 104). This final step in analysis added additional understanding concerning a woman's existential lived experienced of help seeking after sexual offences victimization.

\section{Trustworthiness}

The Lincoln and Guba (1985) trustworthiness criteria were chosen as the approach to guide rigor in the current study. Lincoln and Guba determined the criteria for trustworthiness to be credibility, transferability, dependability, and conformability. Lincoln and Guba (1985) established their criteria for trustworthiness in response to their 
desire to develop evaluative criteria equal in rigor to the conventional criteria used when evaluating statistical evidence, but was appropriate for use with qualitative research. A compelling factor to the development of their trustworthiness criteria was their reaction to accusations of qualitative research lacking rigor. Lincoln and Guba (1985) presented their criteria as analogous to conventional criteria, but pointed out they did this to also illustrate the "inappropriateness of conventional terms when applied to naturalism and to provide alternatives that stand in a more logical and derivative relation to the naturalistic axioms" (p. 301). At the time Lincoln and Guba (1985) developed their criteria, they positioned qualitative research in a paradigm they labeled as naturalistic. They have since redefined their position and now posit themselves in the constructivism paradigm (Lincoln \& Guba, 2013)

For some scholars Lincoln and Guba (1985) positioning their criteria as analogous to conventional criteria has been a point of contention (de Witt \& Ploeg, 2005; Manning, 1997, Sparkes, 2001). Tobin and Begley (2004) point to member checks, a component of the trustworthiness criteria of credibility, as one of their points of contention. They assert member checking contradicts the epistemological notion of multiple realities and that there is no one truth (Tobin \& Begley, 2004). Rolfe (2006) asserts "each study should be justified on its own merits", there can be no "generic framework for assessing the quality of qualitative research" (p. 309).

Lincoln and Guba's (1985) trustworthiness criteria are only one of many constructs of evaluative criteria that have been developed to achieve rigor when using qualitative methods. There is considerable debate, however, regarding what criteria constructs are appropriate and how they should be applied. Sandelowski (1986) suggested 
the criteria of credibility, fittingness, auditability, and conformability. Maxwell (1992) presented the criteria of descriptive validity, interpretive validity, theoretical validity, generalizability, and evaluative validity. And last, Meleis (1996) established the criteria of contextuality, relevance, communication styles, awareness of identity and power differential, disclosure, empowerment, and time. After considering the variety of constructs for use, Lincoln and Guba's (1985) criteria for trustworthiness was determined to be the most appropriate for the current study. Also supporting the researcher's decision to use trustworthiness was the number of researchers who had used trustworthiness as their criteria for rigor in phenomenological research conducted in South Africa (Brysiewicz, 2008; Collier-Reed, Ingerman, \& Berglund, 2009; Hoffman, Myburgh, \& Poggenpoel, 2010; Mavundla, 2000; Pietersen, 2007; Tshitangano, Maputle, \& Netshikweta, 2013; Warden, Mayers, \& Kathard, 2008).

Lincoln and Guba's (1985) criteria for trustworthiness includes credibility, transferability, dependability, and conformability. Kafle (2011) reported that "all these quality claims [of trustworthiness] may not fit appropriate[ly] with hermeneutic phenomenology" (p. 196). Credibility according to Lincoln and Guba (1985) may be achieved through five techniques: 1) prolonged engagement, persistent observation, and triangulation; 2) peer debriefing; 3) negative case analysis; 4) referential adequacy; and 5) member checks. In the current study credibility was achieved using prolonged engagement, persistent observation, triangulation, and member checks (e.g., member checks as defined in the context of the current study). Prolonged engagement supported the researcher in "learning the context, to minimize distortions, and to build trust" (Lincoln \& Guba, 1985, p. 307). While conducting the study the researcher lived in South 
Africa over a three month period of time. The researcher had previously spent three months in South Africa conducting a pilot study (Steinbrenner, 2011). During both visits, the researcher developed a beginning familiarity with the South African culture, and the South African context. Lincoln and Guba (1985) assert "it is not possible to understand any phenomenon without reference to the context in which it is embedded" (p. 302). Building trust also occurs with prolonged engagement, trust is a vital component to conducting research using interviews.

According to Lincoln and Guba (1985) developing trust is a process that occurs over time. While conducting the pilot study the researcher developed a trusting relationship with service providers. And as a result those service providers assisted the researcher in identifying potential participants from their clients. Thus the researcher had the opportunity to continue to build trust with the service providers which assisted in establishing trusting relationships with study participants. Additionally, trust was built as the participants gained the understanding the researcher valued their participation and the information they shared.

Persistent observation advances the researcher's ability to refine the focus of their research and maintain focus on matters of importance that assist in leading to understanding (Lincoln \& Guba, 1985). Persistent observation is the process of identifying and focusing on the "characteristics and elements of a situation that are most relevant... persistent observation provides depth" (Lincoln \& Guba, 1985, p. 304). The process of persistent observation strengthened the researcher's ability to maintain a strong orientation to the phenomenon understudy. 
Triangulation according to Lincoln and Guba (1985) may be established using "multiple and different sources, methods, investigators, [or] theories" (p. 305). Triangulation in the current study was achieved using different data sources (e.g., two books and a manuscript). This approach to triangulation established contextual validation. Using three additional data sources provided the needed resources to compare meanings, concepts, and contexts which provided support to the credibility of the study.

Credibility was also achieved through the process of member checks (Lincoln \& Guba, 1985). Member checks in this current study were defined as the researcher discussing with each participant details from their interviews to provide clarification. This was important in that the researcher was not South African, and it was important that clarity of understanding be pursued so that the study outcome properly reflected the lived experience of the participants. The researcher conducted member checks with the study participants throughout the research period. This was accomplished through the researcher reviewing transcripts and discussing her understandings with the participants in subsequent interviews. However, it was not possible to do a member check with the woman who participated in only one interview. Therefore the researcher carefully summarized and verified the interview content that was available. This process of member checks assisted the researcher in accomplishing the methodological goal of building understanding of the participants experience as it was lived. The building of understanding was imperative to the development of essential themes that characterize the phenomenon of help-seeking after experiencing a sexual offence.

Transferability when applied in the context of conventional rigor is achieved through external validity. However, in the context of trustworthiness transferability is 
very different (Lincoln \& Guba, 1985). In trustworthiness transferability must always be understood in the context of the "time and context" of that particular research that is being conducted (Lincoln \& Guba, p. 316).

Whether they hold in some other context or even in the same context at some other time is an empirical issue. . Thus the naturalist cannot specify the external validity of an inquiry; he or she can provide only the thick description necessary to enable someone interested in making a transfer to reach a conclusion about whether transfer can be contemplated as a possibility. (Lincoln \& Guba, 1985, p.

Therefore transferability in this study was achieved by establishing thick description. Thick description provided understanding of time and context at the systems levels of the micro-, meso-, exo-, and macrosystems.

According to Lincoln and Guba (1985) to establish dependability and confirmability (e.g., the qualitative parallel to reliability and the absence of bias) an audit trail should be created. The audit trail for a qualitative study should include the following elements: (a) raw data, (b) data reduction and analysis products, (c) data reconstruction and synthesis products, (d) process notes, and (e) materials relating to intentions and dispositions (Lincoln \& Guba, 1985, pp. 319-320). Establishment of the audit trail for this study was guided by Lincoln and Guba's recommendations (Lincoln \& Guba, 1985). The audit trail included: audio recorded interviews and transcripts, the two books and the manuscript used as data sources, identified thematic statements, thematic statement groupings, analysis of descriptive terms, notes and drawings created in the process of 
interpreting data, interpretive notes and drawings created in the process of analysis, and field notes.

To assist in the organization of the research data and associated notes the researcher used computer software.

To further establish dependability and confirmability the researcher employed reflexivity. Throughout the research process, researcher notes were kept to record thoughts, experiences, or assumptions that emerge. The researcher's notes were used to support the process of reflexivity. Reflexivity is the process of the researcher gaining personal understanding. To accomplish reflexivity in the research process researchers must consistently ask themselves "what do I know ... how do I know what I know ... what shapes and has shaped my perspective. . with what voice do I share my perspective. . . what do I do with what I have found" (Patton, 2002, p. 66). Shope (2006) asserts it is important not to deny who the researcher is as a person, and that must always be part of discussion, and always revisited through the process of reflexivity. The process of reflexivity was ongoing. Therefore this researcher reflexively contemplated and acknowledged previous understandings of the phenomenon being studied. Of particular importance was reflexivity about the country of South Africa and of the people of South Africa as the research process occurred.

\section{Summary}

To effectively investigate the research question, what is the lived experience of help-seeking behavior of South African women after sexual offence victimization, the research method of hermeneutic phenomenology was chosen. Guiding the research process was the methodological approach of van Manen (1990). The study design was a 
hermeneutic phenomenological qualitative study. Purposive criterion sampling was used, and the sample size was six participants and three literature data sources. Data collection took place using interviews. And, data was also gathered from three South African literature resources. Thematic analyses of the data was done using van Manen's (1990) approach to thematic data analysis. Trustworthiness was achieved using Lincoln and Guba's (1985) criteria of credibility, transferability, dependability, and conformability. 


\section{CHAPTER IV \\ RESEARCH FINDINGS}

The purpose of this study was to investigate the lived experience of help-seeking behaviors of South African women after sexual offence victimization. First, in this chapter participant demographic data will be presented. Next, the essential themes of the phenomenon of help-seeking after sexual offence victimization as experienced by South African women will be reported. The research results presented in this chapter will reflect van Manen's (1990) process of analysis through "reflecting on the themes which characterize the phenomenon" (p. 77) and "the process of writing and rewriting" (p. 112). Additionally, a final stage of analysis guided by van Manen's (1990) four existentials of lived space, lived body, lived time, and lived other was completed. The existential analysis is presented last.

\section{Participants}

Six South African women participated in this study. A total of 11 interviews were completed. Each woman experienced sexual offence victimization and sought help at some point after the offence occurred. To protect the identity of the participants the researcher gave each of the women a pseudonym

Lerato. Lerato is a 24 year old black South African woman. The name Lerato is a Sesotho name that means love. This pseudonym is significant because of the story she shared of her love for her child. A characteristic the researcher noted was that Lerato was quick to laugh. During the first interview with Lerato the researcher interpreted her laugh 
as a nervous laugh. But, with further dialogue and as the first interview progressed it became clear that Lerato had a keen sense of humor and a quick wit. She had completed 12 years of school and planned to attend university as soon as she was finished with the court proceedings associated with her sexual offence victimization case. Her court case had continued for over three years and there seemed to be no end in sight. She talked about her inability to enter university until the court case was finished. Lerato further explained that the court case was very disruptive to her life. On the days she had to appear in court, by the time she traveled into town, spent the time required of her for the court proceedings, and then traveled back home it took a full day. There were a number of times she had specifically arranged her schedule to attend court only to learn once she was there that the scheduled court proceeding for her case had been canceled for the day. Lerato was concerned that all the time she had to be available for court proceedings would interfere with her attendance to class. Thus she did not want to take that risk and undermine her success by returning to school before her case was completed.

Additionally, she explained the court case was emotionally exhausting. She had to see her rapist each time she was in court and that experience greatly affected her ability to focus. Given everything that Lerato had been through and continued to go through she remained very positive about going to university. She was determined the day was nearing when she could move forward with her educational goals. At the time of her first interview she was unemployed. However, by the time she completed her second interview she was working part time to earn money to pay for the cost of registering for university. She wanted to make sure she would have the money needed when the time came to register. 
Lerato had been repeatedly raped by her father during many of her teen years. As a result of the rapes Lerato became impregnated by her father and was forced to abort each pregnancy but the last.

...after I found out that I was pregnant, that's when I stopped everything, and then I just said you are no longer going to touch me anymore. That's when I just decided I'm going to put everything to an end. Of which by then he was forcing me to abort and all that, so I just said no. This thing has got to come to an end...So after the baby...he never touched me again. Yes, he tried doing so and then I just refused him to touch me anymore so that's why things just got out of hand. He started threatening me like real bad...but I never let him touch me after that.

Lerato delivered a son whom she loved very much. Two years later while Lerato was away from home trying to decide what to do about reporting her victimization her son died. The death of her son escalated her urgency to report her victimization, and following his death she began her help-seeking experience in earnest.

Vivienne. Vivienne was a 40 year old white South African woman. She completed matric (e.g., graduated high school) and continued with her education graduating from a post-secondary technical school. At the time of her interview she was employed and earned approximately R1500 (e.g., approximately \$150 US dollars) each week. When Vivienne separated from her husband she moved far from her hometown to the town where her sister lived. After moving, she lived with her sister and her sister's boyfriend. It was during this time she was raped by her sister's boyfriend. Vivienne's rapist was a former police officer with the South African Police Service. When Vivienne told her sister about the rape her sister made Vivienne move out of the house.

I didn't know anyone here except my sister, and it was her boyfriend. So...she moved me out of the house when I told her and I went to stay with a friend of hers. I knew no one, and that's why I went to the police.

Vivienne's help-seeking experience started with her reporting the rape to the police. 
Bontle. Bontle was a 23 year old black South African woman. She was in her senior year of university and preparing to graduate at the end of the term. Bontle was preparing for a professional future in the discipline of mathematics. As her first interview began the researcher quickly learned Bontle was a very articulate, intelligent woman. At the time of her interviews she was not working, but she received an undisclosed amount of support from her parents each week. Immediately following graduation she planned to move back to her hometown. She was very excited to be moving home so that she would be able to spend much more time with her mother. However, she stated with a laugh she was not so excited about beginning her professional career because of all the responsibilities that would come with it. She laughed again and said she guessed that was all part of growing up. When Bontle was in her mid-teens she and her best friend were gang raped.

After I got raped, I was with my friend...the two of us...got raped on the same night. We fell asleep and when we woke up...we were still at the place where we got raped...it was very early in the morning...and these guys were still there...We just want to go home! Where are our cell phones?... They took us to this other house...Your cell phones are in here. So no one opened the door...and the guys asked us where we lived. We said we just live up the road even though we didn't. So we walked, we didn't even know where we were we just walked until we found an old man sitting there. He was driving a taxi. We were like, please just take us to the police station we just need to get to the police station.

It was at the police station that Bontle's help-seeking experience began and it lasted for many more years.

Mbali. Mbali was an engaging 22 year old black South African woman. The researcher gave her the pseudonym Mbali, which means flower. Like a flower in spring she was blossoming into a strong and very determined woman. Mbali had been on a long journey to get to where she was when the researcher met her. She was in her sophomore 
year of university, and shared with the researcher she came from a family that placed a great deal of importance on education. At the time of her interviews she was receiving financial support from an undisclosed source. She received R300 (e.g., approximately $\$ 30.00$ US dollars) a week in addition to R250 (e.g., approximately \$25.00 US dollars) at the end of each month as needed. She also worked intermittently at part time jobs when she needed extra income.

Mbali was 13 years of age when she experienced sexual offence victimization. Intruders entered her family's home late one night. On that night she and her mother were both raped. Not long after she and her mother were raped Mbali learned it was rumored in the community that her father had set up the rapes because her mother had divorced him.

after...the rapists left, my mother called one of our neighbors who was a police officer, so she called him and he came and he took me to the police station. My mother was also raped, but she stayed behind for statements and everything...

After going to the police station, a police officer then took Mbali to a hospital for medical services, she spent the next eight hours there. The hospital was dealing with a shortage of nurses and doctors thus it took a very long time for Mbali to be seen. At that point Mbali started her help-seeking experience. Much like Bontle, Mbali's help-seeking experience continued for many years.

Nontle. Nontle was a bright 26 year old woman who had completed matric (e.g. graduated high school) and finished additional training in a professional role assisting victims of violence. She lived with her mother and father, and worked in a paid professional position in her community helping people find the assistance and services they needed after victimization (e.g., criminal victimizations including sexual offences 
victimization). Her professional role also included working as an advocate for victims of sexual violence. Like many of her clients Nontle had experienced sexual offence victimization. She was an ingenious woman who turned the negative experience of rape into a positive outcome. In the year after she had experienced victimization she became a volunteer in her community police station. During her time as a volunteer she assisted women and children from the community who had experienced sexual offence victimization. She explained to the researcher that while volunteering she discovered her love of helping people and shared with the researcher that during that time she came to the conclusion she was born to help people. After ending her volunteer role she returned to school and graduated from a program that prepared her for the professional role she was working in at the time of the study interviews. It was very clear to the researcher that Nontle had a great passion for her work.

Nontle was 19 when she experienced sexual offence victimization. She was raped at a railway station just outside of town. The rapists were armed and they threatened to kill her. She begged for her life and offered to give them all that she had with her. They took her phone, her choir apparel she had with her that day, her athletic garments, and all the money she had.

So when they took my things they said run before we change our mind. And that's when I ran out and when I ran the blood was dripping out, because I was a virgin....I then walked to town, and then...I was tired and I didn't know where to go. And then I remember I had a friend...

Nontle went to a friend's apartment who was in the choir with her and that is when Nontle began her help-seeking experience.

Annalie. Annalie was a 41 year old white South African woman. She had an abundance of energy and took pride in living a healthy lifestyle. Annalie was very goal 
oriented and had worked hard to accomplish her academic goals. She had completed a bachelor's degree, specialized training, and at the time of her interviews she was working on a master's degree. Annalie was a very articulate and outspoken woman with a strong character. Annalie managed a group of people and was proud to declare she had a very good working relationship with her employees. Annalie's weekly salary from her professional role was approximately R8000 (e.g., roughly $\$ 800$ US dollars). Annalie was a single mother and lived in a house with her young daughter and disabled mother. She cared for her mother in the evenings and on weekends. About three years before the interview for this study Annalie was raped during the night in her home as her mother and daughter were sleeping in other rooms.

Initially I didn't want to seek help, because the guy when he went out he...threatened me, and I thought but I mustn't go to seek for help. Then I thought...oh no this couldn't happen to me, it was sorta disbelief. Then my mom and a friend I had phoned...said to me oh no I need to report it...I decide no I must not report because it was not a violent rape. And then my mom and my friend said...this must be reported.

Annalie was able to arrange her medical care so that she had immediate access to the prophylactic treatment she needed to prevent HIV transmission and pregnancy. After she received medical care she telephoned the police. Later in the night she was processed for forensic evidence. For Annalie, her help-seeking experience began with encouragement from her mom and a friend.

\section{Other Data Sources}

In addition to participant interviews, three other data resources were used to explore the lived experience of help-seeking by South African women. They were It's me Anna (Lotter, 2005), Little Girl Arise (Umbilo, 2002), and Thinking through Lesbian Rape (Muholi, 2004). 
Anna. It's me Anna is a book written by the South African author Elbie Lotter (2005). It's me Anna is based on Lotter's lived experience of sexual offence victimization by her stepfather. The main character of the book is Anna, a white South African girl. Anna's father and mother divorced when she was very young. When Anna turned eight her mother introduced her to Danie (i.e., her mother's boyfriend) and within a short period of time her mother and Danie were married. On Anna's tenth birthday her stepfather Danie began to sexually abuse her and he continued to sexually abuse her into her mid-teens. Along with sexual abuse Anna's stepfather also physically abused her. Anna's stepfather forced her to have sex with him almost daily, and when she did not meet his sexual expectations he would beat her. Anna's mother gave birth to a daughter when Anna was 13 years old. As time passed her stepfather began to threaten to sexually abuse her baby sister if Anna did let him sexually abuse her. At 16 Anna learned she was pregnant. Not long after learning she was pregnant she came home early from school one day and found her stepfather sexually abusing her three year old sister in their backyard pool. Anna told her mother about her stepfather sexually abusing her sister but Anna's mother refused to believe her. That is when Anna's long journey of help-seeking began.

Thandeki. South African author Thandeki Umlilo's (2002) autobiography Little Girl Arise describes her life experiences of sexual offence victimization by her father, uncle, and others. Thandeki's sexual offence victimization began when she was in preschool. One day her father called her into her parent's bedroom and told her to "touch and stroke" his penis (p. 4). Because he was her father she did not argue. For many years Thandeki's mother and father's marriage had been very strained, and Thandeki posited that as a result her father used her to meet his sexual desires. Her father's sexual abuse 
continued for many years until Thandeki left home to become a nun, at that time she began her help-seeking experience.

Kid. Zanele Muholi (2004) a South African photographer, former community activist, visual activist, and lesbian, authored an article "Thinking Through Lesbian Rape". In her article she discussed stories of physical and sexual violence against lesbians, and focused on violence that was committed by members of the lesbians' communities. Muholi interviewed 47 women about violence. One of the stories she included, is a story of Kid. A young black lesbian who was raped by a man she considered to be a close friend. Kid contacted Muholi to help her after being raped, and at that point Kid began her help-seeking process.

\section{Summary}

Many South African women do not seek help after sexual offence victimization. However, all six of the participants, as well as Anna, Thandeki, and Kid were included in this study because they did seek help. All the women but Thandeki reported their victimization to the South African Police Services (SAPS). Some of the women were pleased with their interaction with SAPS and others were not. Most of the women received medical services: some believed the medical care they received was very good and others were quite disappointed with the medical care they received. All but Thandeki and Anna were recipients of services provided by social workers. And, each of the women received some form of mental health counseling (e.g., formal or informal mental health counseling). Of all the women in this study including Anna, Thandeki, and Kid, only two of them had their cases tried in court. Only Bontle's victimizers were jailed. In the remainder of this chapter the essential themes of the phenomenon of help-seeking as 
lived by South African women after sexual victimization will be discussed. Additionally the existential analysis of lived space, lived body, lived time, and lived other will also be discussed.

\section{Findings}

Thematic statements (van Manen, 1990) were first identified through reading and reflecting on each interview. The identified thematic statements from each participant interview and from the other data sources were then reflected on again, and synthesized with thematic statements developed from each participant's set of interviews. The last step of thematic analysis involved a synthesis of the essential themes and determination of their meaning (e.g., the essences of the themes) across the whole data set. The researcher then conducted a final step of data analysis. The essential themes and their meanings were again reflected on and the process of interpretation was conducted, guided by van Manen's (1990) four existentials; lived space, lived body, lived time, and lived other.

\section{Essential Themes}

Data analysis revealed four essential themes from the women's interviews and the other data sources. They were decision making, silence, critical junctures in mental health, and moving forward. Decision making is conceptualized as a complex process that is impacted by many factors. Most often it does not occur as a singular event, but typically occurs as a part of a series of decision making events. This process is informed by a woman's perceptions and experiences. Silence is an accepted and often expected reaction to sexual offence victimization. Silence is described as never talking about sexual victimization. Silence is compelled by shame, by self-blame, a desire to forget the 
experience as a way of coping with victimization, and as a means of keeping the victimization a secret. Critical junctures in mental health are conceptualized as any point in time a woman experiences psychological distress after she has experienced sexual offence victimization. While experiencing psychological distress a woman may choose to seek help, or may be disposed to experience a further decline in her mental health status. The essential theme moving forward denotes a woman's experiences that move her toward and into healing. Moving forward is a process that takes place over time. For example, a woman may experience or be threatened with retaliation which may slow her forward movement into healing. However, other experiences work to move a woman forward, advancing her into healing. A discussion of each essential theme and examples that exemplify the themes follow.

\section{Decision Making}

Decision making after sexual offence victimization is a complex process with myriad factors influencing help-seeking decisions. Study findings revealed factors influencing a woman's decision making process were impacted by her perceptions and experiences. Her help-seeking decisions may have been impacted by her perceptions of: the degree of severity of violence she experienced during the sexual victimization, what is expected of her socially or culturally, the risk of losing resources, or who will be the appropriate service providers. Experiences impacting her decision-making process may include interactions she has previously had with service providers such as the police, nurses, social workers, or others. Study findings revealed women will most often need to make many decisions as they seek help and therefore the process should be conceptualized as a series of complex and interrelated decision making events. 
Perceived severity of violence. Research findings indicated a woman's perception of the severity of violence she experienced during her sexual offence victimization influenced her decision of whether or not to undertake help-seeking behavior. Findings demonstrated that a woman would potentially be more compelled to report sexual victimization to the police if she perceived it was a violent act. For example, Annalie grappled with this issue after being raped. She did not perceive her experience as a violent act.

I didn't know, must I report it or must I not report it. So I decide no I must not report because it was not a violent rape.

Annalie explained to the researcher that the rapist did not hit her or otherwise physically injure her; therefore she perceived her rape as not being a violent rape. Later in the interview Annalie reflected on a rape she had heard about in the news. She described the rape as a violent rape. She told the researcher the rape had been committed by three men who had been hired to rape and kill a man's wife. The hired men raped the wife, cut her breasts, and inserted items into her vagina before killing her.

It was really a traumatic rape, a violent rape, and I can still remember that morning I heard the news over the radio...So I thought I got raped in a sort of gentle...in a gentle way...I was so thankful for the way I was raped, not being raped in a violent way.

Annalie's perceptions of rape seemed to fall along a continuum where on one end were violent rapes defined as forced sexual acts accompanied by other violent behaviors resulting in physical injury, and on the other end was a nonconsensual sexual act that was not accompanied by violent behaviors. Her perception of rape indicated that she would be more likely to report a rape that was accompanied with physically injurious violent 
behaviors. Therefore her decision to report would be contingent on her perception of the severity of the violence of the rape.

The notion that a rape may only be defined as rape when there is evidence of physical injury carries over into service delivery. Muholi (2004) describes Kid's experience of a doctor conducting a post assault medical examination. As the doctor completed the exam he stated he did not see any sign of forceful penetration. With that comment he was expressing his doubt that Kid had been raped. The doctor's comment exemplifies the issue of service providers maintaining a perception that rape could have only occurred when there is physical injury present. This perception is problematic and contributes to the idea that a woman should only seek care if she has been physically injured.

Perceived sociocultural expectations. Study findings revealed a woman's perceptions of how she was expected to act within her sociocultural context influenced her decision making process. Nontle described decision making in the context of her culture. She discussed the perceived sociocultural expectation for a woman or girl child may be that she first tells a family member that she has been sexually victimized. Therefore if a young girl in her culture wants to report sexual offence victimization the process would begin with the child speaking to her mother. The mother would then go to the elders of the family and inform the elders that they must deal with the problem. However, there are many stories in South Africa of mothers making the decision to not report their child's sexual victimization. Mother's not reporting their children's sexual victimizations particularly occurs when a girl reports that she has been raped by a family member such as a father or a stepfather. 
Nontle gave an account of an occurrence in her community of a young girl telling her mother that she was being raped by her father. The mother choose not to report her daughter's sexual victimization to the family's elders,

...If your mom doesn't do that (e.g., report the rape to the elders) then you won't get any help because the mother will say to her daughter no...it's not true...how can your father do this? Do you understand? This is... your father! The mother will say if I go there to tell another person, what would another person say about what my family is doing?

In this account the daughter made the decision to tell her mother about her victimization according to the daughter's perception of her sociocultural expectations of help-seeking behavior. However, the mother made the decision to not report her daughter's victimization because the mother was worried about the social implications of what people in the community would say about the child's father and their family.

Nontle provided another example of how perceived sociocultural expectations could influence decision making. She used an example of gender norms of her cultural group and how they impact the help-seeking decision making process.

It goes back to gender where it says a woman is the neck and the man is the head. So everything that the woman should do, it should be discussed with the man, so with this problem of rape...discussing it with the father you will see how it will appear, you will see how this child is "not telling the truth"...and then he may kill that child because she talked.

Nontle continued to elaborate on how gender norms within her culture influence decision making and how that affects a woman's perceived ability to report sexual abuse.

... because of the cultural beliefs, because as a woman I can't really talk because I am the neck and not the head. And, if the head doesn't move to the right, and stands still, I also need to stand still. But at the end of the day the decision maker in the house is the head...I am the neck, I am advising. But the last decision is the head. 
South Africa has a long history of patriarchy. The impact of patriarchy has played out in many ways. Embedded sociocultural notions perpetuating gender inequality, such as the man is the sole family decision maker and that he is the provider for the family have contributed to perpetuating women's dependence on men. A woman's dependence on a man's provision of resources influences a woman's willingness to report a child's victimization by a father or stepfather. Lotter (2005) presented an example of a mother making the decision to not report sexual victimization by a family member because of the mother's concern of the risk of losing financial resources.

A few nights after Anna (e.g., the main character of Lotter's book) had returned home from being hospitalized for an attempted suicide, her stepfather tried to rape her again. Anna made the decision at that point to end her stepfather's sexual abuse. Anna told her mother that her stepfather had been raping her almost every night for years. Instead of Anna's mother believing her daughter, and supporting and helping her to report the sexual abuse, the following occurred:

Anna's mother: “Anna, don't talk such nonsense! Your father...

Anna: "He's not my father!"

Anna's mother: "Shut up! He's a respected member of the community. Good God, he's an elder in the church. To accuse him of something like that! We know you've got problems, we know that something's bothering you, but to make accusations like that...It's a good thing you're going to a psychologist on Monday. I can't help you anymore. Maybe she can."

Anna: "Mum?”

Anna's mother: "I don't ever want to hear you say something like that again. Where do you think we'd be without him? Where? He," she pointed at him, "he gave us - you - a roof over your head. He pays your school fees. He makes sure that you have food and clothes" (Lotter, 2005, p. 107). 
Anna had tried to get help from one of the few people she trusted in her life. Instead, her mother believed that protecting her means to financial resources took precedence over protecting her child.

Perceptions of appropriate service provider. Vivienne chose to report her rape to the police even though her rapist was a former police officer. She made the decision to report her rape to the police because she did not know where else to go for help. She perceived the police as the appropriate resource for reporting the rape. However, she told the researcher she had made the "biggest mistake" reporting her rape to the police.

The man who did it to me, he was an ex-cop. And the police, they were all his friends and they laughed at me...I was just so disappointed. Because it felt like I was wasting my time. Why speak up, nothing happens, I would rather just live with it.

In Vivienne's case her rapist had been a member of the group who was charged with protecting people not hurting people. She explained to the researcher her decision was based on the commonly accepted notion the police were there to protect and serve. However, there is a problematic history in the way the South African police have treated victims who reported sexual offence victimization. Issues related to their treatment of victims include victim blame, verbal abuse, and secondary victimization. After Vivienne's experience of secondary victimization at the hands of the police she stated If it were to happen again, I hope it doesn't, but if it does I will just keep quiet and live with it. I won't go and look for help. Because nothing happens. You don't get help.

Vivienne abandoned her efforts of reporting her victimization to the police. She did access medical care but had a bad experience with the service provider and did not return for follow up care. Vivienne did eventually receive help from a nongovernmental organization that specialized in assisting women who have been victims of violence. She 
received assistance in finding a safe place to stay for a period of time, and at that location she was able to access some counseling.

In South Africa if a woman is in need of mental health counseling after a sexual victimization she will be referred to a government psychologist if she cannot afford a paid psychologist. An issue with accessing government psychological services described by Mbali was her effort to make an appointment for counseling, but there were no appointments immediately available. She was experiencing psychological distress and as a result she had an immediate need for care. Mbali was told she would not be able to see the psychologist for a month. During the following month she coped with her distress, but when the time came for her appointment she canceled. Not long after the canceled appointment she came very close to acting on her thoughts of suicide.

I was like I don't have that problem anymore, so I don't see the point of going, so I canceled...I feel like if you have a pressing issue right now that you should get help right now. Because that's when you need the help, how do you know I am not just going to go out and do something crazy.

Bontle discussed her distrust of the psychologists available to students on her campus. Her distrust was rooted in a rumor being passed by students.

There's this thing that is going around campus that we mustn't go see the psychologists because they've just graduated... and they're doing their practicals with us students, you know you just don't feel safe with it...just how confidential is the information I give to them.

The women perceived certain services in their help-seeking process were the appropriate services to meet their care needs. For example in the case of the police it is commonly accepted that they are tasked with protecting people. However, as expressed by Vivienne they caused her considerable secondary victimization, and had little interest in assisting her. For Mbali, she perceived seeking an appointment for psychological 
counseling as the appropriate route to access a service she needed. In theory the psychologist was an appropriate resource, however, in practice the service could not provide her with the timely care she so desperately needed, and placed her at risk. In the case of Bontle as a student, there was the perception that the campus psychologist would be an appropriate service. However, the element of trust was missing. In this study, women's decision making influenced by perceptions put them at risk to not receive the care they needed, or at risk of accessing perceived appropriate services only to end up suffering more harm.

Decision making influenced by experience. Nontle discussed her experiences with care providers when acting in her professional role of helping community member's access care after sexual victimization. Nontle explained to the researcher that according to Batho Pele Principles (e.g., principles which guide South African service delivery in the public sector) services should always be delivered with patience, respect, and dignity. And, according to the South African constitution all citizens deserve human dignity, and have the right to access health care facilities. But, Nontle reported that her experiences at a care center for victims of sexual offences did not reflect the Batho Pele principles or the rights guaranteed to South African citizens' according to the constitution. The South African government had specifically established that care center and care centers like it, throughout the country to provide centralized victim friendly care services (e.g., medical, police, social, and legal services).

Nontle shared a story of helping a woman who had asked Nontle to stay with her as she received care because she had been very traumatized by her victimization and wanted the presence and support of someone she knew and trusted. 
I went in with...the victim, and the nurse just shouted at us, telling me what do I want in there, I am not supposed to be in there, and then telling us we should not touch anything in this office it is not ours, we are just there to get helped, so I said okay I will just go out but you're not supposed to talk to us like this and then the nurse said...this is my property here, I'll talk to you...like whatever I like whenever, so I just said you know I just want help, you just keep quiet, let me just keep quiet and go out...

Nontle explained that it was fully within their rights to complain to the nurse about her service delivery. However, they would have run the risk of not receiving any care at all. Nontle knew that according to the South African constitution they had the right to be treated with dignity and the right to access needed healthcare services. And, according the Batho Pele principles everyone should have the right to equal access of services and be treated with courtesy and respect. Nontle made the decision to help the woman to access services despite Nontle's previous and current experiences with medical service providers at the care center.

Annalie's decision making process for medical care after being raped, was influenced by her experience and knowledge of the medical care required after sexual victimization. She knew the importance of rapidly accessing and receiving medical care to prevent the transmission of HIV, and to reduce the risk of other medical issues related to victimization. She discussed with the researcher that she was very fortunate because she had ready access to medical care and was able to rapidly obtain it. However, Annalie expressed great concern for the realities and challenges to women who have to wait for medical care. She described her observations of disparities in access to medical services that her community members experienced. She explained the police in her community seemed to place little importance on women who had been sexually victimized and were 
in need of receiving timely care after victimization. She emphasized the importance of

HIV prophylactic treatment as soon as possible after rape.

Sometimes on a Monday I get rape cases...that have happened early Sunday morning or late Saturday or Sunday nights. Why do they (e.g., the police) wait till Monday morning...HIV prophylactic treatment ASAP...is vital. So why do the police wait until Monday morning to bring the victim for assessment... Whether it is HIV, pregnancy or STI, the sooner you get the examination the fresher the semen are, the better the specimens are, the better the chance to get some evidence, you know...this is real life situations...the quicker you get the examination done the better evidence you collect...it's their right to get that service ASAP, not sometime near in the future.

Annalie further discussed care services and her concern with accessibility, availability, and delivery of services.

...victims go to the police first here, it's only in a larger town many kilometers away that there is a care centre specifically tasked with caring for victims of sexual offences. But that care centre is only operating from 7-4, 7-7, only Mondays to Fridays, not over the weekends...not after hours...so if you look when does rape occur in South Africa...it will always be they are mostly early morning hours or during night time... for the people...in my community, they...go to the police and the police must know community members rights to access care.

All the participants at some point in their interviews discussed the power government authorities wielded in South Africa. And, that regardless of the laws and policies in place South African citizens are often vulnerable to corrupt behaviors of those in power. For example, Lerato was uniquely vulnerable to the corrupt behaviors of those who wield power. Lerato's father was an employee of the justice system. In his position as member of the justice system he had the power to potentially skew the legal process in his favor. Therefore Lerato's decision making process of whether to report her father's sexual abuse was made more complex. 
Lerato described a decision making process that was influenced by the knowledge of the power her father had over her as a member of the justice system, and by her experience of observing the justice system and how it operated.

...because the person who did rape me, it was my father... because...my father...was working for justice...I thought as much as it's pointless to go and report the whole matter because the guy might, just you know, just overthrow everything, and then...nothing would come out of it...For me this whole rape thing took about four to five to six years happening and it was quite difficult for me to just go and report it. I guess... as South Africans, if somebody who's...in the law enforcement...justice department or whatever, it's more difficult for you as a person to go and lay charge against them...because sometimes it might end up not going forward like it is supposed to, so that's the culture of South Africa. It depends on who you are...as the suspect and then you as the victim.

Specifically, Lerato's father worked for an organization within the justice system that was involved with the responsibility of prosecuting crimes including sexual offences. ...for me it was more of a difficult experience...I do not trust, I didn't believe I could get adequate help...or be protected as much as I wanted to be...

Lerato described victimization by her father that took place over a period of years. During those years she experienced a number of pregnancies and forced abortions. With the last pregnancy she made the decision to tell her father the raping could not continue and that she would have the child.

Her father did not rape her again after the birth of her son. But, it was not until two years later that she decided to report her father. Over those two years Lerato continued to struggle with her decision making to report her father's years of sexual abuse. She told no one about her father's wrongdoings throughout all the years he sexually abused her. Nor, did she tell anyone during the two years after he stopped. When she did finally tell someone, she told a male friend who was staying in her family's home. Lerato described his reaction to the researcher. 
...he also didn't know how to react to what I did tell him...because he looked to my father...as this person you can trust...so he didn't know how to go about the whole thing... he said he would just go back home...and then make a plan so that I can move out of my home for time being then we'll just see how...we are going to go with this whole thing. Maybe report the matter and all that, but that was before the passing of my baby. My baby passed on while I was here trying to figure what I was going to do.

The plan she and her friend devised and undertook was that her friend would move back to his hometown, and soon after Lerato would travel to his home where she would stay while she explored her options and decided what to do. During the time she was at her friend's home her son passed away. With her son's passing she made her decision to report her father.

...it was because of the passing of my son... I realized whatever it is, if maybe I could go to court... he was the evidence sexually so after he passed on then I realized okay, the only thing I had to bring this man to book is now gone so whether I am ready or not I have to do this.

Lerato's decision making process was influenced by the experience of her father being her abuser, the fact he was an employee of the justice system, and, her knowledge that if she reported him, her father could significantly alter the process so that fairness and justice would be questionable - even impossible.

Lerato's decision making process is an example of decision making influenced by experience. However, this is also an example of the complexity of decision making for many women when they are victims of sexual offences. Additionally, her process exemplifies that her help-seeking was a series of decision making events. First, she thought she wanted to report her father, but then decided she would not because of his role in the justice system, and due to her belief that it would be pointless to report him. She then came to the conclusion to take the risk of telling him he had to stop raping her. Then, with great resolve, she discussed her victimization with her friend. The final, 
definitive factor that led her to decide to report her father was the death of her child. Lerato's experience of decision making was a grueling process, impacted by many factors and influenced by experience.

Complex decision making events. Study findings indicate it is important to understand that help-seeking decision making is a complex process. It is typically part of a series of decision making events. An example of the complexity of help-seeking decision making, occurring as a series of decision making events is Kid's experience with help-seeking. Kid made the decision to not tell anyone about her victimization in the first hours after she was raped. She then sought the help of Muholi, a person she "barely knew" to help her navigate help-seeking (Muholi, 2004, p. 120). Kid had the fortitude and resolved to continue to pursue care even after she was subjected to secondary victimization by service providers. Ultimately Kid made all her help-seeking decisions with the knowledge of the contempt many black South African's have for black South African lesbians and the risk associated with people learning she was a lesbian. Muholi emphasized there were additional factors that added to the complexity of Kid's decision making process.

What must be appreciated in all of this is that Kid is poor, unemployed, and living with her aunt who is not only disabled but also the sole breadwinner in the household. Taking the train into Johannesburg from Kagiso is expensive, not to mention dangerous. But this was her only mode of transportation as Johannesburg was in the midst of a general taxi strike. Trying to navigate Johannesburg without a car is a hectic experience on most days. But imagine for a moment the emotional and physical pain of it after your body has been violated and raped, when it feels like your body is an exhibit for everyone. In a sociocultural context where rape is still a fairly taboo subject, these feelings are overwhelming. And yet this young woman chose not to hide. (Muholi, 2004, p. 120). 
As illustrated the process of help-seeking decision making is complex and most often is a series of decisions that are impacted by a variety of factors. For each woman there were many attributes that created complex decision making situations. Some of the characteristics of the attributes were unique to individuals and their situations. In other situations when women sought help after victimization there were shared and common characteristics contributing to the complexity of decision.

Study findings revealed decision making as an essential theme of the phenomenon of help-seeking after sexual offence victimization. Many factors impact a woman's helpseeking decisions, including her perceptions and life experiences. Perceptions that may influence her help-seeking decisions include: perceptions of the degree of severity of her victimization, her perceptions of sociocultural expectations, her perceived risk of losing essential resources, or her perceptions of service providers. Furthermore, study findings revealed a woman's experiences throughout her life also influenced her decision making process. Experiences with the police, nurses, or any other service provider with whom she had previous contact influenced her help-seeking decision making process.

\section{Silence}

In South Africa silence is an accepted and most often expected reaction to rape. It is described as never talking about sexual offence victimization. There is no discussion of victimization with family, friends, and the silence extends to the community. Silence may also be described as a secret. Silence is the process of never sharing with anyone the very personal experience of sexual offence victimization. And, if the secret is shared with someone there may be considerable risks associated with breaking of silence. 
The participants of this study have broken their silence and each shared their experiences with service providers, with their families, and with some select friends. There is no way of knowing how many women remain silent regarding their sexual offence victimization. However, in a country where research indicates one in three women have been raped, but only one in nine report sexual offence victimization to the police, one can estimate there are many women who do not break the silence. Silence was discussed as being a problem in help-seeking and in healing after victimization.

Not talking about victimization. Bontle expressed not talking about her experience of victimization, especially with her family, as the least helpful aspect of her healing.

This not talking doesn't help...I think the least helpful thing was not talking. Especially around your family, it was terrible. Cause even till this day we still...you don't talk about.

Bontle found her participation in group therapy and listening to other people talk about their experiences of abuse was very helpful in the process of healing. When others broke their silence and talked about their experiences it allowed Bontle to understand she was not alone. Bontle knew her experience of rape was bad, but there were others who spoke of experiences that were far more horrific than hers. Hearing stories in group meetings put faces to other's experiences of rape, and the stories of rape were then not only stories she heard in the news, but stories she heard from other woman who too had experienced the horror of sexual victimization.

I think that it goes back to the group...meetings, because you walk around now thinking this just didn't happen to me, it's happened to so many other people, and you could be sitting next to that person... I've heard some stories that are sickening, and really disgusting that make you think, you know you're not the only person, there's a million other people going through this. 
For Bontle this was quite profound. Sharing her experience with the women in the group meetings allowed those women to show empathy and provide support to Bontle, and in turn for her to empathize with them and show support to them.

I think speaking to someone makes them know what you're feeling, and what you're going through...I think it was very helpful because you know that you are not alone...I mean what's the statistic now, every one in three women get raped. I am...crying everyday but I know there's someone out there who has been through something three times, ten times worse than me. So I think it helps to realize you are not alone in this ever...I know this is a bit selfish to say but sometimes when you think someone has been through something worse than you... you feel so much better about your own life.

Mbali broke her silence and talked to a person about her sexual offence

victimization. When Mbali reported telling someone about her experience she described it as a wakeup call.

At first I wanted to forget the whole thing and stuff. But in the back of your mind it is always lingering...It got uncomfortable if others brought up the whole issue of rape and sexual abuse. I'd get uncomfortable, but I wouldn't talk about it...I didn't tell anybody about my whole ordeal, I didn't go around saying I was raped and stuff like that. When I finally did it was like a wakeup call...

Mbali's wakeup call was her experience of gaining understanding of the power of not staying silent about the rape. When she was asked what would be her advice to victims of sexual offences she replied with the following,

Not to hold it in. Talk about it. Talking is very important. Just talk to someone, even if it's a social worker, or anybody who can help. But you should be specific about people that you speak to, because some people cannot handle such information. Find someone that's been there, someone who knows the profession (e.g., counseling), anything like that that can help you...talking to someone really helps.

Silence in the form of secrets. To keep a secret is a deliberate action. Whatever is being kept secret must be protected from disclosure. Secret information has power. If the information is not kept secret there are consequences. The consequence may be that 
one is ostracized from her family, her secret may be used as weapon against her, or the woman is no longer able to protect herself from the reality of the pain the victimization has caused in her life. For a woman who has been victimized by her father, the consequences of telling her secret may be overwhelming. The consequence for Lerato after disclosing the secret of her father's victimization to her siblings was their doubt in her character and being ostracized from her family.

I was an emotional wreck...not having any family member...support you, worst of all I understood, they were my father's children, here I was as their sister...claiming that the very same person that they looked up to as a father did this to me. I knew that they wouldn't believe it but, you know all I needed from them was just to be neutral in all of this and just say okay we'll see the results...but they weren't...they didn't believe me, I got kicked out of home...I was the liar he was the victim. I was the one who according to them... who victimized him in all of this. I was the one that was the bad person in all of this, you know... and worst of all I lost my son.

Thandeki Umbilo (2002) also experienced sexual victimization by her father. She kept her father's abuse secret for many years. Even when her mother asked her if her father was abusing her she did not tell her secret. Thandeki discussed her desire for a life without discord, "This deep longing for a harmonious life also prevented me from revealing the secret. In my little heart I reasoned that silence would create peace" (p. 18). She further discussed her attempt to separate herself from her abuse, "the abuse was a nightmarish secret that lay buried deep within me - a reality I tried to wash out of my consciousness the best I could" (p. 15).

When a shared secret is used as a weapon. Study findings revealed when a secret was shared the protected information of the secret had the potential to then be used as a weapon against the one who held the secret. Bontle suffered consequences for sharing her secret of being raped with her former boyfriend. 
I was very close to him and you know I shared everything with him. And after we broke up he said to me, you will never have children because you were raped. It hurt, because...I poured my heart out to him. He used that one thing against me, where he could have used a million things against me but he used that one thing ... I cried for... about two weeks straight...I told my mom... and my mom said you know that you don't tell people. And that's how we take it, you don't tell people, it's your secret, it's something that happened to you and no one else should know about it.

For Bontle, when her boyfriend used her secret of being raped as a weapon it was devastating. She had shared her secret with him in confidence. She trusted him enough to share something very personal, and in an act of spite he used her secret to cause great pain. To add insult to injury she had placed even more trust in him because he was a police officer. She stressed to the researcher that as a police officer he of all people should have understood how his words were so hurtful.

Shame and self-blame as seeds of silence. The feeling of shame is an emotion that leads some woman to remain silent about their experience of sexual offence victimization. Shame for Mbali occurred because no one in her family would talk about her victimization. She interpreted her family's silence as the reason she should feel shame. "Cause, in a way I kinda felt ashamed, like okay...this must have been a really awful thing to happen if no one is like talking about it."

The feeling of shame described by Thandeki was an overwhelming shame that caused her to experience dissociation, and separate herself from others. Thandeki described a feeling of shame that was a result of her father persistently raping her over a period of years. Her experiences of shame lead Thandeki to secretiveness.

... abuse breaks down the good self-image and forms a terrible pain which we call shame-toxic shame. It cuts deeply and is basically felt within. It divides us from our selves [sic] and from others. Because of the personal rejection, we disown our selves [sic]. This demands covering up. This covering up can lead to a strong tendency to withdraw and to hide in a cloud secretiveness ... (p. 13). 
The silence of Thandeki's secret was a place of safety for her.

Anna from Lotter's (2005) book tells the story of her experience of sexual offence victimization by her stepfather. He tells her not to tell her mother or father. He tells her that it is their secret. What he did not realize was he had already gained her silence because she was so ashamed of what he had done to her. "'Don't tell your mother or your father. This is our secret. Mine and yours. Do you understand?' I nodded. 'You won't tell?' I shook my head. I wouldn't tell. I was too ashamed, too afraid" (Lotter, 2005, p. $32)$.

Self-blame compelled Mbali to remain silent about her victimization. She spoke to no one about it until she could deal with it no more. For Mbali, self-blame was one of the factors she told the researcher that had led her to thoughts of suicide. Mbali blamed herself for being a victim of rape.

Not to blame yourself. You shouldn't blame yourself. It's not your fault. It's not the way you dressed...you didn't actually ask for it...you didn't go and beg and say rape me...you shouldn't feel bad at all. Cause if you feel bad it's like you judging yourself...and you feel like others are judging you when it's not even true. So just don't be hard on yourself, don't sit around especially, don't sit around crying cause that can lead to a lot of thoughts and stuff.

Silence as cultural expectation. Mbali explained the experience of how families from her culture deal with situations such as a family member being raped. She explained in many ways she and most of her family were westernized in how they approached life. But as she discussed her family's manner of how they dealt with her experience of sexual offence victimization, it was interpreted that her family's reaction was very traditional.

In my culture, it's like, what happens in the family should stay within the family, nobody from outside should know...so seeking help, it's like what happens, happens, we just move on...no one talks about it...it happened, then everyone just 
moves on, they try to sideline the whole matter... my grandmother she spoke about it once and never again.

Nontle explained how the response of silence, instead of the response of helpseeking may be seen as a preferred. Not being able to talk about victimization in Nontle's culture was just the way it was.

... you grow up knowing I have a problem...and maybe it's something that I cannot talk about, I'm just going to bottle it up and then that's just it, things will fix themselves...

Not talking about victimization for Mbali and for Nontle was a culturally embedded response.

Silence is an accepted and often expected behavior after sexual offence victimization in South Africa. In this study silence is described as never talking about the victimization. The silence includes not talking to family or friends about it, and the silence of victimization extends into the community. Study findings revealed women remained silent for varying reasons. Their reasons for silence may have been their own choice, but other times silence was forced on them. Silence may take on the form of a secret and once shared it can become a weapon used by others. In this study silence was associated with feelings of shame and of self-blame. Finally, silence may be a culturally embedded response. Study findings indicated that silence had to be broken as the women made the decision to seek help and in their healing after victimization.

\section{Critical Junctures in Mental Health}

Critical junctures in mental health are described as a woman's experiences of psychological distress at any point in time after sexual offence victimization. The junctures are periods in time when a woman experiences psychological distress that interferes with her ability to function in an optimal manner as she conducts her daily 
business of life. The junctures are described as critical because they may lead to a woman seeking help, or they may lead to further decline in a woman's mental health status.

Women in this study discussed instances of psychological distress that continued to occur years after they had been victimized. The distress they experienced in some cases profoundly impacted their lives. Bontle discussed attempting suicide because of the psychological distress she experienced. Likewise, Mbali experienced suicidal thoughts and came very close to attempting suicide.

It is important to understand the critical junctures as pivot points. The juncture may be a point where the woman continues to sink lower into her despair. In contrast they can be points in which the juncture leads the woman to access help (e.g., counseling) with an outcome of positive growth and understanding of her traumatic experiences. It was stressed to the researcher that if the woman wanted and needed counseling it was essential to receive help immediately. If counseling was not immediately available the woman was at risk of self-harm or experiencing further mental distress that could lead to devastating consequences. Additionally, continual and sustained access to counseling throughout a woman's lifespan was important.

Breaking down. When Lerato's son passed away and she reported her victimization, she described herself as being an emotional wreck, thus not being able to cope with her situation. Fortunately, at that point in time she was able to access counseling.

While I was waiting for courts, okay, I did receive counseling... I was an emotional wreck I couldn't cope...counseling was the most important thing then for me just to be okay to cope with the whole situation of...loosing almost everything, family, and everything that I had then. I could feel that there was somebody who could understand what you're going through. Somebody was willing to listen to what you're going to say and support you regardless of what. 
At the time of Lerato's interviews she described dealing with the legal proceedings as a continued source of emotional stress.

I had to just drop out of school because I was not doing very well. Because each and every time I would think of going to court I would just have a breakdown, also...emotionally it's not nice you know. Even like this Monday, I had to be there, see my father, it's not a very nice thing you know...it's like living the nightmare over and over again. So that has caused me problems and it has slowed my life down, it has put a hold into my life.

Lerato discussed she would probably want to have further counseling in the future to help her as she moved forward.

Of course, yes, yes, it's of great help...there was a point in my life when I thought, okay, counseling they're just going to tell me everything is going to be [alright]... you know sometimes as people we think that we could, we can cope on ourselves, but that's not always the case sometimes we just need to be vulnerable and let somebody in our lives and tell them how we feel.

Thandeki described her world collapsing around her when she 40 years old. She states "then I understood why people commit suicide and I believe if I was that way inclined I may have well taken that road as an escape" (p. 1). She had over the years sought help, and had received some very brief informal counseling from a teacher, and she had received informal counseling from the others in her religious order. But it was not until she turned 40 and was at a critical juncture that she was able to find the help she needed to move her towards healing.

Bontle was raped while she was in the eighth grade. She explained she felt she was fortunate to receive counseling in the subsequent years. She attributed her access to counseling to be associated with attending private school which she acknowledged that for many in South Africa would not be an option. Even though Bontle received counseling and she said the counseling was very helpful she still ended up trying to 
commit suicide while in ninth grade. At that point her parents decided her situation was serious enough to require psychiatric services. She was hospitalized because of her suicide attempt and received formal care while in the hospital, including antidepressant medication. She returned to school, received counseling as needed, and was subsequently successful in completing high school. She graduated and entered university. It was during her third year of university that she had what she described as a complete breakdown. She was able to access immediate mental health care and as a result of the care she received, she said she was able to circumvent a bad outcome. It was at that point Bontle began to participate in group therapy sessions

Group is amazing, you walk around and...think we're the only person with a problem. But there's people that have been through bigger problems, and some people did not even go to the extent of going to the police station, or seeking help, they're just living with it. Every day of their lives like it just never happened. So, I call myself very lucky, I think that's why it becomes easier for me to speak about it, because, I've been through the whole process of help. And with just bottling it in, I don't think I would have lived for another five years.

Bontle said if she felt the need for counseling again she would readily seek it out.

She did feel at the time of her interviews she was over the worst, however, she had learned through experience that there could come a time when she would need counseling again. Because Bontle clearly understood the positive affect counseling had had on her life, along with her complete lack of desire to experience again the psychological distress she had experienced in the past she was very open to accessing counseling services again if needed.

The power of counseling. Bontle was very hurt by her former boyfriend's statement that she would not ever have children because she was raped. For her personally, and within her culture, she discussed children were very important and she 
definitely planned on a future filled with children. Her boyfriend's hurtful statement was very disturbing to her because he was someone she thought she could trust. She had told him many private thoughts and for him to blatantly disrespect her was very unsettling. Bontle indicated that if she had not had all the counseling she had undergone over the years, his statement could have had the power to place her back in the mental state she found herself in so many years earlier when she attempted suicide.

It's up and down, its touch and go...But I am in a good space, a really good space ...Yeah I am in an amazing space. You think about it sometimes but....tears doesn't come to your eyes, your happy you know. It's an experience. So now to thank god, instead of hate him for it. I am glad I went through it and I am where I am now.

Mbali received psychological counseling for a week after her victimization. But, after that week she decided she did not want to continue with the counseling. She discussed with the researcher she was fine for the next two years. And then she experienced what she described as a nervous breakdown and that was when she decided she needed to find help.

When I finally realized I need help, I was sitting in my room and, it was all just coming back a lot, and I think it just came back all at the same time, and I locked myself in my room and cried the whole day...I got to the...point to where I thought I should just kill myself...I was actually ready, I was like I am going to take all these pills that I have and I am going to just drink them all, and just sleep and die. That's when I thought to myself I really need help, I cannot deal with this anymore...Getting help is very important...I believe that we all need help. It makes no sense shutting it out and thinking you will forget it. You will never forget. If I didn't get help...I probably wouldn't even be here. I probably would have been dead.

Study findings indicated there were critical junctures in women's mental health.

The junctures occurred when a woman experienced psychological distress at any point in time after sexual offence victimization. The junctures have been described as critical because they functioned to help guide a woman into help-seeking, or they acted to lead a 
woman into experiencing a further decline in her mental health status. Psychological distress was found to occur at any time after a woman had been victimized. Findings revealed that when a woman received counseling, the counseling contributed to their moving forward and into healing.

\section{Moving Forward}

The theme of moving forward is described as a woman's experiences after victimization as she moves toward and into healing. Lerato explained to help herself to move forward she decided to forgive her victimizer, her father. She had a very difficult time even getting to the point where she could think of forgiveness and said it took two years to reach the point where she decided she could forgive him.

How do you forgive someone that has done such a thing to you? How do you do that when this person never thought of you as a human being? This person never even considered your feelings...So how do you do that...I was...so angry...but then as time went by, I realized each and every time...I see this person or talked about this person I would be so angry I'd feel like exploding, so maybe just let him go...but you know it is not easy it takes time, it takes time.

For Lerato forgiveness released her from the anger she felt. She explained she had accepted what happened to her. She described that she was not as bitter as she had been. So by forgiving and letting go she is making forward progress. During Lerato's second interview she told the researcher she felt she was emotionally strong and ready to move on with her life.

Thandeki attributed much of her experience of moving forward to forgiveness of what had happened in her past. And for her, forgiveness was a very important facet of her religious beliefs.

Some say that forgiveness is not the ultimate aim, but as a Christian I had no peace until I extended to each perpetrator the 'hand' of forgiveness. 
As part of her process of moving towards healing Thandeki wrote poems and stories, and drew pictures that she said helped her access her past. As her counseling continued and as she dealt with the hurt, the shame, the anger, and all the other feelings and emotions that were so profoundly part of her past she became what she described as empowered.

This can only be done when one has received sufficient empowerment. This empowerment means that we have dealt with much of our pain and in the process have become more fully human...more in touch with the sacredness of our being, more the vibrant person we were ordained to be.

For both Lerato and Thandeki developing the ability to forgive was a long slow process. Thandeki states, "I just realize...that I was subjected to ten/eleven years of abuse and it has taken that long to reach the point I am at today" (p. 110). For Lerato, Thandeki, and Mbali forgiveness was a very important and integral component of their moving into healing.

Mbali shared a story with the researcher about how she received informal counseling and mentoring from a person she trusted at her university. One of her instructors included the subject of sexual violence in a lecture. What he said resonated with her in a very powerful way. His words and her trust in him compelled her to open up and talk to him about her victimization. Over approximately a year she met with the instructor. When she described her experience of talking with him she made it clear she felt very safe telling him about all that she was thinking. She reported that she never felt he was judging her. She described how this instructor helped her to accept what had happened to her, how to take back the power the rapist had over her, and how to move forward into healing. Mbali described to the researcher some of what she found so helpful in what he said. 
'Whoever did this to you Mbali is out there living, not even thinking about you, you are actually punishing yourself.' He was quite honest with me. The people that did this to me are out there, probably one of them is even married and moving on with life. 'They are living, they are happy while you Mbali are miserable.' He was like, the only problem with my situation is I gave them too much power, and if I ever want to move on with my life I have to take the power back...sometimes I didn't want to hear what he had to say...especially in the beginning...I would look at him...and tell him...you don't know, you don't know, he would tell me 'it doesn't matter that I don't know, but the fact is you have to get back to yourself.'

For Mbali, her instructor's informal counseling and his mentoring had a profound effect on her, and was a major factor in her healing process.

It never goes away. . . You move forward. It is not like you forget, but you adapt. And you live with it, you learn to forgive yourself. And, just keep moving and forgiving others as well. I am content with my life. I'm content.

Nontle found volunteering at the police station in her community to be a very empowering experience and very important in her process of moving forward toward healing.

Best thing that I did was to volunteer at the police station. That made me feel better. Even though I cried with the first victim...it helped. After the crying I feel that it was saying the last tears were coming out, you know, and then from there I helped victim's throughout and now I am better.

Nontle continued her empowerment process as she used her experience as a volunteer to redirect her educational pursuits so that she could obtain the qualifications necessary to work with victims of violence including sexual violence. She strongly believes that as a survivor she has a deeper understanding of victimization.

... as a survivor I really understand what happened to this person and how this person feels and I will help her or him according to how that person is feeling.

Nontle has many plans to help people who have experienced victimization and is very determined to see her plans through. 
Annalie received trauma counseling within 24 hours after her victimization. She described the questions the counselor asked as those that encourage a person to speak about their feelings and emotions. Annalie said the counselor helped her to think rationally about her experience. He helped her to realize she should not blame herself for what happened.

He said to 'me but you can't blame yourself because you didn't fight that guy...because the guy had a weapon. Though it was a stone, a big stone,' he said 'but that was the weapon and I felt intimidated by it'.... he said that he 'could have easily smashed my skull to pieces and there could have been blood all over the place the next morning.' Instead my daughter is feeling fine, my mom's fine, and I'm sorta fine. So, he put the rational thoughts back in my mind and took away my self-blame, he made me realize that I couldn't blame myself. So that was very helpful.

Vivienne did not describe moving forward. Vivienne unlike the other women in the study continued to express a great deal of anger. She told the researcher she believed she would not be able to not get over the anger she felt. Vivienne never sought counseling outside the short period of counseling she received from a social worker while staying at a crisis shelter. She told the researcher she felt that seeking psychological help was not important to her and she would just deal with her situation.

Study findings revealed that moving forward and into healing after sexual offence victimization occurred over a period of time. Moving forward was described as occurring through forgiving the victimizer, counseling, education, and leaving self-blame behind. Personal empowerment was found to be a very strong and important element of moving forward into healing. Not letting go of anger was found to be an obstacle to moving forward and into healing.

\section{Existential Findings}


The existential findings of lived space, lived body, lived time and lived other are universal themes experienced by every one of the woman in the study. These existential states represent each woman's version of her physical existence. Lived space is how she feels the space she exists within. Lived body refers to her bodily experience of the world. Lived time is time as it is felt and not as it is according to a clock. And last, lived space is the lived relation with others in the shared interpersonal space.

Lived space. A home is a very personal space typically shared by those who are closely related. It is perceived as a safe space where people may remove themselves from the world outside. People who come and go from the home either reside in the home or have been invited to enter the dwelling. If someone enters a person's home and they have not been invited that person is an intruder. Once that space has been invaded by an intruder safety of home is violated. What once protected a person from the outside world no longer protects.

Annalie, her daughter, and her mother had only lived in their home for a short time prior to Annalie's victimization. Previously they had lived on a farm in a rural area of South Africa. On the farm she had not felt the need to protect herself from what lay outside her home and she did not worry about locking her doors. That all changed the night an intruder came into her new home and raped her. The intruder entered her home through an unlocked door.

He taught me to lock my doors, you know he made me aware of safety. Because before I couldn't care less if my doors were closed or not closed, so, actually he made me aware of my surroundings, of the real situation I am currently in, in South Africa. It is a violent country, let's face it, you can't sleep in a house with open doors for heaven sake. You have a responsibility, not even toward myself but towards my daughter, towards my mom. And he made me aware of that, I thought hell I had a lesson to learn out of this. And then I was grateful, I was very, very grateful for me not having other scars, except for the emotional scars. I don't 
really think about the rape incident any more I have put it in the past. You know If I have put something in the past, it is in the past...I have moved own. I don't have any ghosts, any hauntings, except I lock my doors now, I lock my bedroom door. I don't have flashbacks, I don't have...things that haunt me. It's just that I can't sleep with an unlocked door or an open door.

What was once perceived as a safe space whether the doors were locked or not, became a place where Annalie felt vulnerable.

Lived space for Anna took on a different meaning after her stepfather starting sexually victimizing her. For a young girl, a bedroom in her parent's home is usually assumed to be a place of innocence. It is a place where a girl can be free and not worry about harm. However, for Anna her room became a place of danger and shame. She had no protection from her stepfather's abuse. When she did try to take back her feeling of security by locking her doors her mother would not allow it.

Lived body. A person exists bodily in the world. A person dresses themselves with the objective of comfort or style, or in whatever they perceive as appropriate clothing for their day ahead. For Mbali, after she was raped she began to experience her bodily presence in the world very differently. She did not dress for comfort or style anymore; instead she dressed to hide her bodily self.

...you feel dirty, you just feel unworthy, you don't like what you see in the mirror. You're always finding fault. You're always trying to change something. And then the hiding away of your body. I used to hide, I used to wear long things all the time...cause I didn't feel comfortable at all...I didn't like short things. I just wanted to wear dresses that are long, that cover everything, when people paid compliments I really didn't see what they were talking about.

For Vivienne her bodily experience of being in the world became an experience of feeling blame when she sought medical services. The police told her to go to the care center for victims of sexual violence to receive a medical exam. The care centers were established so that victims could feel safe and not experience revictimization. 
When I went for the examination the nurse was very rude. She made me feel like I did something wrong...I understood it is a month after the rape...she just said to me what do you want me to prove? I don't know I am just here because the police sent me. She was mean, she was rude. She had no, how do you say it, tenderness in her. She didn't feel anything. I'm not saying she must feel sorry for everyone she helps, but no compassion, she was just "just lie there and open your legs". I'm like "what"? She did whatever she had to do and then she said get dressed

Instead of a compassionate, victim friendly experience, Vivienne left feeling like she had been raped again.

Lived time. The universal theme of lived time is particularly profound for a woman who is waiting to receive medical service after being raped. Annalie described her concern for the women in her community who do not receive timely care after being raped. Post exposure prophylaxis (PEP) for HIV should be administered within 72 hours after victimization and the sooner it is administered the better the chances are for prevention of HIV. Each minute that passes before beginning PEP treatment can seem like hours for the woman who knows the medications must be started within 72 hours of victimization. Annalie used the example of the time it takes to provide a statement to the police could be time used to start treatment.

My statement took three hours and its three hours that you could have access to medication and you could start your prophylactic treatment. Isn't it a gamble of someone's life?

Nontle described her experience of the passage of time while waiting for medical care. She described it as "she had stayed for a long time there. It was cold". As a victim of sexual violence she had already gone through the horrible experience of rape. And then when she arrived at the care center she was made to wait in the clothing she had on when she was raped, she could not drink, eat, or urinate, all she could do was wait. 
Lived other. The lived other is how people relate in a shared interpersonal space. Study findings revealed, for the young girl who is persistently raped by her father, the shared interpersonal space is a space of abuse, of power, and of dominance. In many South African homes the father is a figure of authority and is in the position of dominance. Therefore the girl is subject to an unequal balance of power that results in her having very little control over her life. Anna experienced the relation of the lived space within in her home with her stepfather. She faced a space that was filled with constant fondling and opportunistic abuse any time her mother was not present in a room.

The lived existential of space, body, time, and other, are universal themes shared by all women. However, each woman will experience her existential experiences in the context of her life world (e.g., the context of her reality).

\section{Summary}

The purpose of this study was to investigate the lived experience of help-seeking behaviors of South African women after sexual offence victimization. Four essential themes emerged from participant interviews and other data sources, they were: (1) decision making, (2) silence, (3) critical junctures in mental health, and (4) moving forward. Decision making is a complex process that is influenced by many factors including a woman's perceptions and life experiences. Study findings revealed a woman's help-seeking decisions may be influenced by: her perceptions of the severity of the violence she experienced during the sexual victimization, perceptions of what is expected of her socioculturally, her perceived risk of losing resources, or by her perceptions of the appropriate service provider. Her life experiences with service providers such as the police, social workers, nurses, or any other service providers also 
influence her help-seeking decision making process. Study findings indicate help-seeking is conducted through a series of complex decision making events.

Silence is an accepted and most often an expected reaction to victimization. Silence is described as never talking about victimization and may be described as a secret. No one including family or friends talk about sexual victimization and that silence extends to the community. Silence may be culturally embedded and maintained because of these norms. Research findings indicate silence is associated with the development and persistence of feelings of shame, and self-blame. Importantly, silence was a problem when women sought help after victimization.

Critical junctures in mental health are described as a woman's experiences of psychological distress at any point in time after sexual offence victimization. These critical junctures are pivot points that can result in the woman experiencing increasing distress, or compel a woman to seek the help she needs. Study findings revealed women were affected by psychological distress years after they had been victimized. Yet, the distress could be minimized with the help from others. Of most significance was the importance women place on mental health counseling, especially counseling that is immediately available.

Moving forward is described as a woman's experiences after victimization as she moves toward and into healing. Study findings reveal moving forward and into healing after sexual offence victimization occurred over a period of time. Moving forward was described as occurring through forgiving the victimizer, counseling, education, and leaving self-blame behind. Personal empowerment was found to an important element of moving forward into healing. 


\section{CHAPTER V \\ DISCUSSION}

The purpose of this study was to explore the lived experience of help-seeking behaviors of South African women after sexual offence victimization. This chapter will provide a summary of the study, a discussion of the research findings in the context of Bronfenbrenner's ecological systems theory, limitations, implications, future research, and conclusion.

South Africa is reported to have the highest rate of rape and sexual assault in the world (Cox et al., 2007; Martin, 2002). However, research indicates there is a low level of reporting sexual victimization to the police (Jewkes \& Abrahams, 2002; Mullick et al, 2010), along with a low level of people who access health care services after sexual victimization (Abrahams, \& Jewkes, 2010; Christofides et al., 2006). Little is understood about a woman's experience of help-seeking after sexual offence victimization. This research provides insight from South African women who sought help after their experience of sexual offence victimization.

This hermeneutic phenomenological study used van Manen's methodological approach. The research question was what is the lived experience of help-seeking behaviors of South African women after sexual offence victimization. The study was conducted in South Africa over a three month period of time. There were six South African women who participated in 11 interviews with the researcher. Other data sources included: Elbie Lotter's (2005) book It's me Anna, Thandeki Umilio's (2002) book Little 
Girl Arise, and the article Thinking Though Lesbian Rape written by the activist Zanele Muholi (2004).

Bronfenbrenner's ecological systems theory (BEST) was used as the theoretical framework for this study. BEST provided a lens through which to view which ecological environment impacted a woman's experience as she moved through the help-seeking process. Understandings from this study framed with BEST facilitate the ability to focus future research and interventions.

\section{Discussion of Research Findings}

The essential themes that emerged from this research were: decision making, silence, critical junctures in mental health, and moving forward. The themes emerged as the researcher analyzed the experiences from 11 participant interviews, Lotter's (2005) character Anna, Umlilo's (2002) experience in her autobiographical book, and Kid's experience in Muholi's (2004) article. The purpose of this section is to provide an overview of the themes, and compare and contrast with current literature.

\section{Decision Making.}

Help-seeking for each woman in this study began with a decision. The helpseeking path she traveled was influenced by many factors including her individual perceptions and experiences. Study findings indicated the decision to undertake helpseeking after a sexual offence victimization may be influenced by the woman's perceived severity of violence, perceptions of sociocultural expectations, perceived risk of losing resources, or what services the woman perceives to be appropriate to address her needs. Her past experiences with the police, nurses, social workers, or any other person she may have had contact with in the past also influenced her help-seeking decision making. 
Study findings revealed that a woman often had to make a series of complex and interrelated decisions as she sought help after sexual victimization. Each time a woman made a help-seeking decision it was the result of a complex process that involved consideration of all factors pertinent to her particular situation.

Perception of severity of violence. The decision to seek help after victimization was influenced by a woman's perceived severity of violence. Study findings indicated decision making was influenced by whether, in the words of a study participant, the rape was a "violent rape" or a "gentle rape". This finding is consistent with other studies exploring the acknowledgement of rape and reporting rape to the police (Kahn, Jackson, Kully, Badger, \& Halvorsen, 2003; Kahn, Mathie, \& Torgler, 1994). Women acknowledged they had been raped when the characteristics of their rape was congruent with stereotypical rape characteristics such as stranger rape, use of high levels of force, involvement of a weapon, and resultant physical injury (Burgess \& Holmstrom, 1979; Du Mont, Miller, \& Myhr, 2003; Kahn et al, 1994). When a rape lacked those characteristics women did not acknowledge they had experienced rape (Kahn et al, 1994: Kahn et al, 2003). Overall, reporting rape to the police was more likely if the experience had the qualities consistent with stereotypical rape characteristics (Chen \& Ullman, 2010; Cohn, Zinzow, Resnick, \& Kilpatrick, 2013; Kahn, \& Mathie, 1994; Patterson, Greeson, \& Campbell, 2009; Rohrs, 2011; Ullman, 1999).

Perceived sociocultural expectations. Findings from this study indicate a woman's sociocultural context impacts her help-seeking decisions. If she is a young woman and has been sexually victimized by her father or stepfather, sociocultural expectations may be that she should seek help from her mother, and report the 
victimization to her first. However, her mother may chose not to seek further help for her daughter. Jewkes et al. (2005) reported findings from a study examining experiences and perceptions of child rape. They reported mothers frequently did not report their daughter's victimization. The reason given for not reporting was the mother did not want to lose their means or access to resources (Jewkes et al., 2005). Findings from a large study conducted in South Africa exploring views on sexual violence revealed almost 50\% of the women surveyed said if faced with financial hardship they may not stop the abuse of their daughter (CIET South Africa, 2000). A second South African study exploring teenage girls' perceptions of vulnerability to sexual violence indicated one of the girls had been asked by her stepfather to be his second wife (Bhana, 2012). The South African researchers also found in husband wife relationships when the husband was not sexually fulfilled there was a risk of him forcing himself on a girl child family member (Bhana, 2012). Findings from this current study correspond with Bhana's (2012) findings. Jewkes et al (2005) found the culturally driven notion of respect based in hierarchal perceptions of gender and age contributed to sexual violence involving young girls. And, entitlement, control, and punishment were found to be executed on women and girls through the use of sexual violence (Jewkes et al., 2005).

Perception of appropriate service providers. The current study's finding that decision making was influenced by the perception of what is an appropriate service is important. The participants' perceptions of appropriate services meant they knew what services should be available and which service providers should supply particular services. However, also of importance is this study's findings revealing considerable problems with service delivery and with the service providers themselves. 
The government of South Africa has enacted laws to protect and provide needed services for South African victims of sexual offences (e.g., The Criminal Law [Sexual Offences and Related Matters Amendment Act, 2007[Act No. 32 of 2007]; SOA 2007). Additionally, there are a variety of policies in place regarding the manner in which the services should be delivered. Batho Pele Principles (Department of Public Service and Administration, 1997) are eight principles that guide public service delivery. They are: consultation, service standards, access, courtesy, information, openness and transparency, redress, and value for money (See Appendix D).

In the case of the South Africa Police Service (SAPS) the government has provided instruction regarding the delivery of SAPS services (e.g., National Instruction 3/2008 Sexual Offences; NI 3/2008 SO). Both the law (e.g., SOC 2007) and the detailed instructions regarding application of the law (e.g., NI 3/2008 SO) are precise in their guidance. The law provides all citizens the right to be treated with human dignity and have access to health care among other things. The NI 3/2008 SO (e.g., National Instruction 3/2008 Sexual Offences) provides extensive instruction on the processes involved with caring for victims of sexual offences. This study's findings indicate that service delivery by SAPS is not meeting the standards as supplied in the instructions. For example, this study's findings revealed that there were situations where there was a lack of respect shown to the women who were utilizing police services, and the women were provided little dignity. This incongruence of what is spelled out in the law and in the Batho Pele principles, particularly respect and dignity (SOC 2007), is consistent with other studies reporting issues with revictimization, victim blame, questioning the veracity of a victim's rape, and verbal abuse (Francis \& Baird, 2000; Rohrs, 2011; Rumney \& van 
der Bijl, 2010; Steinbrenner, 2011; Vetten et al., 2008). Other instructions provided to SAPS in the NI 3/2008 SO indicate a victim must receive a medical exam as rapidly as possible. Findings from this current study indicate there are women who must wait for long periods of time before police transport them to a medical facility for care. South African research concurs with the finding of police delaying the transportation of victims to health care facilities (Francis \& Baird, 2000; Rohrs, 2011; Steinbrenner, 2011). Some medical facilities require SAPS to provide forensic evidence collection kits; this too may cause a delay in the victim receiving medical treatment (Christofides et al, 2003; Rohrs, 2011). When a sexual assault examination kit (SAEK) does not arrive to the clinic at the same time, or soon after the victim has arrived to receive medical treatment and her forensic exam, there may be a delay in the medical staff seeing the woman until the SAEK arrives. Findings for the current study revealed a similar situation of women being required to wait for their medical care and forensic exams until a SAEK was available.

One aspect of services that the participants in this current study were not aware of was their right to receive medical care without reporting to the police. Findings indicated victims did not know they were not required to report their victimization to the police before they could receive post-exposure prophylaxis. This finding is similar to other studies findings where there was an inaccurate perception that victims must first report to the police before they could receive medical care (Christofides et al., 2003; Rohrs, 2011). There is concern victims may not pursue post-victimization medical care if they believe they must first report to the police (Rohrs, 2011).

Mental health services are very important to victims of sexual violence. The accessibility and availability of counseling services is essential for victims to manage the 
psychological impact both in the period immediately following victimization and in the long term (Campbell, 2008; Martin \& Parcesepe, 2013). Literature supports the importance of post assault mental health services (Campbell, 2008; Christofides et al., 2005; Jina \& Thomas, 2013; Jordan, Campbell, \& Follingstad, 2010; Kumar, Nizame, \& Srivastava, 2013; Mason \& Lodrick, 2013; Patterson, Greeson, \& Campbell, 2009). The findings from this current study revealed the importance of having an adequate number of mental health service providers available who can rapidly arrange counseling for a woman who is experiencing an acute need for mental health care. This findings concurs with Campbell's (2008) discussion of the importance of post assault mental health care immediately following victimization. Findings from the current study indicated that regardless of the point in time during a woman's life that sexual offence victimization occurred, there is a need for the availability of counseling. Additionally, based on the current study findings counseling must be immediately available at the time the woman is experiencing mental distress to avert a decline in her mental health status.

Decision making influenced by experience. Findings from multiple studies reveal there are problematic issues related to medical care service delivery (Christofides et al, 2003; Coovadia, Jewkes, Barron, Sanders, \& McIntyre, 2009; Jina, Jewkes, Christofides, \& Loots, 2013; Rohrs, 2011; Steinbrenner, 2011). Woods and Jewkes (2006) reported nurses scolded patients and made them feel "ashamed and afraid" (p. 113). Study findings from the current study concur with other studies findings regarding nurse behaviors (Coovadia et al., 2009; Steinbrenner, 2011; Wood \& Jewkes, 2006). An example from the current study was Nontle's experience of a nurse shouting at her and 
the victim she was assisting at a specialized care center for victims of sexual offences. Vivienne also reported abusive behavior from a nurse at a specialized care center. South African researchers Coovadia, Jewkes, Barron, Sanders, and McIntyre (2009) reported nurses have been known for "rudeness, arbitrary acts of unkindness, physical assault and neglect ... particularly in sexual and reproductive health services" (p. 829). However, one must consider that the work of nurses is challenging (Frank, 2006; Kekana, du Rand, \& van Wyk, 2007; Koekemoer \& Mostert, 2006; Nyathi \& Jooste, 2008; Pillay, 2009; Rohrs, 2011), and made more so by the lack of resources (Klopper, Coetzee, Pretorius, \& Bester, 2012; Koekemoer \& Mostert, 2006; Pillay, 2009; Rohrs, 2011), lack of training (Abdool \& Brysiewicz, 2009; Christofides et al., 2003; Christofides et al., 2005; Rohrs, 2011; Uys \& Naidoo, 2004), high work load levels (Kekana et al., 2007; Koekemoer \& Mostert, 2006; Pillay 2009), lack of clarity of one's job responsibilities (Koekemoer \& Mostert, 2006), and staffing shortages (Frank, 2006; Kekana et al., 2007; Klopper et al., 2012; Koekemoer \& Mostert, 2006; Nyathi \& Jooste, 2008). Each of the challenges are associated with job dissatisfaction (Kekana et al., 2007; Klopper et al., 2012; Pillay, 2009) which may be manifesting in nurses behaviors. Conversely, the researcher found problematic nurse behavior could not be generalized to all nurses. Nurses in some government care centers in urban areas and nurses in outlying areas (e.g., small towns and rural areas) were described as very helpful and as providing needed services in a compassionate and caring manner by the participants in this current study.

Gaps in service provider training have been identified in literature as an issue in service deliver. In the North-West Province primary healthcare nurses were reported to 
not have any training in care for victims (Christofides et al., 2003). Additionally in the same study it was reported nurses did not refer victims for counseling because "I just never think of it" (p. 25), “don't know who I can refer them to" (p. 25), or "it's not my role" (p. 25). Nurses play a very important role in the care of victims. It is very important all nurses working in primary healthcare receive training in caring for victims of sexual offences due to the high rate of sexual victimization in South Africa. Moreover, it is paramount that the nurses in the care centers and in other care environments provide services in a compassionate and caring manner.

\section{Silence}

Study findings revealed silence is an accepted and most often expected reaction to sexual offence victimization in South Africa. Study participants described silence as never talking about sexual victimization to family members or friends. Participants found not talking about their victimization impacted their process of healing. Silence was maintained according to findings in this current study because of myriad factors including: it was not an accepted practice to talk to family or friends about victimization; not remaining silent and keeping abuse secret placed a person or their family in harm's way; self-blame and shame compelled a woman to keep silent; and silence was related to sociocultural expectations.

Not talking about victimization. Findings from this study revealed it was important to talk to others about victimization. Participants found talking about their experience was very beneficial in their process of healing. This finding concurs with findings from research conducted to explore the meaning of recovery as experienced by the women who had been raped. Smith and Kelly (2001) found that if women talked 
about their experience to others it played an important role in helping them in their healing process. Additionally, women in the Smith and Kelly (2001) study found that speaking to others provided them with the "will to live, the ability to feel understood, and the strength to begin their journey of recovery" (p. 349). Ullman's (1996) study found that women's recovery was positively affected when they perceived they were being listened to, which resulted in the women experiencing less psychological symptoms.

Silence in the form of secrets. Findings from Vetten et al. (2008) revealed young girls were likely to be told by their victimizer to keep the abuse secret. Findings from this study concur. However, this study's findings also revealed that the request to keep the assault secret was accompanied with threats to the girl's safety or to the safety of her family members. A young girl is vulnerable to an adult male's power and authority, particularly in patriarchal sociocultural structures as seen in South Africa. As a result there is opportunity for the man to manipulate the girl using his position of power and authority to coerce her into silence. This finding contrasts with Vetten et al. (2008) finding that the young girls in their study had typically not been threatened with physical harm by the adult males who raped them.

Keeping rape a secret is also found to be a form of protecting oneself. A finding from the current study indicated once a secret is shared it can then become a weapon. In the case of Bontle, she told her boyfriend about her rape because she trusted him. He used the power of her secret as means to deeply hurt her. This resulted in her experiencing psychological stress and the feeling of being raped again. This finding concurs with other studies that have found disclosure of rape leads to opening oneself up to revictimization. The revictimization was often a result of others suggesting the victim was to blame for 
what happened (Aherns, 2006; Campbell, 2008; Patterson et al., 2009). Tankink (2013) reported findings from a study conducted in the South Sudan concerning silence after women were sexually victimized. Tankink (2013) reported a South-Sudanese woman told her husband she had been raped. She told her husband about the rape because she believed if a woman had sex with another man the husband should know. For a period of time after telling her husband about the rape she avoided having sex with him, but in that cultural context a woman was obligated to provide her husband with sex. Her husband demanded she have sex with him and from that point on her husband became increasingly violent during sex, and he began to beat her.

Shame and self-blame as seeds of silence. Not talking about victimization was spoken of in the current study as leading to self-blame and shame. Study findings revealed that when a victim felt shame for what she had experienced she keep her experience a secret. Abrahams and Jewkes (2010) reported when a woman's family members would not talk to her about her experience of rape this lead to a woman feeling she was to blame for the rape. Abrahams and Jewkes (2010) findings also concur with this study's finding that victims internalized the family's silence as the family blaming her for the rape, and in turn led the victim to feel shame. In Tankink's (2013) SouthSudanese study rape was associated with great shame, therefore women talked to no one about their experiences of rape (Tankink, 2013). Tankink explained, for the Sudanese women shame was not associated with the feeling of guilt for being rape, instead shame was associated with cultural values. The women did not internalize the rape as feelings of guilt or self-blame because they knew they had no control over being raped (e.g., being raped in the context of conflict). The shame they felt was a result of their cultural values 
being violated. In a study conducted in Palestine, mental health care in the context of Palestinian culture was analyzed, Shalhoub-Kevorkian (1999) reported not talking about victimization was associated with feelings of blame and worsening mental health status. Ullman (1996) also reported self-blame being related to psychological symptoms.

Silence as sociocultural expectation. Research suggests that silence in the sociocultural context has roots in patriarchy (Posel, 2005). Patriarchal structures place men in a role of dominance, and women and girls in a subordinate role. South Africa has a long history of gender inequality rooted in patriarchy. Despite the 1993 Interim Constitution of the Republic of South Africa, which declared women were "able to claim their rights as equal citizens in an ostensibly 'non-racial and non-sexist' society" little has changed (Meintjes, 1996, p. 47; Posel, 2005). In many cases in South Africa patriarchy manifests as men acting in the role of the provider of resources. Findings from this study and other studies indicate, as results of providing resources men expect something in return. The men expect to have rights to access all the sexual resources in a household including their daughters and step-daughters of any age. Therefore as revealed in the findings of this study and reported by other researchers, a woman may remain silent and do not report her daughter's victimization when she believes there may be a risk of losing resources such as financial resources if access to sexual resources are denied (CIET South Africa, 2000; Jewkes et al, 2005).

A study was conducted to conceptualize gender and violence within the context of Kenya, Ghana, and Mozambique (Parkes et al., 2013). Findings from Kenya revealed in some cases when village elders where asked to arbitrate a sexual victimization, the elder would not hold the man responsible, instead they would require the girl to forgive the 
man (Parkes, 2013). Shalhoub-Kevorkian (1999) reported when girls in Palestine were raped often times they were forced to marry the man who raped them, or, in some other cases the girls were put to death to save family honor. In both Kenya and Palestine the men were not held accountable for their crime of rape, instead the girls were blamed for what had happened, and blamed for causing their families to be disgraced. In both situations, sociocultural norms impacted how the rapes were dealt with by the girls, their families, and their communities. Compelling the actions of the girls being forced to forgive their rapist, or being blamed for the rape, are the notions of 'not causing problems in the family', or 'not causing the family disgrace in their communities'. ShalhoubKevorkian (1999) makes the point "cultural norms and values lead ... women to the conclusion that it is best to conceal things" (p. 169). As reported in this study and in concurrence with other research, sociocultural factors impact a women's response to victimization.

\section{Critical Junctures in Mental Health.}

The findings of this study indicate psychological distress can happen at any point in a woman's life after victimization. Junctures in mental health are points of time in a woman's life when she is experiencing psychological distress. These points in time are described as critical junctures because participants discussed the junctures as pivot points that could either lead a woman to seeking help, or could lead to a further decline in the woman's mental health status. An example of a critical juncture from the current study is Mbali reaching the point where she wanted to give up on life and was experiencing thoughts of suicide. However, at that point when she was ready to give up she discovered her desire to live. This led her to finding help. A second example of a critical juncture 
from this study's findings is Lerato's experience of being told that her baby had passed. At that point she made the decision it was time to report her father to the police. Therefore instead of sinking into despair, she became very determined, and found the resolve to report him.

The impact of sexual violence on women's mental health and treatment has been well researched (Campbell, Ahrens, Self, Wasco, \& Barnes, 2001; Foa et al., 1999; Machado, Azevedo, Facuri, Vieira, \& Fernandes, 2011; Martin \& Parcesepe 2013; Sullivan \& Bybee, 1999). From this work it is clear with treatment victims of sexual offences do experience improved mental health.

Victims of rape may experience depression, fear, anxiety, suicidal ideation, and suicide attempts (Koss, Figueredo, \& Prince, 2002). But, not all women will experience psychological distress post victimization, and if they do it will vary woman to woman (Campbell et al., 2009). The findings from this current study concurs with Campbell et al. (2009) and others (Machado et al., 2011; Martin \& Parcesepe, 2013), there are variations in what women experience related to their post assault mental health. Findings revealed some women experienced what they described as depression, and others described suicidal thoughts and suicide attempts. These findings reflect Koss et al. (2002) findings of victims experiencing depression, suicidal ideation, and suicide attempts.

Burgess and Holmstrom (1976) introduced rape trauma syndrome as a group of symptoms they observed in women who came into their victim counseling program. Since that point rape trauma syndrome (RTS) has been used to identify a group of physical and emotional reactions to rape. RTS is described as a version of PTSD (posttraumatic stress disorder; Ledray, 2006). PTSD and RTS share the following 
diagnostic characteristics: exposure to a traumatic event; re-experiencing the trauma; symptoms of avoidance and numbing; and symptoms of increased arousal (Ledray, 2006, p. 285). Rape crisis counseling centers in South Africa make use of the RTS symptoms in their literature and on their websites to help victims understand what they may be experiencing post victimization. This study did reveal findings that reflect RTS symptomology as described by Burgess and Holmstrom (1974) including fear, selfblame, anger, humiliation, and depression

An important finding in this study was that women experienced psychological distress at any point in time after victimization, with some experiencing distress many years after they had been raped. Koss and Figueredo (2004) assert emotional distress may be experienced up to two years after victimization. However, the findings from this current study revealed a woman may experience psychological distress for many years after victimization.

Breaking down. Study findings revealed regardless of when a woman experienced psychological distress after sexual victimization, immediate access to mental health counseling was desired. If immediate care was not available participants described how this created a risk for further decline into greater psychological distress.

Additionally, if immediate care was not available and a woman was experiencing thoughts of suicide there was a strong potential she would act on her suicidal thoughts. Sullivan and Bybee (1999) found when victim's needs were immediately address there was a reduction of distress and victims experienced a sustained improvement in their quality of life. 
At 40 years of age Thandeki described her world as collapsing around her, it was not until she went into counseling that she was able to break free from that state. Lerato described that she was an emotional wreck when her son passed away. Bontle had attempted suicide while in her teens, She survived the suicide attempt and found the ability to continue until the point when she was at university and the stress became too much. She described experiencing a complete breakdown at that point, and sought help as quickly as she could. These findings concur with research concerning the impact sexual violence has on a woman's mental health. Women's experiences with mental health issues were found to have similarities among victims internationally (e.g., Brazil, India, South Africa, and the United States) depression, anxiety, post-traumatic stress are all associated with sexual violence victimization (Jina \& Thomas, 2013; Kumar et al., 2013; Machado et al., 2011; Martin \& Parcesepe, 2013; Mason \& Lodrick, 2013).

The power of counseling. An important finding of this study was the emphasis participants placed on mental health counseling. The researcher had assumed participants would place a stronger emphasis on medical services, particularly in a country where there is such a high rate of HIV, but that was not the case. Medical services were considered important as were other services such as social services and legal services. However, the greatest emphasis was placed on mental health services. The researcher suggests the emphasis was because of the positive experiences participants had with mental health counselling, and the positive benefits the participants experienced as a result of participating in mental health counseling.

Findings from the current study indicate mental health services are very important for victims of sexual offences, and are required in both the distal and proximal phases of 
a woman's life after she has experienced sexual offence victimization. In a report published by the World Health Organization (Atlas: Nurses in Mental Health-World Health Organization, 2007) it was reported that overall women found mental health services important to their healing. Christofides et al. (2005) conducted a large South African study to better understand women's experiences and their preference for post assault services. Findings from the study indicated the women found counseling very important. Seedat et al. (2009) and Jordanova et al. (2007) reported a strong relationship between stressors such as negative life events which included "being the victim of a serious physical attack or assault" to be associated with common mental disorders such as depression and anxiety. This is congruent with findings from this current study. Therefore it is reaffirmed that victims need and understand the importance of access to counseling. Campbell, Wasco, Ahrens, Sefl, and Barnes (2001) explored survivor's experiences with community service providers. Their findings revealed "survivors overwhelmingly rated their contact with mental health professionals, rape crisis centers, or religious communities as healing $(70 \%, 75 \%$, and $85 \%$ respectively; Campbell, Wasco, Ahrens, Sefl, \& Barnes, 2001, p. 1250).

\section{Moving Forward.}

Moving forward is the experience of a woman moving toward and into healing after sexual offence victimization. Moving forward is a process that takes place over time. The process of moving forward is catalyzed by varying factors. One factor is the decision to forgive. Moving away from the place where the victimization occurred was catalytic to stimulate the process of moving forward. Mental health counseling was considered a factor helpful to moving forward. Additionally, talking about victimization 
was discussed as an important factor to moving forward. The concept of moving forward may also be thought of as regaining self and regaining control of one's life. Westmarland, Alderson, and Kirkham (2012) investigated the health, mental health, and well-being benefits of rape crisis counseling. They administered their instrument, Take Back Control, at initiation of counseling and then repeated every six weeks during the period of time counseling took place. Results indicated the measure "I feel empowered and in control of my life" had the greatest change. Frazier (2003) found regaining control after sexual assault was a very important factor to healing. This is congruent with the findings of this study with a specific example of Mbali who spoke of regaining control as a key factor to her healing. She stated through her informal counseling she was able to "just get back to me".

Mbali found the resolve through informal counseling to learn to love her post assault self. She was forever changed because of the rape, but she learned to love the person she had become. Mbali's experience of learning to love herself was similar to Smith and Kelly's (2001) study finding of the notion of redefining self. Redefining self (Smith \& Kelly, 2001) was similar to Nontle and Annalie's process of moving forward. Smith and Kelly's (2001) study finding of redefining self was described as "regaining what one has lost as a result of being raped. . [and] the ability for increased growth" (p. 346). Nontle returned to school to obtain the education she required to be able to help others who had been victims of violence. Annalie learned to let go of self-blame and reclaim who she was before she was raped.

In this current study, for Lerato and Thandeki forgiveness was very important to moving forward. Lerato discussed her process of forgiving her father allowed her to 
move forward. She discussed it was a hard thing to do, but once she had gotten to the point where she could forgive him she was able to release the anger she had felt for so long. Thandeki's experience of finding forgiveness was similar in that it took a long time to get to the point where she could forgive. For Thandeki it was very important to her to find forgiveness because of her religious beliefs. Forgiveness was found to be an important research finding in a study looking at recovery after sexual victimization (Smith \& Kelly, 2001). Women in the study described forgiveness as forgiving themselves and forgiving their rapist.

Vivienne was the only participant who did not discuss moving forward, she was very angry and expressed she just could not let the anger go. When reflecting on the other study participant's processes of moving forward, and research findings from other studies, it could be anticipated that Vivienne, like others, may experience a break down and will either decide to find counseling or move into further despair.

There has been little research evaluating the outcomes of mental health counseling after sexual victimization. In a literature review Brown, Horvath, Kelly, and Westmarland (2010) examined the evidence, knowledge and practice in responses to rape. There review demonstrated that there is very little research to date that had undertaken the evaluation of the outcomes of mental health counseling after sexual victimization.

\section{Findings in the Context of Bronfenbrenner's Ecological Systems}

Each woman's experience of help-seeking after sexual offence victimization was situated and unique to her lifeworld. The ecological system a woman exists within provides the context for her lived experience. When applying Bronfenbrenner's 
ecological systems theory to sexual offence victimization, one considers the ecological systems a woman grew up within and currently exists within, and the impact the ecological systems have had on her and her actions. Importantly the ecological systems she has grown up within impact her perceptions of her experiences and the manner of how she acts on her experiences. Help-seeking after sexual offence victimization is a series of complex processes. Therefore, her decision making processes will be impacted by the people, the objects, the symbols, the social and cultural systems, economic systems, political systems, and belief systems that have been within her ecological environments over her life and by her experiences in those ecological environments that have shaped and formed her behavior and development (Bronfenbrenner, 1979).

When applying Bronfenbrenner's ecological systems theory it is important to consider a woman's immediate environment, and to consider the broader context of her ecological environments. Additionally, it is very important to maintain the understanding that the reality of her existence is not based only on the concrete aspects of her existence, but the reality of her existence is also situated in her perceptions of her experiences. 


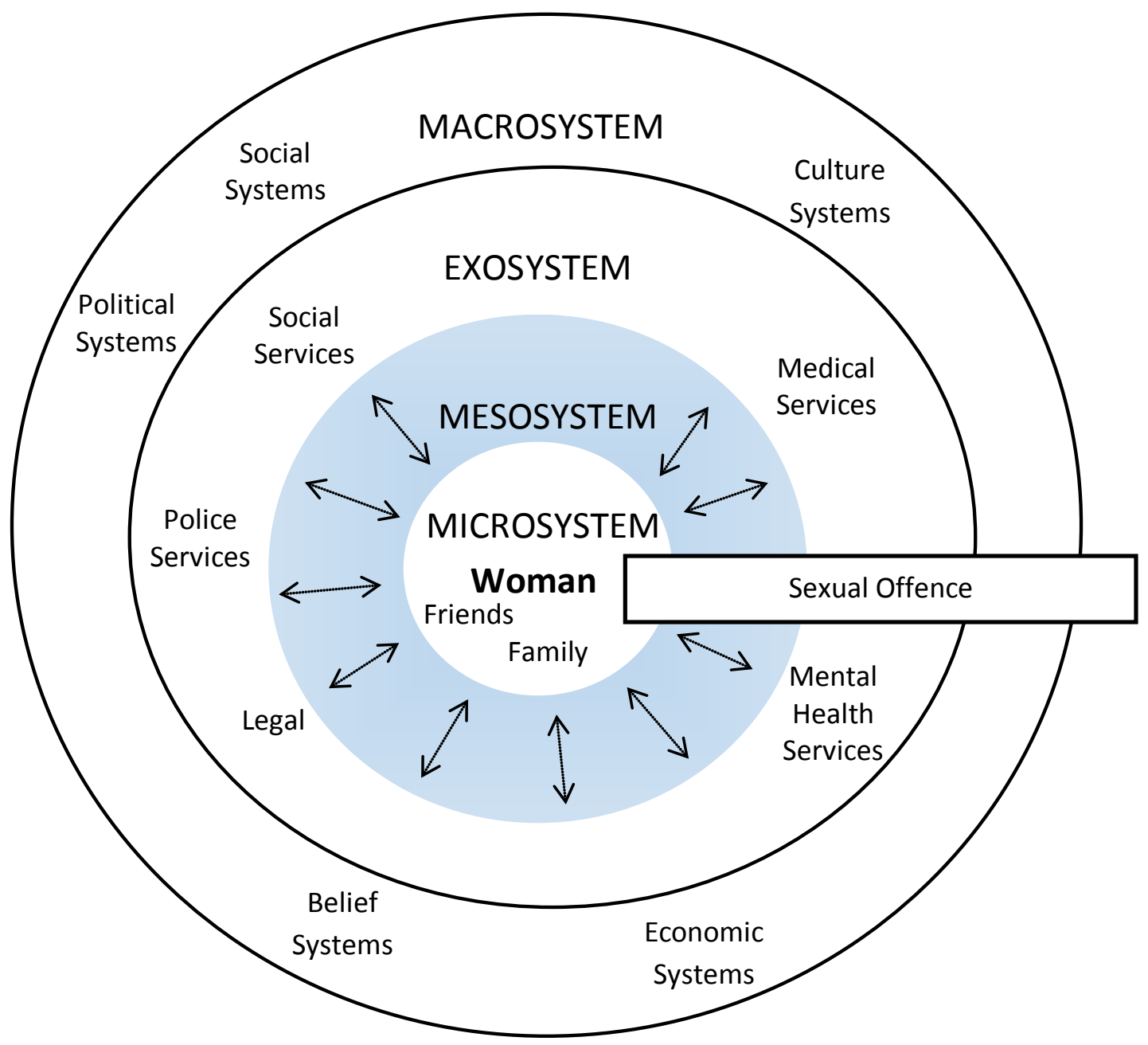

Figure 2. Sexual Offence Victimization Impacts all Ecological Systems

As a result of the findings in this study it is revealed that all of the ecological systems in which a woman exists are impacted by sexual offence victimization. Therefore the lived experience of sexual offence victimization can be understood in context of the theory. The systems that are impacted by the victimization include all systems which are as follows: the microsystem, the system in which she is most intimately involved; the mesosystem, a system of interrelations that are formed when she participates in and 
experiences new settings; the exosystem, a system she does not actively participate in, but affects her life; and last, the macrosystem, a system all her other systems exist within. When a woman is sexually victimized by a stranger, the stranger will enter her microsystem through her mesosystem, and therefore force entrance into her most intimate system. The microsystem is "experienced . . not only in its objective properties but also in the way in which these properties are perceived by the persons in that environment" (Bronfenbrenner, 1979, p. 22). Prior to victimization the microsystem was experienced as a system of safety and peace of mind. However, after the victimization it then becomes interrupted. She is forced to deal with a victimization that has forcefully entered her inner most system and therefore affects her experiences and her perceptions of her experiences. A system that was once occupied by family and friends is now also occupied by her victimizer. Therefore a system she had experienced and perceived as a place of safety becomes a source of stress.

For a woman who has been sexually victimized by her father, other family member, or by a close friend, the victimization has been brought on by an individual from her most intimate system, her microsystem. A victimization acted out by a member of her microsystem, however, should be conceived the same as a stranger rape, in that even though her victimizer was a member of her microsystem, once that individual victimized the woman they became victimizer and no longer share the same status in the woman's life as they did before. They have now forcefully entered her life as a victimizer.

What the researcher has referred to as an interruption to one's microsystem is what Bronfenbrenner (1979) conceptualizes as ecological transitions. According to 
Bronfenbrenner (1979) “an ecological transition occurs whenever a person's position in the ecological environment is altered" (p. 26). Bronfenbrenner posits that an ecological transition is "both a consequence and an instigator of developmental processes" (p. 27). Therefore when a woman's microsystem is interrupted through victimization, the consequence of this is her most intimate system has been forcibly entered. And, as a result the event becomes the instigator for the potential development of psychological distress rooted in her loss of control within a system that prior to the victimization she was in control of.

Bronfenbrenner (1979) posits ecological transitions may also occur in the other three systems. And in those systems as in the microsystem, the same notions of consequence and instigation of process will occur. Therefore if there is an alteration in the availability of services in the exosystem, for example there is an increase in the availability of mental health services this will instigate the opportunity for better mental health wellbeing.

The mesosystem as conceptualized by Bronfenbrenner (1979) is a dynamic area, constituted of "the interrelations among two or more settings (e.g., microsystems) in which the ... person actively participates in" (p.25). As an individual moves into new settings, those new settings and new experiences in those settings meld into, and become part of the individual's microsystem (Bronfenbrenner, 1979). Therefore, when a woman is sexually victimized by a stranger the victimizer violently enters into her microsystem from her mesosystem. And, if the victimizer is a family member or a friend they will have violently interrupted her inner most system, a system she cannot escape from. Even though she cannot escape the microsystem she can take it back and regain control with 
the right medical and mental health services. With affective and appropriate services she has the opportunity to regain her safe, peaceful space—-her microsystem.

The woman's exosystem is a system she does not actively participate in, but is affected by. When she seeks help from services, the services she is accessing are located in her exosystem. Examples of what exist within an ecosystem include but are not exclusive to the following: the broader community in which the woman resides, the governing body of that community, the police, and the healthcare resources in the individual's community. If the needed services are not available to her then she will not find those services in the other systems. Those services must be present to her in her exosystem so that she may interact with them, and receive the services needed to continue to erode the control her victimizer has on her microsystem. It is important to understand the entities in a woman's exosystem act on her. Therefore if there are services that are not available to her in the exosystem she will be adversely affected as a result. The same will stand if there is a poor quality of service delivery, as a result she will experience services that may detrimentally affect her wellbeing. However, when needed services are available and the quality of services is good, there is great potential for women who have be sexually victimized to experience healing.

The macrosystem encapsulates all of the woman's lower order systems (e.g., the microsystem, mesosystem, and exosystem), and acts to forms and shape her perceptions through cultural systems, social systems, belief systems, or economic systems. Therefore her macrosystem will impact how she will perceive her sexual victimization and how she will act on her victimization. If she perceives her victimization an act of sexual violence 
will she feel compelled to seek help? How has her macrosystem shaped her perceptions of utilizing services located in her exosystem?

When a woman seeks services, she will experience service delivery within her microsystem. Her microsystem is her experiential system. She does experience all the other systems, and all other systems impact her microsystem, ultimately however services are experienced within her microsystem. Her microsystem will be impacted by her experiences with services. With available, accessible, proper, and effective service delivery that addresses all her needs holistically, the negatives associated with the victimization will have the potential to be ameliorated, and through amelioration she will move towards healing. Healing is accomplished when she has taken back her microsystem, or in other words when she has taken back her life

\section{Limitations}

There are three limitations to this study and should be noted with interpretation of the findings. First, is the limitation of only including English speaking participants. Second is the inability for follow up further on interviews due to time and budget limitations. Finally, the researcher is a North American woman. Efforts were taken to minimize the limitations and will be described with each limitation.

Limiting participants to only those who were conversant in English is a limitation of this study. It was important to conduct interviews in a common language to assure the essence of the phenomenon of women's lived experiences of help-seeking was captured. The researcher discovered while conducting a pilot study in South Africa there were a large number of individuals who spoke English. Therefore the researcher, in consultation with South African academics, and service providers in the community concluded 
English was an appropriate common language to use for this study. Squires (2010) posits phenomenological studies should not be conducted using a translator due to the risk of the "text changing enough during the translation process that the investigator will not adequately capture the essence of the phenomenon in the translated language" (p. 5). Filep (2009) asserts the use of a common language in cross-cultural research requires the researcher and the interviewee to "both have to be conscious of potential misunderstandings" and therefore must work to clarify ideas and concepts to avert misunderstandings.

The second limitation was the inability to further follow up on interviews with participants. This was a result of limited time and research budget. In the future with larger budgets, and longer periods of time in the country there will be the opportunity to allow for a more extensive interview schedule. However, in order to maximize the time the researcher had with participants, as each interview was completed the researcher immediately began the process of transcription. By virtue of doing the transcribing herself, before a subsequent interview, she was able to identify areas where there was a need to develop a better, more clear understanding of what the participant was saying. Given the time and budget limitations for this study, the researcher attempted to conduct the interviews so that they offered a thick description of the South African woman's lived experience of help-seeking after sexual offence victimization. Geertz's (1973) notion of thick description is grounded in the context of culture. He believes conceptually that culture is semiotic, therefore is constituted of all the signs, symbols, beliefs, and whatever else that gives meaning to the culture. Therefore, taking Geertz's (1973) notion of thick description and applying the concept of semiotic, the researcher worked diligently to 
understand as best possible each participant's interview. Each interview was understood from the perspective that everything said was meaningful to capturing the phenomenon of help-seeking after sexual victimization. Additionally, the researcher had spent three months in South Africa in 2011 conducting a pilot study. Thus going into the current study there was some knowledge of the culture, provision of services and understanding of the phenomenon.

The last limitation is, that as a North American woman, there is the risk of not conceptually understanding what is being said (e.g., communicated by participants). In presenting this limitation the researcher acknowledges she held the assumption that there would be conceptual differences between life and language in South Africa versus North America. This proved to be a correct assumption. One example of this was a participant stating to the researcher that all American families eat dinner around a table every night. This identified a conceptual understanding of America that had been informed partly by the broadcasting of many American television shows in South Africa. This served to increase the researcher's awareness of the importance of diligently working to understand the participant's perspective regarding what they were saying. In addition, this served to further increase the researcher's understanding of the importance to diligently practice reflexivity during the research process.

As a North American much of what the researcher knew regarding South Africa had been informed by the following: taking university undergraduate and graduate anthropology classes, watching and hearing American news regarding Apartheid, reading South African history, and watching movies and television shows about South Africa or that were situated in South Africa. What she knew of sexual violence in South Africa was 
informed by: news broadcasts and literature she had read throughout the years, and, time spent discussing sexual violence with a visiting South African professor while taking a graduate cognate course on trauma that was offered at the researcher's university. Additionally, her knowledge of sexual violence had also been informed over the years through reading literature about sexual violence in America and other countries. The researcher completed an ethnographic pilot study in South Africa over a three month period of time in 2011. During this period she was immersed in South African culture and geography, services and the process of the delivery of services for victims of sexual offences. She developed a beginning understanding of sexual violence in the context of South Africa. While conducting the research for this current study she again lived in South Africa for three months, stayed in a women and children's crisis shelter for victims of violence, and continued to build her knowledge of South African culture, geography, and the essence of life in another country.

All these actions served to bring clarity to the absolute need for constantly engaging in the reflexive process, both while in South Africa, and upon returning to the United States and during the writing of this dissertation. She learned that almost every day her assumptions where challenged and repeatedly transformed. In this current study the processes engaged to achieve rigor have also contributed in supporting researcher reflexivity. Lincoln and Guba's (1985) approach of trustworthiness was used in this study and each of the trustworthiness criteria served to maintain researcher reflexivity. The trustworthiness criteria and their application in this study were discussed at length in Chapter three of this research report.

\section{Implications}


There has been limited research done in South Africa exploring South African women's lived experiences of help-seeking after sexual offence victimization. South Africa has a very high rate of sexual violence (Cox et al., 2007; Martin, 2002) therefore, there is considerable need to build understanding of women's experiences of helpseeking after sexual offence victimization. This study's findings contributes knowledge that can be used to inform and direct efforts to more effectively address service needs as identified by South African women. The following is a discussion of the implications of this study's findings on nursing practice, education, and policy.

\section{Nursing}

South Africa has very limited mental health care resources. In a country with very high rates of sexual offence victimization there is a clear need for available mental health services as evidenced by findings from this study. Mbali spoke of her immediate need for counseling but was told there would be a considerable wait before she would be able to see a psychologist. Bontle spoke emphatically of the importance mental health counseling had in her moving forward with her life after she was raped.

The timing of mental health interventions following sexual offence victimization has been found to be important (Foa, Davidson, \& Frances, 1999; Resnick et al., 2007). In the time frame immediately following victimization (e.g., within 72 hours post assault) and after reporting their rapes to the police, women presented at a medical facility to receive a post victimization medical exam. However, prior to receiving their exam they were shown a video. The video presented information of what to expect during their exam and information regarding mental health issues that may occur in the post assault period. The intervention was shown to be somewhat effective in reducing the risk of 
developing PTSD and panic symptomatology (Resnick, Acierno, Holmes, Kilpatrick, \& Jager, 1999). The intervention was a very cost effective approach to reducing psychological distress after victimization. In resource poor settings great consideration must be given to the all aspects of intervention implementation to address mental health care needs.

Practice All primary health care nurses working in clinics and hospitals, and all community health nurses including those working in mobile health clinics are in a unique position to provide much needed information regarding sexual offence services to women anytime they provide care. Because there is a very high rate of sexual offence victimization in South Africa, it is safe to assume many of the women the nurses provide care to have been victimized. Therefore nurses are in a prime position to educate women to the services available for victims of sexual offences (Peterson, 1999)

Study findings have revealed the important role psychiatric mental health (PMH) nurses have, and the potential they have in filling the need to provide care to victims of sexual offences. Forensic nurses who provide medical care to victims are employed in Thuthuzela Care Centres. With the addition of PMH nurses, the care centers could provide a higher level of care to victims. Additionally, the placement of PMH nurses in the care centers would locate nurses in a centralized, accessible location to provide mental health care to victims in need of counseling services. Because of the importance of the availability of immediate care for victims it would also be ideal to have PMH nurses available 24 hours a day to provide care.

When taking into consideration the limited mental health resources in South Africa, other manners of approach to building the capacity of mental health services must 
be considered. An approach that is gaining momentum in low- to middle income countries is the approach of training lay mental health counselors to fill the gap of trained professional mental health counselors. Murray et al. (2013) has developed a mental health counseling intervention for low- to middle-income countries (LMIC) that is delivered by lay counselors. The intervention is designed to be used with depression, traumatic stress, and anxiety. Findings from two intervention implementation pilot studies (Murray et al., 2013) indicate the strong potential lay mental health counseling has in LMIC. An additional benefit the pilot studies findings revealed was the ability to address crosscultural issues in the delivery of mental health counseling when using lay mental health counselors. To fill the gap in mental health service availability, and to maximize the PMH trained nurse work force in place, lay mental health counselor training could be implemented and overseen by the current South African PMH nurses.

Education. The findings of this study clarify the need to direct educational efforts to increase the number of mental health professionals available to provide care for South African women who have are victims of sexual offences. Study findings also indicate the need to train all primary care nurses in the care of victims of sexual offences.

The World Health Organization in coordination with the International Council of Nurses collaborated on research concerning mental health nursing (Atlas: Nurses in Mental Health-WHO, 2007). The report was developed because there was little information available discussing mental health nursing, particularly in low-to middleincome countries. The data was gathered using a standardized questionnaire. The questionnaire was translated and administered in six different languages, and administered in Africa, the America's, South-East Asia, Europe, Eastern Mediterranean, 
and Western Pacific. The following recommendations emerged from study data: (1) recognize nurses as essential human resources for mental health care, (2) ensure that adequate numbers of trained nurses are available to provide mental health care, and (3) incorporate a mental health component into basic and post-basic nursing training (Atlas: Nurses in Mental Health-WHO, 2007, pp. 51-52).

Addressing the recommendations presented in the WHO report in South Africa, would require considerable effort and require buy in from all the stakeholders, including the government. There are psychiatric mental health nursing programs at a number of the universities in South Africa. Maximizing those available resources would be required, as well as all those involved working together as a team focused on the greater good of the country. There is a tremendous need for the greater availability of mental health services in South Africa, particularly for women who have experienced sexual offence victimization. Following the WHO report recommendations has the potential to substantially benefit those who have been victimized by sexual offences.

Along with increasing the number of mental health nurses, there is also a need to direct efforts at educating all South African primary health care (PHC) nurses in the provision of care for victims of sexual offences. This is particularly important for the nurses working in areas located far from Thuthuzela Care Centres. PHC nurse's education should deliver curriculum that includes all aspects of care provision for victims of sexual offences, including the South African Department of Health's two week forensic training program.

Policy. In order "to combat international violence against women and girls" the bill, S. 2982/H.R. 4594 International Violence against Women Act 2010 (S. 2982, 2010, 
p.1) has been presented to the United States government. The bill proposes to develop international strategies and assistance to reduce and prevent violence against women and girls (S. 2982, 2010, § 3). The IVAWA 2010 is an appropriations bill, which sets out to establish a governing structure to oversee the reduction of violence globally, in addition to establishing funding mechanisms to support the reduction of violence and create economic empowerment. To accomplish this the bill proposes the following; the designation of the office of Ambassador-at-Large for Global Women's Issues, the designation of a Women's Development Advisor, comprehensive international strategy and assistance to reduce and prevent violence against women, a mechanism to ensure the accountability of the US's response to violence against women and girls internationally, enhance training of foreign military and police forces with the training focused on the reduction of violence against women and girls, the impetus to address violence against women as related to conflict in conflict and post-conflict settings, provide humanitarian relief, and last provide funding and other support for multilateral efforts to end violence against women and girls (S. 2982, 2010).

Garcia-Moreno and Watts (2011) posit violence against women as a peace and security issue, however, little has been done to address this globally important issue. "In spite of this recognition, investments in prevention and in services for survivors remains woefully inadequate" (Garcia-Moreno \& Watts, 2011, p. 2). The United Nations reports one in three women globally have been "beaten, coerced into sex, or otherwise abused in her life" (S. 2982, 2010, § 2, p. 2). Kofi Annan, the secretary-general of the United Nations asserts, it is "perhaps the most shameful human rights violation and perhaps the most pervasive" (Annan, 1999, para. 3). Enacting IVAWA 2010 presents an opportunity 
for the US to take a lead position in the very important effort of reducing sexual violence against women worldwide.

\section{Future Research}

Findings from the study revealed a number of areas related to the care of victims of sexual offence that needs further research. The researcher will use Bronfenbrenner's ecological systems model to discuss recommended research. Using Bronfenbrenner's ecologic systems model provides a broader way to conceptualize the multiple needs of studying this phenomenon.

Microsystem. The microsystem is where the woman is located and where she is an active participant, and therefore where she directly interacts with people. As Heise (1998) describes it is "where subjective meanings [are] assigned" to the interactions she has with other. Therefore questions arise from findings of this research. What is the nature of the mental health impact on a woman who is sexually abused by a member from her microsystem (e.g., her father, uncle, brother, etc)? What are the mental health responses a woman experiences as a consequence of that construct of violence? What impact do others in her microsystem have on her responses?

Mesosystem. Brofenbrenner (1979) describes the mesosystem as a system that includes a woman's family and friends, however, the mesosystem also includes a woman's experiences when she actively participates in a new setting. Therefore, when she is raped by a stranger, the stranger forces himself into her microsystem. What effect

does stranger rape have on a South African woman? Is her response different than when she is raped by her father, or her uncle? How does age affect her response? 
Exosystem. Medical service, legal services, mental health services all exist within this system. What is the impact of centralized services on women's care provision? How do socioeconomic and geographical factors impact a woman's experiences in this system?

Macrosystem. The macrosystem is made of systems that a woman has no control over. The macrosystem encapsulates all of her other systems, and thus impacts all of them. Therefore it is important to build a better understanding of: what are sociocultural factors that impact South African women's help-seeking experiences, how do economic systems affect women's help-seeking, and if South Africa continues to not prioritize properly funding services for women who have been sexual victimized what are the consequences?

It is clear from findings of this research there are many factors that affect a woman's help-seeking experiences. Exploring questions such as those above, through the lens of each system has the potential to reveal important findings that could be very valuable in the development interventions.

Because the majority of mental health research has been conducted in the United States there is a gap of understanding regarding the experiences of psychological distress in the context of South Africa. Do the symptoms of psychological distress that South African women experience fit the western models of mental health disorders as presented in the DSM-5 (Diagnostic and Statistical Manual of Mental Disorders)? The DSM-5 is used in South Africa in the same manner it is used in the US to guide diagnoses and subsequent treatments. Does it adequately address the mental health care needs of South African women after victimization? Given the low level of mental health providers in 
South Africa what are other mechanisms that have the potential to fill the gap in available providers?

\section{Conclusion}

The purpose of this study was to explore the lived experience of help-seeking behaviors of South African women after they have experienced a sexual offence victimization. Four essential themes emerged; decision making, silence, critical junctures in mental health, and moving forward. Study findings revealed a woman's decision making after sexual offence victimization is influence by her perceptions and experiences. Perceptions that may impact decision making include the severity of the violence, perceived sociocultural expectations, the perceived risk of losing resources, or the perception of appropriate services providers. Experiences were found to influences decision making. Silences is described as an accepted and most often expected reaction to rape. There is no talk among family, friends, or in the community about sexual offence victimization. Silence may manifest as secrets that if revealed have the potential to place a women at great risk. Compelling factors of silence for some women were shame and self-blame, and for other's their silence was rooted in cultural expectations. Critical junctures in mental health are a woman's experience of psychological distress that may occur at any time after sexual offence victimization. Critical junctures are conceptualized as pivot points where a woman may descend further into psychological distress, or they may act as a catalyst leading to help-seeking. At the point in time when the woman experiences psychological distress, findings from this study indicated it was important that the woman have immediate access to mental health care, or risk further psychological distress including self-harm. Moving forward is described as a woman's 
experiences after victimization as she moves toward and into healing. Some experiences may act to slow her progress, and others may act to drive her progress into healing.

The findings from this study add insight into a woman's lived experience of helpseeking in South Africa. The findings can be used to direct further research efforts to continue the process of discovering how best to meet the help-seeking needs of South African women after sexual offence victimization and provide women with the means needed to move forward and into healing.

The stories of these women provide impetus for change in South Africa. The strength and endurance required of these women as they experienced pain, shame, blame, humiliation, and brutality is remarkable. Their ability to move forward into healing is even more remarkable. It is very important to learn from their experiences. Their stories must not be forgotten. The stories of their lives and experiences should compel nursing scientists, other scholars, and policy activists to strengthen their efforts to do all possible to effect change in order support and advance care for women who have experienced sexual offence victimization in South Africa and the world. 


\section{REFERENCES}

Abdool, N. N. T., \& Brysiewicz, P. (2009). A description of the forensic nursing role in emergency departments in Durban, South Africa. Journal of Emergency Nursing, $35,16-21$.

Abrahams, N., \& Jewkes, R. (2010). Barriers to post exposure prophylaxis (PEP) completion after rape: A South African qualitative study. Culture, Health \& Sexuality, 12, 471-484. doi:10.1080/13691050903556316

Abrahams, N., Martin, L. J., \& Vetten, L. (2003). An Overview of gender-based violence in South Africa Response. Retrieved from www.mrc.ac.za/crime/cvi first_review_pg40 87.pdf

Ahrens, C. (2006). Being silenced: The impact of negative social reactions on the disclosure of rape. American Journal of Community Psychology, 38, 263-274.

Annan, K. (1999). Remarks on International Women's Day: Inter-Agency videoconference for a World Free of Violence against Women. Retrieved from http://www.un.org/News/Press/docs/1999/19990308.sgsm6919.html

Atlas: Nurses in Mental Health-World Health Organization. (2007) Retrieved from http://www.who.int/mental_health/evidence/nursing_atlas_2007.pdf

Belmont Report. (1979). Retrieved from http://www.hhs.gov/ohrp/policy/belmont.html

Belo, M., \& Pather, M. (2008). Profile of rape victims attending the Karl Bremer Hospital 
Rape Centre, Tygerberg, Cape Town. South African Family Practice, 50, 46-46e.

Benner, P. (1985). Quality of life: A phenomenological perspective on explanation, prediction, and understanding in nursing science. Advances in Nursing Science, 8, (1)1-14.

Benner, P. (1994). Introduction. In P. Benner (Eds.), Interpretive phenomenology: Embodiment, caring, and ethics in health and illness (pp. xiii-xxvii). Thousand Oaks: Sage.

Bergum, V. (1991). Being a phenomenological researcher. In J. M. Morse, Qualitative nursing research: A contemporary design. Newbury Park, CA: Sage.

Bhana, D. (2012). Girls are not free-In and out of the South African school. International Journal of Educational Development, 32, 352-358.

Bronfenbrenner, U. (1979). The Ecology of Human Development: Experiments by Nature and Design. Cambridge: Harvard University Press.

Bronfenbrenner, U. (1994). Ecological models of human development. In International Encyclopedia of Education, Vol.3, (2 ${ }^{\text {nd }}$ Ed.). Oxford: Elsevier.

Brown, J., Horvath, M., Kelly, L., \& Westmarland, N. (2010). Connections and disconnections: Assessing evidence, knowledge, and practice in responses to rape. Retrieved from https://www.dur.ac.uk/resources/sass/BrownHorvathKellyandWestmarland2010C onnectionsanddisconnectionsassessingevidenceknowledgeandpracticeinresponsest orape.pdf

Brysiewicz P. (2008). The lived experience of losing a loved one to a sudden death in KwaZulu-Natal. South Africa. Journal of Clinical Nursing, 17, 224-31. 
Burgess, A. W. \& Holmstrom, L. L. (1979). Rape: Crisis and Recovery. Brady: Bowie, Maryland.

Campbell, R. (2008). The psychological impact of rape victims' experiences with the legal, medical, and mental health systems. American Psychologist, 63, 702-717. doi: 10.1037/0003-066X.63.8.702

Campbell, R., Ahrens, C. E., Sefl, T., Wasco, S. M., \& Barnes, H. E. (2001). Social reactions to rape victims: Healing and hurtful effects on psychological and physical health outcomes. Violence and Victims, 16, 287-302.

Campbell, R., Dworkin, E., \& Cabral, G. (2009). An ecological model of the impact of sexual assault on women's mental health. Trauma, Violence, and Abuse, 10, 225 246.

Campbell, R., Wasco, S. M., Ahrens, C. E., Sefl, T., \& Barnes, H. E. (2001). Preventing the "Second rape": Rape survivors' experiences with community service providers. Journal of Interpersonal Violence, 16, 1239-1259. doi: $10.1177 / 088626001016012002$

Changwa, M. C., \& Pather, M. K. (2008). The management of sexual assault victims at Odi District Hospital in the North-West province: How can the quality of hospital care be improved. South African Family Practice, 50, 45-45d.

Chen, Y., \& Ullman, S. E. (2010). Reporting of sexual and physical assaults to police in the National Violence Against Women survey. Violence Against Women, 16, 262279.

Christofides, N. L., Jewkes, R. K., Webster, N., Penn-Kekana, L., Abrahams, N., \& 
Martins, L. (2005). Other patients are really in need of medical attention: The quality of health services for rape survivors in South Africa. Bulletin of the World Health Organization, 83, 495-502.

Christofides, N. J., Muirhead, D., Jewkes, R. K., Penn-Kekana, L., \& Conco, D. N. (2005). Women's experiences of and preference for services after rape in South Africa: Interview Study. British Medical Journal, 332, 209-213.

Christofides, N., Webster, N., Jewkes, R, Penn-Kekana, Loveday, Martin, L., . . Kim, J. (2003). The state of sexual assault services: Findings from a situational analysis of services in South Africa. Retrieved from http://www.mrc.ac.za/gender/sexualassault.pdf

CIET South Africa. (2000). 1997-2000 Surveys on sexual violence in South Johannesburg. Retrieved from http://www.ciet.org/_documents/2006224131250.pdf

Cohn, A. M., Zinzow, H. M., Resnick, H. S., \& Kilpatrick, D. G. (2013). Correlates of reasons for not reporting rape to police: Results from a nation telephone household probability sample of women with forcible or drug-or-alcohol facilitated/incapacitated rape. Journal of Interpersonal Violence, 28, 455-473.

Collier-Reed, B. I., Ingerman, A., \& Berglund, A. (2009). Reflections on trustworthiness in phenomenographic research: Recognising purpose, context and change in the process of research. Education as Change, 13, 339-355.

Coovadia, H., Jewkes, R., Barron, P., Sanders, D., McIntyre, D. (2009). The Health and Health System of South Africa- Historical Roots of Current public health challenges. Lancet, 374, 817-834. 
Cox, S., Andrade, D., Lungelow, W., Schloetelburg, W., \& Rode, H. (2007). The child rape epidemic: Assessing the incidence at Red Cross Hospital, Cape Town, and establishing the need for a new national protocol. South African Medical Journal, 97, 950-955.

Creswell, J. W. (2007). Qualitative Inquiry and Research Design: Choosing Among Five Approaches ( $2^{\text {nd }}$ ed.). Thousand Oaks: Sage

Dalstrom, D. O. (2013). The Heidegger dictionary. London: Bloomsbury. de Witt, L., \& Ploeg, J. (2005). Critical appraisal of rigour in interpretive phenomenological nursing research. Journal of Advanced Nursing, 55, 215-229. Department of Health Republic of South Africa. (2005). National management guidelines for sexual assault care. Pretoria: South African Department of Health.

Department of Justice and Constitutional Development Republic of South Africa. (n.d.). Service charter for victims of crime in South Africa: The consolidation of the present legal framework relating to the rights of and services provided to victims of crime. Retrieved from http://www.justice.gov.za/VC/docs/vc/vc-eng.pdf

Department of Labour Republic of South Africa (n.d.). Domestic Workers: What You Should Know. Retrieved from https://www.labour.gov.za/downloads/documents/useful-documents/basicconditions-of-employment/domesticworker2012.pdf

Department of Public Services and Administration. (1997). White paper on transforming public service delivery. Retrieved from http://unpan1.un.org/intradoc/groups/public/documents/un/unpan005184.pdf

Dilthey, W. (1976). The construction of the historical world in the human studies. In H. 
P. Rickman (Ed) Dilthey: Selected writings (pp. 171-245). Cambridge: Cambridge University Press.

du Mont, J., Miller, K. L., \& Myhr, T. L. (2003) The role of "real rape" and "rape victims stereotypes in the police reporting practices of sexually assaulted women. Violence Against Women, 9, 466-486.

Dunkle, K. L., Jewkes, R. K., Brown, H. C., Yoshihama, M., Gray, G. E., McIntyre, J. A., \& Harlow, S. D. (2004). Prevalence and patterns of gender-based violence and revictimization among women attending antenatal clinics in Soweto, South Africa. American Journal of Epidemiology, 160, 230-239.

Earle, N. (2008) Social work as a scarce and critical profession. Retrieved from http://www.labour.gov.za

Filep, B. (2009). Interview and translation strategies: Coping with multilingual setting and data. Retrieved from http://www.soc-geogr.net/4/59/2009/sg-4-59-2009.pdf

Foa, E. B., Dancu, C. V., Hembree, E. A., Jaycox, L. H., Meadows, E. A., \& Street, G. P. (1999). A comparison of exposure therapy, stress inoculation training, and their combination for reducing posttraumatic stress disorder in female assault victims. Journal of Consulting and Clinical Psychology, 67, 194-200.

Foa, E. B., Davidson, J. R. T., \& Frances, A. (Eds.). (1999). The expert consensus guidelines series: Treatment of posttraumatic stress disorder. [Supplement]. Journal of Clinical Psychiatry, 60, 1-77.

Fourie, S. (2011). Forensic nursing curriculum: Advanced diploma in nursing (Post Basic). University of the Free State.

Francis, V., \& Baird, M. I. (2000). Francis Baird 2000 A rape investigation in the 
Western Cape: A study of the treatment of rape victims at three police stations in the Cape Flats South Africa. Retrieved from http://www.vera.org/content/rapeinvestigation-western-cape-study-treatment-rape-victims-three-police-stationscape-flat

Frank, S. (2006). The impact of working with trauma: Risk and resilience factors among health care providers. South Africa Journal of Psychiatry, 12, 100-104.

Frazier, P. A. (2003). Perceived control and distress following sexual assault: A longitudinal test of a new model. Journal of Personality and Social Psychology, 84, 1257-1269.

Gadamer, H. (1975/2011). Gadamer: Truth and method. New York: Continuum International Publishing Group.

Garcia-Moreno, C., Jansen, H. A. F. M., Ellsberg, M., Heise, L., Watts, C. (2005). WHOMulti-country Study on Women's Health and Domestic Violence against Women. Retrieved from http://www.who.int/gender/violence/who_multicountry_study/en/

Garcia-Moreno, C., \& Watts, C. (2011). Violence against women: An urgent public health priority. Bulletin of the World Health Organization 2011, 89, $2-2$. doi10.2471/BLT.10.085217

Geertz, C. (1973). The interpretation of cultures. New York: Basic Books.

Goga, S., \& Van der Westhuizen, C. (2012). Scarce skills information dissemination in South Africa. Retrieved from http://www.hsrc.ac.za/Research_Publication$\underline{2524 . p h t m l}$

Government Gazette (2007). No. 32 of 2007: Criminal Law (Sexual Offences and Related Matters) Amendment Act, 2007. Pretoria: The Government Printing Works. 
Grondin, J. (1994). Introduction to philosophical hermeneutics. New Haven: Yale University Press.

Heidegger, M. (1953/2010). Being and time. Albany: State University of New York Press.

Heise, L. L. (1998). Violence against women: An integrated ecological framework. Violence Against Women, 4, 262-290.

Heise, L., Ellsberg, M., \& Gottmoeller, M. (2002). A global overview of gender-based violence. International Journal of Gynecology and Obstetrics, 78, S5-S14.

Hirschowitz, R., Worku, S., \& Orkin, M. (2000). Quantitative Research Findings on Rape in South Africa. Retrieved from http://www.statssa.gov.za/publications/rape/rape.pdf

Hoffmann, W.A., Myburgh, C. \& Poggenpoel, M. (2010). The lived experiences of lateadolescent female suicide survivors: A part of me died. Health SA Gesondheid 15(1), 1-9. doi: 10.4102/hsag.v15i1.493

Human Rights Watch. (1997). South Africa: Violence against Women and the MedicoLegal System. Retrieved from http://www.unhcr.org/refworld/docid/3ae6a7e43

Husserl, E. (1931/2012). Ideas: General introduction to pure phenomenology. London: Routledge.

Jewkes, R., \& Abrahams, N. (2002). The epidemiology of rape and sexual coercion in South Africa: An overview. Social Sciences \& Medicine, 55, 1231-1244.

Jewkes, R., Abrahams, N., \& Mvo, Z. (1998). Why do nurses abuse patients? Reflections from South African obstetric services. Social Science Medicine, 47, 1781-1795.

Jewkes, R., Dunkle, K., Nduna, M., \& Shai, N. (2010). Intimate partner violence, 
relationship power inequity, and incidence of HIV infection in young women in South Africa: A cohort study. The Lancet, 376, 41-48.

Jewkes, R., Penn-Kekana, L., Rose-Junius, H. (2005). "If they rape me, I can't blame them": Reflections on gender in the social context of child rape in South Africa and Namibia. Social Science \& Medicine, 61, 1809-1820.

Jewkes, R., Sikweyiya, Y., Morrell, R., \& Dunkle, K. (2009). Understanding Men’s Health and Use of Violence: Interface of Rape and HIV in South Africa. Pretoria: South African Medical Research Council.

Jina, R., Jewkes, R., Christofides, N., Loots, L. (2013). Knowledge and confidence of South African health care providers regarding post-rape care: A cross-sectional study. Retrieved from http://www.biomedcentral.com/1472-6963/13/257

Jina, R., \& Thomas, L. S. (2013). Health consequences of sexual violence against women. Best Practices \& Research Clinical Obstetrics and Gynaecology, 27, 1526.

Jordan, C. F., Campbell, R., \& Follingstad, D. (2010). Violence and women's mental health: The impact of physical, sexual, and psychological aggression. The Annual Review of Clinical Psychology, 6, 607-628. doi: 10.1146/annurev-clinpsy090209-151437

Jordanova, V., Stewart, R., Goldberg, D., Bebbington, P. E., Brugha, T., Singleton, N., . . Meltzer, H. (2007). Age variation in life events and their relationship with common mental disorders in a national survey population. Social Psychiatry and Psychiatric Epidemiology, 42, 611-616.

Kafle, N. P. (2011). Hermeneutic phenomenological research method simplified. Bodhi, 
$5,181-200$.

Kahn, A. S., Jackson, J., Kully, C., Badger, K., \& Halverson, J. (2003). Calling it rape: Differences in experiences of women who do or do not label their sexual assault as rape. Psychology of Women Quarterly, 27, 233-242.

Kahn, A. S., Mathie, V. A., \& Torgler, C. (1994). Rape scripts and rape acknowledgement. Psychology of Women Quarterly, 18, 53-66.

Kekana, H. P. P., du Rand, E. A., \& van Wyk, N. C. (2007). Job satisfaction of registered nurses in a community hospital in the Limpopo Province in South Africa. Curationis, 30(2), 24-35.

Kelly, J. G. (2006). Becoming Ecological: An Expedition into Community Psychology. New York: Oxford University Press.

Killian, S., Suliman, S., Fakier, N, \& Seedat, S. (2007). Rape survivors and the provision of HIV post-exposure prophylaxis. South African Medical Journal, 97, 584-586.

Kim, J. \& Motsei, M. (2002). "Women enjoy punishment": Attitudes and experiences of gender-based violence among PHC nurses in rural South Africa. Social Science \& Medicine, 54, 1243-1254.

Klopper, H. C., Coetzee, S. K., Pretorius, R., \& Bester, P. (2012). Practice environment job satisfaction and burnout of critical care nurses in South Africa. Journal of Nursing Management, 20, 685-695.

Koekemoer, F. E., \& Mostert, K. (2006). Job characteristics, burnout, and negative workhome interference in a nursing environment. South African Journal of Industrial Psychology, 32(3), 87-97.

Koss, M. P., \& Figueredo, A. J. (2004). Cognitive mediators of rape's impact on 
psychosocial health across 2 years of recovery. Journal of Consulting and Clinical Psychology, 72, 1063-1072.

Koss, M. P., Figueredo, A. J., \& Prince, R. J. (2002). Cognitive mediation of rape's mental, physical, and social health impact: tests of four models in cross-sectional data. Journal of Consulting and Clinical Psychology, 70, 926-941.

Kumar, A., Nizamie, S. H., \& Srivastava, N. K. (2013). Violence against women and mental health. Mental Health and Prevention, 1, 4-10.

Lammers, K., Martin, L., Andrews, D., \& Seedat, S. (2010). Reported rapes at a hospital rape centre: Demographic clinical profiles. South African Medical Journal, 100, $362-363$.

Law Reform Examiner. (2008). In the spotlight: South Africa's new sexual offences act. Retrieved from http://www.ghjru.uct.ac.za/sexual-offence-bill/Law-ReformExaminer.pdf

Ledray, L. E. (2006). Sexual assault. In V. A. Lynch, \& J. B. Duval (Eds.), Forensic Nursing (pp. 279-291). St. Louis: Elsevier Mosby.

Leiter, M. P., Harvie, P., \& Frizzell, C. (1998). The correspondence of patient satisfaction and nurse burnout. Social Science Medicine, 47, 1611-1617.

Lincoln, Y. S., \& Guba, E. G. (1985). Naturalistic inquiry. Newbury Park: Sage Publications.

Lincoln, Y. S., \& Guba, E. G. (2013). The Constructivist Credo. Walnut Creek, California: Left Coast Press.

Lotter, E. (2005). It’s me, Anna. Cape Town: Paperbooks Publishing.

Machado, C. L., Azevedo, R. C. S., Facuri, C. O., Vieira, M. N., \& Fernandes, A. S. 
(2011). Posttraumatic stress disorder, depression, and hopelessness in women who are victims of sexual violence. International Journal of Gynecology and Obstetrics, 113, 58-62.

Manning, K. (1997). Authenticity in constructivist inquiry: Methodological considerations without prescription. Qualitative Inquiry, 3, 93-115.

Martin, L. J. (2002). Forensic evidence collection for sexual assault: A South African perspective. International Journal of Gynecology and Obstetrics, 78, S105-S110.

Martin, S. L., \& Parcesepe, A. M. (2013). Sexual assault and women's mental health. Violence Against Women and Mental Health, 178, 86-95.

Mashego, T., \& Peltzer, K. (2005) Community perception of quality of (primary) health care services in a rural area of Limpopo Province, South Africa: A qualitative study. Curationis, 28(2), 13-21.

Mason, F., \& Lodrick, Z. (2013). Psychological consequences of sexual assault. Best Practices and Research Clinical Obstetrics and Gynaecology, 27, 27-37.

Mavundla, T. R. (2000). Professional nurses' perception of nursing mentally ill people in a general hospital setting. Journal of Advanced Nursing, 32, 1569-1578.

Maxwell, J. A. (1992). Understanding and validity in qualitative research. Harvard Educational Review, 62, 279-300.

McConnell-Henry, T., Chapman, Y., \& Francis, K. (2009). Husserl and Heidegger: Exploring the disparity. International Journal of Nursing Practice, 15, 7-15. DOI: $10.1111 / \mathrm{j} .1440-172 x .2008 .01724 . x$

Meel, B. L. (2008). Trends of rape in the Mthatha area, Eastern Cape, South Africa. South African Family Practitioner, 50, 69-69b. 
Meintjes, S. (1996). The women's struggle for equality during South Africa's transition to democracy. Transformation, 30, 47-64.

Meleis, A. (1996). Culturally competent scholarship: Substance and rigor. Advances in Nursing Sciences, 19, 1-16.

Merleau-Ponty. M. (1945/2012). Phenomenology of perception. New York: Routledge.

Minnaar, A., \& Mistry, D. (2004). Outsourcing and the South African Police Services. Retrieved from www.issafrica.org/pubs/Monographs/No93/Chap4.pdf

Moran, D. \& Cohen, J. (2012). The Husserl dictionary. London: Continuum International Publishing Group.

Morse, J. (1991). Strategies for sampling. In J. M. Morse (Ed.) Qualitative nursing research (pp.127-145). Newbury Park, CA: Sage Publications.

Muholi, Z. (2004). Thinking through Lesbian rape. Agenda, 61, 116-125.

Mullick, S., Teffo-Menziwa, M., Williams, E., \& Jina, R. (2010) Women and sexual violence. In F. S. Padarath (Ed.), South African Health Review 2010. Durban: Health Systems Trust.

Munhall, P. L. (2012). Nursing Research: A Qualitative Perspective (5 ${ }^{\text {th }}$ ed.). Sudbury, MA: Jones \& Bartlett Learning.

Murray, L. K., Dorsey, S., Haroz, E., Lee, C., Alsiary, M. M., Haydary, A., . . Bolton, P. (2013). A common elements treatment approach for adult mental health problems in low- and middle- income countries. Cognitive and Behavioral Practice, 21, 111-123.

National Instructions. (2008). Sexual Offences. Retrieved from http://www.info.gov.za/view/DownloadFileAction?id=87211 
Neville, H. A., \& Heppner, M. J. (1999). Contextualizing rape: Reviewing sequelae and proposing a culturally inclusive ecological model of sexual assault recovery. Applied and Preventive Psychology, 8, 41-62.

Nuremberg Code. (1949). Retrieved from http://history.nih.gov/research/downloads/nuremberg.pdf

Nursing Services of South Africa. (2012). Pay Rates Government Hospitals and Community Clinics. Retrieved from http://www.nurses.co.za/index.php?option=com_content\&task=view\&id=71\&Ite $\underline{\operatorname{mid}=26}$

Nyathi, M., \& Jooste, K. (2008). Working conditions that contribute to absenteeism among nurses in a provincial hospital in the Limpopo Province. Curationis, 31(1), $28-37$.

Parkes, J., Heslop, J., Oando, S., Sabaa, S., Januario, F., \& Figue, A. (2013). Conceptualising gender and violence in research: Insights from studies in schools and communities in Kenya, Ghana, and Mozambique. International Journal of Educational Development, 33, 546-556. doi:10.10.1016/j.ijedudev.2013.01.001

Parse, R. R. (1990). Parse's research methodology with an illustration of the lived experience of hope. Nursing Science Quarterly, 3(1), 9-17.

Patterson, D., Greeson, M., \& Campbell, R. (2009). Understanding rape survivors’ decisions not to seek help from formal social systems. Health and Social Work, 34, 127-136.

Patton, M. Q. (2002). Qualitative research and evaluation methods ( $3^{\text {rd }}$ ed.). Thousand Oaks: Sage. 
Peterson, I. (1999). Training for transformation: Reorientating primary health care nurses for the provision of mental health care in South Africa. Journal of Advanced Nursing, 30, 907-915.

Pietersen, C. (2007). Interpersonal bullying behaviors in the workplace. Journal of Industrial Psychology, 33(1), 59-66.

Pillay, R. (2009). Work satisfaction of professional nurses in South Africa: A comparative analysis of the public and private sectors. Retrieved from http://www.human-resources-health.com/content/7/1/15 doi:10.1186/1478-44917-15

Posel, D. (2005). The scandal of manhood: 'Baby rape' and the politicization of sexual violence in post-apartheid South Africa. Culture, Health, \& Sexuality, 7, 239-252.

QSR International. (2013). Qualitative data analysis software Version 10. Victoria, Australia: QSR International Pty, Ltd.

Rape Crisis Trust. (2014). Volunteering. Retrieved from http://rapecrisis.org.za/support-us/volunteering/

Resnick, H., Acierno, R., Holmes, M., Kilpatrick, D. G., \& Jager, N. (1999). Prevention of post-rape psychopathology: Preliminary findings of a controlled acute rape treatment study. Journal of Anxiety Disorders, 13, 359-370.

Resnick, H., Acierno, R., Waldrop, A. E., King, L., King, D., Danielson, C., . . . Kilpatrick, D. (2007). Randomized controlled evaluation of an early intervention to prevent post-rape psychopathology. Behavioral Research and Therapy, 45, 2432-2447.

Richards, L., \& Morse, J. (2007). Read me first for a user's guide to qualitative methods 
( $2^{\text {nd }}$ ed.). Thousand Oaks: SAGE.

Rodgers, B. L. (2005). Developing nursing knowledge: Philosophical traditions and influences. Philadelphia: Lippincott Williams \& Wilkins.

Rohrs, S. (2011). I feel for rape survivors, but I don't have the time. I'm always running: Barriers to accessing post-rape health care in South Africa. Cape Town: The Gender, Health \& Justice Research Unit.

Rolfe, G. (2006). Validity, trustworthiness and rigor: Quality and the idea of qualitative research. Methodological Issues in Nursing Research, 53, 304-310.

Rumney, P. N. S., \& van der Bijl, C. (2010). Rape, attitudes, and law enforcement in South Africa. New Criminal Law Review, 13, 826-840.

S. 2982: International Violence Against Women Act of 2010, 111 th Congress $2^{\text {nd }}$ Session (2010).

Sandelowski, M. (1986). The problem of rigor in qualitative research. Advances in Nursing Science, 8, 27-37.

Sandelowski, M. (1995). Sample size is qualitative research. Research in Nursing and Health, 18, 179-183.

Sarte, J. P. (1956). Being and nothingness. New York: Washington Square Press.

Seedat, S., Stein, D. J., Jackson, B. J, Heeringa, S. G., Williams, D. R., \& Myer, L. (2009). Stress and mental disorders in the South African Stress and Health Study. Retrieved from http://www.samj.org.za/index.php/samj/issue/view/89/showToc Sexual Offences Act 2007. (2007). Criminal Law Sexual Offences and Related Matters Amendment Act, Republic of South Africa. No. 32 (2007). Retrieved from http://www.ghjru.uct.ac.za/sexual-offence-bill/Sexual-Offences-Act-2007.pdf 
Sexual Offenses and Community Affairs. (2008). Process designs: Thuthuzela Care Centres. National Prosecuting Authority.

Shalhoub-Kevorkian, N. (1991). Towards a cultural definition of rape: Dilemmas in dealing with rape victims in Palestinian society. Women's Studies International Forum, 22, 157-173.

Shope, J. H. (2006). You can't cross a river without getting wet: A feminist standpoint on the dilemmas of cross-cultural research. Qualitative Inquiry, 12, 163-184.

Shukumisa. (2011). The sexual offences Indaba 2011: A response form the Rape Crisis Cape Town Trust. Retrieved from http://www.shukumisa.org.za/ndex.php/2011/07/response-from-rape-crisis

Smith, M. E., \& Kelly, L. M. (2001). The journey of recovery after a rape experience. Issues in Mental Health Nursing, 22, 337-352.

South African Police Service. (2013). An analysis of the national crime statistics:

Addendum to the annual report 2012/2013. Retrieved from http://www.saps.gov.za/resource centre/publications/statistics/crimestats/2013/do wnloads/crime_stats_analysis.pdf

Sparkes, A. C. (2001). Myth 94: Qualitative health researchers will agree about validity. Qualitative Health Research, 11, 538-552.

Squires, A. (2008). Methodological challenges in cross-language qualitative research: A research review. International Nursing Studies, 46, 277-287.

Steinbrenner, S. Y. (2011). Sexual Assault Services and Service Providers in the Free State Province, South Africa. Unpublished research report.

Sullivan, C. M., \& Bybee, D. I. (1999). Reducing violence using community-based 
advocacy for women with abusive partners. Journal of Counseling and Clinical Psychology, 67(1), 43-53.

Swart, L., Gilchrist, A., Butchart, A., Seedat, M., \& Martin, L. (2000), Rape surveillance through district surgeon offices in Johannesburg, 1996-1998: Findings, evaluation, and prevention implications. Retrieved from http://web.ebscohost.com/ehost/detail?sid=8cb4a66e-c9d4-417f-b31eec729875e1e3\%40sessionmgr114\&vid=1\&hid=126\&bdata=Jmxhbvettenmc9ZX Mmc210ZT1laG9zdC1saXZl\#db=aph\&AN=3510820

Tankink, M. T. A. (2013). The silence of South-Sudanese women: Social risks in talking about experiences of sexual violence. Culture, Health \& Sexuality, 15, 391-403.

Thuthuzela Care Centre pamphlet. (n.d.) Thuthuzela Care Centres: Turing victims into survivors. Pretoria: Department of Health.

Tobin, G. A., \& Begley, C. M. (2004). Methodological rigour within a qualitative framework. Journal of Advanced Nursing, 48, 388-396.

Tshitangano, T. G,, Maputle, S. M., \& Netshikweta, L. M. (2013). Availability of tuberculosis infection control plans at rural hospitals of Vhembe district, Limpopo Province of South Africa. African Journal of Primary Health Care \& Family Medicine, 5(1), 1-6. http://dx.doi.org/10.4102/phcfm.v5i1.480

Ullman, S. E. (1996). Social reactions, coping strategies, and self-blame attributions in adjustment to sexual assault. Psychology of Women Quarterly, 20, 505-526.

Ullman, S. E. (1999). Social support and recovery from sexual assault: A review. Aggression and Violent Behavior, 4, 343-358.

Ullman, S. E., \& Filipas, H. H. (2001). Correlates of formal and informal support seeking 
in sexual assault victims. Journal of Interpersonal Violence, 16, 1028-1047. DOI: $10.1177 / 088626001016010004$

Umlilo, T. (2002). Little girl arise. Pietermaritzburg, South Africa: Cluster Publications. United States Agency for International Development. (2010). Fact Sheet: Project Thuthuzela Care Centres (TCC). Retrieved from http://sa.usaid.gov/south_africa/library/fact_sheets

University of Louisville (2011). Investigator's Guide for Human Research: A guide for investigators at the University of Louisville and affiliated research institutions. Louisville: University of Louisville.

Uys, L. R., \& Naidoo, J. R. (2004). A survey of the quality of nursing care in several health districts in South Africa. Retrieved from http://www.biomedcentral.com/1472-6955/3/1

van Manen, M. (1990). Researching the Lived Experience: Human Science for an Action Sensitive Pedagogy. Albany: State University of New York Press.

Vetten, L., \& Haffee, S. (2005). Urban predators: An analysis of gang rapes reported at six inner-city Johannesburg police stations. Retrieved from http://www.isn.ethz.ch/isn/DigitalLibrary/Publications/Detail/?ots591=0c54e3b3-1e9c-be1e-2c24a6a8c7060233\&lng=en\&id $=104784$

Vetten, L., Jewkes, R., Sigsworth, R., Christofides, N., Loots, L., \& Dunseith, O. (2008). Tracking Justice: The Attrition of Rape Cases through the Criminal Justice System in Gauteng. Retrieved from http://www.csvr.org.za/index.php?option=com content\&view=article\&id=1579\% 


\section{Atracking-justice-the-attrition-of-rape-cases-through-the-criminal-justice-}

\section{system-in-gauteng-\&Itemid $=2$}

Vetten, L., Le, T., Leisegang, A., \& Haken, S. (2010). The Right and the Real: A Shadow Report Analysing Selected Government Departments' Implementation of the 1998 Domestic Violence Act and 2007 Sexual Offences Act. Johannesburg:

Tshwaranang Legal Advocacy Centre.

Vetten, L. van Jaarsveld, F., \& Riba, P. (2012). A criminal injustice system: The attrition of rape cases in one rural locality, Mpumalanga. Retrieved from http://www.shukumisa.org.za/wp-content/uploads/2013/05/A-Criminal-InjusticeSystem.pdf

Warden, J. A., Mayers, P., \& Kathard, H. (2008). The lived experience of being a speechlanguage therapist in the Western Cape public health system. The South African Journal of Communication Disorders, 5, 49-62.

Waterhouse, S. (2008). The impact of changing criminal justice responses to child victims of sexual abuse. Pinelands, South Africa: Criminal Justice Initiative of Open Society Foundation for South Africa.

Webster, N. (2008). Understanding the South African victims' charter-A conceptual framework. Retrieved from http://www.justice.gov.za/VC/VCdocs.htm

Westmarland, N., Alderson, S., \& Kirkham, L. (2012). The health, mental health, and well-being benefits of Rape Crisis Counselling. Durham, United Kingdom: Durham University and Northern Rock Foundation.

Wildschut, A., \& Mgqolozana, T. (2009). Shortage of nurses in South Africa: Relative or 
Absolute? Retrieved from

http://www.labour.gov.za/downloads/documents/research-

documents/nursesshortage.pdf

Wojnar, D. M., \& Swanson, K. M. (2007). Phenomenology: An exploration. Journal of Holistic Nursing, 25, 172-180.

Womersley, G. \& Maw, A. (2009). Contextualizing the experiences of South African women in the immediate aftermath of rape. PINS, 38, 40-60.

Wood, K., \& Jewkes, R. (2006). Blood blockages and scolding nurses-barriers to adolescent contraceptive use in South Africa. Reproductive Health Matters, 14, 109-118.

World Health Organization (2000). Women's Mental Health: An Evidence Based Review. Retrieved from http://whqlibdoc.who.int/hq/2000/who_msd_mdp_00.1.pdf 


\title{
Appendix A
}

\section{Approval Letters}

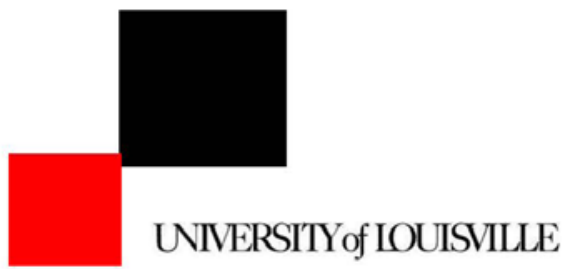

INSTITUTIONAL REVIEW BOARDS

University of Louisville

MedCenter One, Suite 200

$501 \mathrm{E}$. Broadway

Louisville, Kentucky 40202-1798

Office: $\quad 502-852-5188$

Fax: $\quad 502-852-2164$

\author{
To: $\quad$ Shawler, Celeste \\ From: The University of Louisville Institutional Review Board (IRB) \\ Date: Wednesday, May 22, 2013 \\ Subject: Approval Letter \\ Tracking \#: 13.0251 \\ Title: $\quad$ The Lived Experience of Help-Seeking Behaviors of South African \\ Women After Sexual Offence Victimization \\ Approval $\quad 5 / 22 / 201312: 00: 00 \mathrm{AM}$ \\ Date: \\ Expiration $5 / 21 / 201412: 00: 00 \mathrm{AM}$ \\ Date:
}

The revised document(s) for the above referenced study have been received and contain the changes requested in our letter of $05 / 21 / 2013$. This study was reviewed on 05/22/2013 by the chair/vice chair of the Institutional Review Board (IRB) and approved through the Expedited Review Procedure, according to 45 CFR 46.110(b), since this study falls under Expedited Category (7) Research on individual or group characteristics or behavior (including, but not limited to, research on perception, cognition, motivation, identity, language, communication, cultural beliefs or practices, and social behavior) or research employing survey, interview, oral history, focus group, program evaluation, human factors evaluation, or quality assurance methodologies.

The following items have been approved:

- Research Protocol, dated 05/14/2013

- Study information for Care Providers Assisting with Participant Recruitment, dated 05/14/2013

- Interview Questions, dated 05/14/2013

- Demographic Questionnaire, dated 05/14/2013

- Letter of Support and Consent, Health and Wellness Centre, UFS, dated 04/24/2013

- Letter of Support and Consent, Matjhabeng Rape Intervention Care Center, dated 04/07/2013

- Letter of Support, Dr. Sandra Ferreira, dated 04/18/2013

- Letter of Support and Consent, Free State Network, dated 04/22/2013 
- South Africa Safety and Security Assessment, dated 04/19/2013

- VRA-2013-47 Utilization of the University of the Free State as Research Site, dated 04/24/2013

- Informed Consent, dated 04/09/2013

- Item to be Amended at a later date, dated 05/14/2013

This study now has final IRB approval from 05/22/2013 through 05/21/2014. You should complete and return the Progress Report/Continuation Request Form EIGHT weeks prior to this date in order to ensure that no lapse in approval occurs. The committee will be advised of this action at their next full board meeting.

\section{Site Approval}

If this study will take place at an affiliated research institution, such as Jewish Hospital/St Marys Hospital, Norton Healthcare, or University of Louisville Hospital, permission to use the site of the affiliated institution may be necessary before the research may begin. If this study will take place outside of the University of Louisville Campuses, permission from the organization should be obtained before the research may begin. Failure to obtain this permission may result in a delay in the start of your research.

\section{Privacy \& Encryption Statement}

The University of Louisville's Privacy and Encryption Policy requires such information as identifiable medical and health records: credit card, bank account and other personal financial information; social security numbers; proprietary research data; dates of birth (when combined with name, address and/or phone numbers) to be encrypted. For additional information: http://security.louisville.edu/PolStds/ISO/PS018.htm.

1099 Information (If Applicable)

As a reminder, in compliance with University policies and Internal Revenue Service code, all payments (including checks, gift cards, and gift certificates) to research subjects must be reported to the University Controller's Office. Petty Cash payments must also be monitored by the issuing department and reported to the Controller's Office. Before issuing compensation, each research subject must complete a $W-9$ form.

For additional information, please contact the Controller's Office at $852-8237$ or contro II@louisville.edu.

The following is a link to an Instruction Sheet for BRAAN2 "How to Locate Stamped/Approved Documents in BRAAN2":

http://louisville.edu/research/braan2/help/ApprovedDocs.pdf/view

Please begin using your newly approved (stamped) document(s) at this time. The previous versions are no longer valid. If you need assistance in accessing any of the study documents, please feel free to contact our office at (502) $852-5188$. You may also email our service account at hsppofc@louisville.edu for assistance.

Best wishes for a successful study. If you have any questions please contact the 
HSPPO at (502) 852-5188 or hsppofc@louisville.edu.

Thank you.

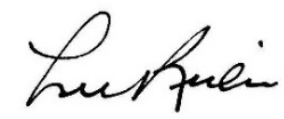

Board Designee: Ridner, S

Once you begin your human subject research the following regulations apply:

1. Unanticipated problems or serious adverse events encountered in this research study must be reported to the IRB within five (5) work days.

2. Any modifications to the study protocol or informed consent form must be reviewed and approved by the IRB prior to implementation.

3. You may not use a modified informed consent form until it has been approved and validated by the IRB.

4. Please note that the IRB operates in accordance with laws and regulations of the United States and guidance provided by the Office of Human Research Protection (OHRP), the Food and Drug Administration (FDA), the Office of Civil Rights (OCR) and other Federal and State Agencies when applicable.

5. You should complete and SUBMIT the Continuation Request Form eight weeks prior to this date in order to ensure that no lapse in approval occurs.

Letter Sent By: Peek, Tamara, 5/22/2013 5:30 PM 


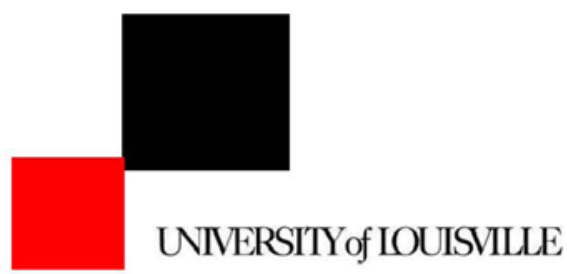

\author{
To: $\quad$ Shawler, Celeste \\ From: The University of Louisville Institutional Review Board (IRB) \\ Date: Tuesday, August 06, 2013 \\ Subject: Approval Letter \\ Tracking \#: AMEND-7360 (13.0251) \\ Title: $\quad$ The Lived Experience of Help-Seeking Behaviors of South African \\ Women After Sexual Offence Victimization
}

The amendment request has been received by the Human Subjects Protection Program Office and approved by the chair/vice chair of the Institutional Review Board (IRB) on 08/05/2013 through the expedited review procedure according to 45 CFR 46.110 (B). The following documents have been reviewed and approved:

- Revised Informed Consent 080313

- Study Information for Care Providers Assisting with Participant Recruitment 08 0313

- SEROBE CRISIS CENTRE Letter dated 042213

- UFS Ethics Letter dated 072613

- Demographic Questionnaire 080313

The amendment modifications include:

- The following items are to be amended into the study: Revised Informed Consent, letter of approval to conduct study from local ethics committee (South Africa), Serobe Crisis Centre letter of support and consent, revised demographic questionnaire, and a revised Study Information for Care Providers Assisting with Participant Recruitment document.

- The informed consent has been revised to meet local (South African) regulatory requirements to conduct research. There is no change to the risk/benefit ratio to the subjects.

- Letter of approval to conduct the study from the local ethical clearance committee, the Faculty of the Humanities Ethics Board, University of the Free State, Bloemfontein, South Africa. 
- The Serobe Crisis Centre letter of support and consent is being added. This letter was not available at the time of the initial IRB approval of the study.

- The revised demographic questionnaire has had an additional question added and the request for age information has been changed from age categories to exact age. The question that has been added is, estimate how much your weekly income is. This question has been added to capture economic status information from the study participants. Economic status information will assist in developing an understanding of the study population. To collect data regarding participants ages, age has been changed from asking for the participant's age category to asking for the participant's exact age. Asking for the participant's exact age will support developing a more exact understanding of the study population.

- The Study Information for Care Providers Assisting with Participant Recruitment document has been revised to include a bullet point stating the interviews will be recorded. This additional information has been added to assure the care providers are providing appropriate information to potential participants.

This action will be reported promptly to the IRB at a scheduled full Board meeting

The following is a NEW link to an Instruction Sheet for BRAAN2 "How to Locate Stamped/Approved Documents in BRAAN2":

http://louisville.edu/research/braan2/help/ApprovedDocs.pdf/view

Please begin using your newly approved (stamped) document(s) at this time. The previous versions are no longer valid. If you need assistance in accessing any of the study documents, please feel free to contact our office at (502) 852-5188. You may also email our service account at hsppofc@louisville.edu for assistance.

Thank you.

\section{Pete $m$ Lusach}

Board Designee: Quesada, Peter

Continue following the regulations below:

1. Unanticipated problems or serious adverse events encountered in this research study must be reported to the IRB within five (5) work days.

2. Any modifications to the study protocol or informed consent form must be reviewed and approved by the IRB prior to implementation.

3. You may not use a modified informed consent form until it has been approved 
and validated by the IRB.

Letter Sent By: Block, Sherry, 8/6/2013 11:53 AM

Full Accreditation since June 2005 by the Association for the Accreditation of Human Research Protection Programs, Inc.

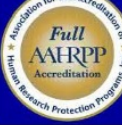




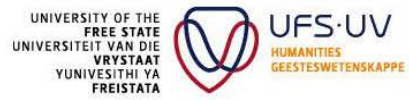

26 July 2013

Ms S. Steinbrenner

University of Louisville

Ethical Clearance Application: The Lived Experience of the Help-Seeking Behaviours of South African Women after Sexual Offence Victimization

Dear Ms Steinbrenner

With reference to your application for ethical clearance with the Faculty of the Humanities, I am pleased to inform you on behalf of the Ethics Board of the faculty that you have been granted ethical clearance for your research.

Your ethical clearance number, to be used in all correspondence, is:

\section{UFS-HUM-2013-006}

However, before your research commences, we require a simplified, shorter version of the informed consent form that you can send to our research ethics office at your earliest convenience. Please indicate that you will be conducting the research and provide the contact details of the South African researcher (Dr Ferreira) as to prevent any form of discouragement to contact the research team.

This ethical clearance number is valid for research conducted for one year from issuance. Should you require more time to complete this research, please apply for an extension in writing.

We request that any changes that may take place during the course of your research project be submitted in writing to the ethics office to ensure we are kept up to date with your progress and any ethical implications that may arise.

Thank you for submitting this proposal for ethical clearance and we wish you every success with your research.

Yours sincerely,

Katinka de Wet

Ethics Committee (Faculty of the Humanities)

Copy: Ms C. van der Walt (Research Co-ordinator)

$\begin{array}{lll}\text { Kantoor van die Dekaan } & \text { T: }+27(0) 514012240 & \text { P.O. Box/Posbus } 339 \\ \text { Office of the Dean } & \text { F: }+27(0) 514017363 & \text { Bloemfontein } 9300 \\ \text { Ofisa ya Dine } & \text { E: beukeshs@ufs.ac.za } & \text { South Africa/Suid-Afrika } \\ & & \text { www.ufs.ac.za }\end{array}$




\section{Revised informed consent form}

Charné Van Der Walt [vdwaltcc@ufs.ac.za]

Sent: Wednesday, August 14, 2013 10:04 AM

To: Steinbrenner, Sheila Young

Dear Ms Steinbrenner

The Ethics Committee of the Faculty of the Humanities are pleased to inform you that they are satisfied with your revised informed consent form and that you can now proceed with your research.

Kind regards,

Charné

느 UfS Logo Charné Van Der Walt

Research Co-ordinator: Office of the Dean: Humanities

Navorsingskoördineerder: Dekaanskantoor: Geesteswetenskappe

PO Box / Posbus 339, Bloemfontein 9300, Republic of South Africa / Republiek van Suid-Afrika

in:

0514017083

는

0514017363

迆

LE: UFS Logo

VdwaltCC@ufs.ac.za

www.ufs.ac.za

Liviversity of the Free State Universiteit van die Vrystaat

University of the Free State: This message and its contents are subject to a disclaimer. Please refer to http://www.ufs.ac.za/disclaimer for full details.

Universiteit van die Vrystaat:

Hierdie boodskap en sy inhoud is aan 'n vrywaringsklousule onderhewig.

Volledige besonderhede is by http://www.ufs.ac.za/vrywaring beskikbaar.

https://exchange.louisville.edu/owa/?ae=Item\&t=IPM.Note\&id=RgAAAABCLOWIIO9B

$2 / 18 / 2014$ 


\section{Appendix B}

\section{Letters of Support and Consent}

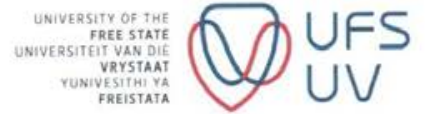

2013-04-24
Office of the Vice-Rector-Academic Kantoor van die Viserektor. Akademies
Sheila Steinbrenner, $\mathrm{PhD}(\mathrm{c}), \mathrm{RN}$

Doctoral Candidate

School of Nursing, K Building

University of Louisville

Louisville, KY 40292

Sandra Ferreira, PhD

Senior Lecturer

Department of Social Work

University of the Free State

Bloemfontein, South Africa 9301
VRA/2013/47

\author{
Celeste Shawler, PhD, PMHCNS-BC \\ Associate Professor \\ School of Nursing, K Building \\ University of Louisville \\ Louisville, KY 40292 \\ Vicki Hines-Martin, PhD, CNS, RN, FAAN \\ Professor \\ School of Nursing, K Building \\ University of Louisville \\ Louisville, KY 40292
}

Dear Ms. Steinbrenner, Dr. Shawler, Dr. Ferreira, and Dr. Hines-Martin,

UTILIZATION OF THE UNIVERSITY OF THE FREE STATE AS A RESEARCH SITE

This is a letter of support for the utilization of the University of the Free State, Bloemfontein, Free State, South Africa, as a research site for the recruitment of research participants and for the conduction of interviews with research participants by Ms. Steinbrenner.

Additionally, this is a letter of consent. We give Ms. Steinbrenner consent to conduct her research at the University of the Free State, Bloemfontein, Free State, South Africa. We understand this research concerns the lived experience of help-seeking behaviors of South African women after sexual offence victimization.

The purpose of this research is to explore the lived experience of help-seeking behaviors of South African women after being victimized by a sexual offence. We understand we will introduce Ms. Steinbrenner's study to individuals for who we have provided care - (Health and Wellness Centre Social Work). Additionally, we will provide those individuals with Ms. Steinbrenner's contact information. We understand those of our students/clients who agree to participate in Ms. Steinbrenner's research will be interviewed at our facility on three separate occasions by Ms. Steinbrenner.
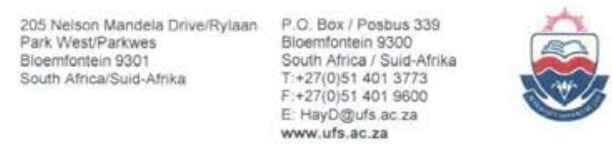
We further understand we will not be conducting the informed consent process with potential study participants, the informed consent process may only be conducted by Ms. Steinbrenner. Additionally, only Ms. Steinbrenner will be conducting interviews with study participants.

Human Subjects protection will be overseen by the University of Louisville, Institutional Review Board (IRB), in conjunction with any human subject's protection oversight we deem required. We understand the IRB at the University of Louisville will follow United States federal guidelines for human subject's protection, in addition to any human subjects protection guidelines required by the South Africa government and/or the University of the Free State. We also understand the research will be conducted in an ethical manner with the upmost respect for all involved

The University of the Free State, Bloemfontein, Free State, South Africa, appreciates the opportunity to participate in the research being conducted by Ms. Steinbrenner, under the oversight of Dr. Sandra Ferreira, University of the Free State, Bloemfontein, South Africa, Dr. Celeste Shawler, University of Louisville, Louisville, Kentucky, US and Dr. Vicki Hines-Martin, University of Louisville, Louisville, Kentucky, US.

Sincerely,

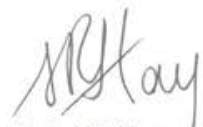

Prof. HR Hay

Vice-Rector: Academic
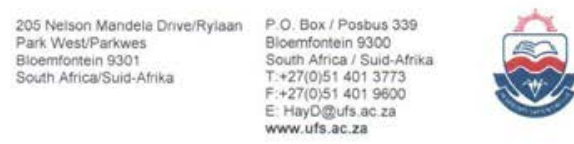


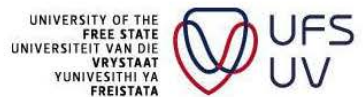

April 24, 2013

Sheila Steinbrenner, $\mathrm{PhD}(\mathrm{c}), \mathrm{RN}$

Doctoral Candidate

School of Nursing, K Building

University of Louisville

Louisville, KY 40292

Celeste Shawler, PhD, PMHCNS-BC

Associate Professor

School of Nursing, K Building

University of Louisville

Louisville, KY 40292

Sandra Ferreira, $\mathrm{PhD}$

Senior Lecturer

Department of Social Work

University of the Free State

Bloemfontein, South Africa 9301

Vicki Hines-Martin, PhD, CNS, RN, FAAN

Professor

School of Nursing, K Building

University of Louisville

Louisville, KY 40292

Dear Ms. Steinbrenner, Dr. Shawler, Dr. Ferreira, and Dr. Hines-Martin,

This is a letter of support for the utilization of the Health and Wellness

Centre, University of the Free State, Bloemfontein, Free State, South Africa, as a research site for the recruitment of research participants and for the conduction of interviews with research participants by Ms. Steinbrenner.

Additionally, this is a letter of consent. We give Ms. Steinbrenner consent to conduct her research at the Health and Wellness Centre, University of the Free State, Bloemfontein, Free State, South Africa. We understand this research concerns the lived experience of help-seeking behaviors of South African women after sexual offence victimization.

The purpose of this research is to explore the lived experience of help-seeking behaviors of South African women after being victimized by a sexual offence. We understand we will introduce Ms. Steinbrenner's study to individuals for who we have provided care - (Health and Wellness Centre - Social Work). Additionally, we will provide those individuals with Ms. Steinbrenner's contact information. We

Health and Wellness Centre iSentrum vir Gesondheid en Welstand

205 Nelson Mandela Drive/Rylaan. Park West'Parkwes, Bloemfontein 9301, South Africa/Suid-Afrika

PoxiPosbus 339 (IB 14). Bloemfontein 9300, South Africa/Suid-Afrika, T: +27(0)51 4013258 , Fi + 27(0)51 4012480

unw ufs ac za 


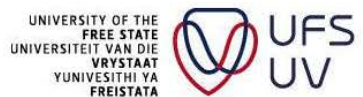

understand those of our students/clients who agree to participate in Ms. Steinbrenner's research will be interviewed at our facility on three separate occasions by Ms.

Steinbrenner. We further understand we will not be conducting the informed consent process with potential study participants, the informed consent process may only be conducted by Ms. Steinbrenner. Additionally, only Ms. Steinbrenner will be conducting interviews with study participants.

Human Subjects protection will be overseen by the University of Louisville, Institutional Review Board (IRB), in conjunction with any human subject's protection oversight we deem required. We understand the IRB at the University of Louisville will follow United States federal guidelines for human subject's protection, in addition to any human subjects protection guidelines required by the South Africa government and/or the University of the Free State. We also understand the research will be conducted in an ethical manner with the upmost respect for all involved.

The Health and Wellness Centre, University of the Free State,

Bloemfontein, Free State, South Africa, appreciates the opportunity to participate in the research being conducted by Ms. Steinbrenner, under the oversight of Dr. Sandra Ferreira, University of the Free State, Bloem fontein, South Africa, Dr. Celeste Shawler, University of Louisville, Louisville, Kentucky, US and Dr. Vicki HinesMartin, University of Louisville, Louisville, Kentucky, US.

Sincerely,

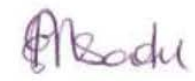

Mrs. Elizabeth Msadu

Assistant Director: Social worker

SACSSP REG NO: 1022928

University of the Free State

205 Nelson Mandela Drive

Park West

Bloemfontein

9301

South Africa 


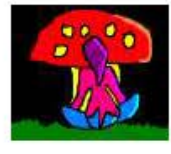

SEROBE CRISIS CENTRE

\section{P. O. Box 13845 NOORDSTAD 9302}

serobe.crisis.centre@gmail.com

(051) 4474566 (office) (051) 4475344 (Fax)

Cell: 0839580602

April 22, 2013

Sheila Steinbrenner, $\mathrm{PhD}(\mathrm{c}), \mathrm{RN}$

Doctoral Candidate

School of Nursing, $\mathrm{K}$ Building

University of Louisville

Louisville, KY 40292

Celeste Shawler, $\mathrm{PhD}, \mathrm{PMHCNS}-\mathrm{BC}$

Associate Professor

School of Nursing, $\mathrm{K}$ Building

University of Louiswille

Louisville, KY 40292

Sandra Ferreira, $\mathrm{PhD}$

Senior Lecturer

Department of Social Work

University of the Free State

Bloemfontein, South Africa 9301

Vicki Hines-Martin, PhD, CNS, RN, FAAN

Professor

School of Nursing, $\mathrm{K}$ Building

University of Louisville

Louisville, KY 40292 
Dear Ms. Steinbrenner, Dr. Shawler, Dr. Ferreira, and Dr. Hines-Martin,

This is a letter of support for the utilization of Serobe Crisis Centre,

Bloemfontein, South Africa, as a research site for the recruitment of research participants and for the conduction of interviews with research participants by Ms. Steinbrenner.

Additionally, this is a letter of consent. We give Ms. Steinbrenner consent to conduct her research at Serobe crisis Centre, Bloemfontein, South Africa. We understand this research concerns the lived experience of help-seeking behaviors of South African women after sexual offence victimization.

The purpose of this research is to explore the lived experience of help-seeking behaviors of South African women after being victimized by a sexual offence. We understand we will introduce Ms. Steinbrenner's study to individuals for who we have provided care. Additionally, we will provide those individuals with Ms. Steinbrenner's contact information. We understand those of our clients who agree to participate in Ms. Steinbrenner's research will be interviewed at our facility on three separate occasions by Ms. Steinbrenner. We further understand we will not be conducting the informed consent process with potential study participants, the informed consent process may only be conducted by Ms. Steinbrenner. Additionally, only Ms. Steinbrenner will be conducting interviews with study participants.

Human Subjects protection will be overseen by the University of Louisville, Institutional Review Board (IRB), in conjunction with any human subject's protection oversight we deem required. We understand the IRB at the University of Louisville will follow United States federal guidelines for human subject's protection, in addition to any human subjects protection guidelines required by the South Africa government and/or the University of the Free State. We also understand the research will be conducted in an ethical manner with the upmost respect for all involved

The Serobe Crisis Centre, Bloemfontein, South Africa, appreciates the opportunity to participate in the research being conducted by Ms. Steinbrenner, under the oversight of Dr. Sandra Ferreira, University of the Free State, Bloemfontein, South Africa, Dr. Celeste Shawler, University of Louisville, Louisville, Kentucky, US and Dr. Vicki Hines-Martin, University of Louisville, Louisville, Kentucky, US.

Sincerely.

Mrs Stephanie Pretorius

(B.A. Social Work (US); Hons. B.A. Medical and Psychiatric Social Work (US))

PROJECT MANAGER/REGISTERED SOCIAL WORKER (SACSSP 10-11677)

Serobe Crisis Centre

PO Box 13845

NOORDSTAD

9302

SOUTH AFRICA

Phone number: (+27 51) 4474566

Fax number: (+2751) 4475344

Email address: serobe.crisis.centre@gmail.com 

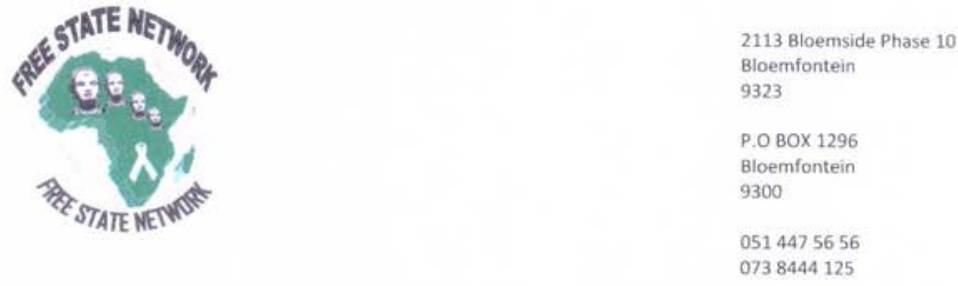

April 22, 2013

Sheila Steinbrenner, $\mathrm{PhD}(\mathrm{c}), \mathrm{RN}$

Doctoral Candidate

School of Nursing, K Building

University of Louisville

Louisville, KY 40292

Celeste Shawler, PhD, PMHCNS-BC

Associate Professor

School of Nursing, K Building

University of Louisville

Louisville, KY 40292

Sandra Ferreira, PhD

Senior Lecturer

Department of Social Work

University of the Free State

Bloemfontein. South Africa 9301

Vicki Hines-Martin, PhD, CNS, RN, FAAN

Professor

School of Nursing, K Building

University of Louisville

Louisville, KY 40292

Dear Ms. Steinbrenner, Dr. Shawler, Dr. Ferreira, and Dr. Hines-Martin.

This is a letter of support for the utilization of Free State Network on Violence Against Women and Children, Bloemfontein, South Africa,as a research sitefor the recruitment of research participants and for the conduction of interviews with research participants by Ms. Steinbrenner.

Additionally, this is a letter of consent. We give Ms. Steinbrenner consent to conduct her research atFree State Network on Violence Against Women and Children, Bloemfontein, South Africa. We understand this research concerns the lived experience of help-seeking behaviors of South African women after sexual offence victimization. 
The purpose of this research is to explore the lived experience of help-seeking behaviors of South African women after being victimized by a sexual offence. We understand we will introduce Ms. Steinbrenner's study to individuals for who we have provided care. Additionally, we will provide those individuals with Ms. Steinbrenner's contact information. We understand those of our clients who agree to participate in Ms. Steinbrenner's research will be interviewed at our facility on three separate occasions by Ms. Steinbrenner. We further understand we will not be conducting the informed consent process with potential study participants. the informed consent process may only be conducted by Ms. Steinbrenner. Additionally, only Ms.

Steinbrenner will be conducting interviews with study participants.

Human Subjects protection will be overseen by the University of Louisville, Institutional Review Board (IRB), in conjunction with any human subject's protection oversight we deem required. We understand the IRB at the University of Louisville will follow United States federal guidelines for human subject's protection, in addition to any human subjects protection

guidelines required by the South Africa government and/or the University of the Free state. We also understand the research will be conducted in an ethical manner with the upmost respect for all involved.

The Free State Network on Violence Against Women and Children, Bloemfontein, South Africa,appreciates the opportunity to participate in the research being conducted by Ms. Steinbrenner, under the oversight of Dr. Sandra Ferreira, University of the Free State,

Bloemfontein, South Africa, Dr. Celeste Shawler, University of Louisville, Louisville, Kentucky, US and Dr. Vicki Hines-Martin, University of Louisville, Louisville. Kentucky, US.

Sincerely,

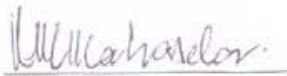

Name: A.M Mahasela.

Diretor

On Behalf of Free State Network On Violence Against Women and Children

PO Box 1296

BLOEMFONTEIN

9300

SOUTH AFRICA

Phone number: (+27 51) 4475656

Email address: fsnvaw@mweb.co.za

Physical Adress

President Building

St Andrews Street

Bloemfontein

9301

Forth Floor

Room 407 


\section{MATJHABENG RAPE INTERVENTION CARE CENTRE}

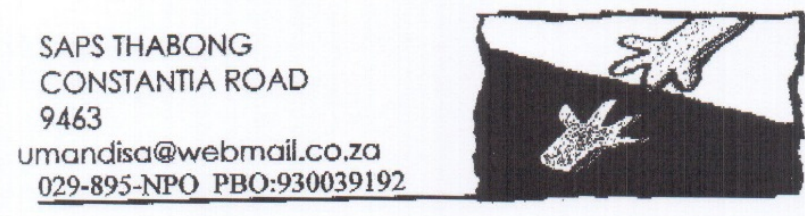

SAPS THABONG

CONSTANTIA ROAD

umandisa@webmail.co.za

029-895-NPO PBO:930039192
P.O. BOX 2932

WELKOM

9460

TEL: (057) 9102370

CELL NO. 0721581838

April 7, 2013

Sheila Steinbrenner, $\mathrm{PhD}(\mathrm{c}), \mathrm{RN}$

Doctoral Candidate

School of Nursing, K Building

University of Louisville

Louisville, KY 40292

Celeste Shawler, $\mathrm{PbD}$, PMHCNS-BC

Associate Professor

School of Nursing, K Building

University of Louisville

Louisville, KY 40292

Sandra Ferreira, $\mathrm{PhD}$

Senior Lecturer

Department of Social Work

University of the Free State

Bloemfontein, South Africa 9301

Vicki Hines-Martin, PhD, CNS, RN, FAAN

Professor

School of Nursing, K Building

University of Louisville

Louisville, KY 40292

Dear Ms. Steinbrenner, Dr. Shawler, Dr. Ferreira, and Dr. Hines-Martin,

This is a letter of support for the utilization of the MATJHABENG RAPE AND INTERVENTION

$C A R E C E N T R E$, as a research site for the recruitment of research participants and for the conduction of interviews with research participants by Ms. Steinbrenner.

Additionally, this is a letter of consent. We give Ms. Steinbrenner consent to conduct her research at the MATJHABENG RAPE AND INTERVENTION CARE CENTRE. We understand this research concerns the lived experience of help-seeking behaviors of South African women after sexual offence victimization.

The purpose of this research is to explore the lived experience of help-seeking behaviors of South African women after being victimized by a sexual offence. We understand we will introduce Ms.

Steinbrenner's study to individuals for who we have provided care. Additionally, we will provide those individuals with Ms. Steinbrenner's contact information. We understand those of our clients who agree to participate in Ms. Steinbrenner's research will be interviewed at our facility on three separate occasions by Ms. Steinbrenner. We further understand we will not be conducting the informed consent process with potential study participants, the informed consent process may only be conducted by Ms. Steinbrenner. Additionally, only Ms. Steinbrenner will be conducting interviews with study participants.

Human Subjects protection will be overseen by the University of Louisville, Institutional Review Board (IRB), in conjunction with any human subject's protection oversight we deem required. We understand the IRB 
addition to any human subjects protection guidelines required by the South Africa government and/or the University of the Free state. We also understand the research will be conducted in an ethical manner with the upmost respect for all involved.

The MATJHABENG RAPE AND INTERVENTION CARE CENTRE appreciates the opportunity to participate in the research being conducted by Ms. Steinbrenner, under the oversight of Dr. Sandra Ferreira, University of the Free State, Bloemfontein, South Africa, Dr. Celeste Shawler, University of Louisville, Louisville, Kentucky, US and Dr. Vicki Hines-Martin, University of Louisville, Louisville, Kentucky, US.

Sincerely,

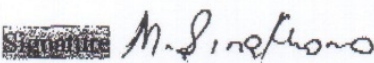

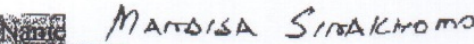

(6)

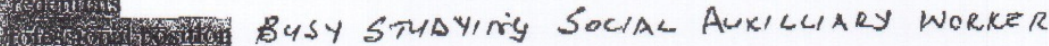

MATJHABENG RAPE AND INTERVENTION CARE CENTRE

P.O. Box 2932

Welkom

South Africa

9460

Phone number: (+27 57) 9102370

Email address: umandisa@webmail.co.za

Yours truly,

Mandisa Sinakhomo

Project Manager 


\section{Appendix C}

\section{Informed Consent}

\section{Subject Informed Consent Document}

The Lived Experience of Help-Seeking Behaviors of South African Women after Sexual Offence Victimization

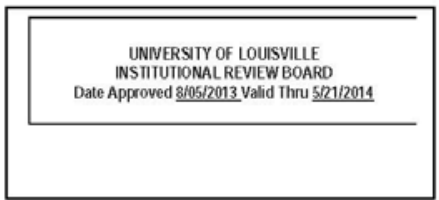

IRB assigned number: 13.0251

Investigators names \& addresses:

\begin{tabular}{|l|l}
\hline Sandra Ferreira, PhD, MSW & Sheila Young Steinbrenner BSN, RN \\
Senior Lecturer, Department of Social Work & Celeste Shawler, PhD, PMHCNS-BS \\
University of the Free State & 555 S. Floyd Street HSC K Building \\
Bloemfontein, South Africa & University of Louisville \\
South Africa & Louisville, Kentucky 40202, USA \\
Phone: $+27-51-401-2760$ & Phone: $01502-852-8391$ (US)
\end{tabular}

Sites where study is to be conducted:

\begin{tabular}{|l|l|}
\hline $\begin{array}{l}\text { Serobe Crisis Centre } \\
\text { PO Box } 13845 \text { North City } \\
\text { Bloemfontein, South Africa } 9302\end{array}$ & $\begin{array}{l}\text { Free State Network on Violence against Women } \\
20 \text { Aliwal Street } \\
\text { Bloemfontein, South Africa } 9300\end{array}$ \\
\hline $\begin{array}{l}\text { Matjhabeng Rape Intervention Care Centre } \\
11767 \text { Oppenheimer Park, Matima Road } \\
\text { Welkom, South Africa } 9463\end{array}$ & $\begin{array}{l}\text { University of Free State } \\
\text { Park West } \\
\text { Bloemfontein, South Africa } 9301\end{array}$ \\
\hline
\end{tabular}

Phone number for subjects to call with questions: Dr. Sandra Ferreira $+27-51-401-2760$

\section{Introduction and Purpose}

- You are invited to participate in a research study being done by Sheila Young Steinbrenner.

- The purpose of this study is to talk to women about when they looked for help after rape or sexual assault.

\section{Procedures}

- You will be asked to do 3 interviews (about 1 hour each) at times good for you.

- Interviews will be recorded.

- You do not have to answer any interview questions that you do not want to answer.

- You may have a service provider in the room during the interview if you want.

\section{Risks}

- There could be a risk of mental distress if you do the interviews.

- There may be other risks that we do not know about yet.

\section{Research Related Mental Distress}

- If you have mental distress while you are in this study, because you are in this study, you will be helped, please call Dr. Sandra Ferreira at +27-51-401-2760.

\section{Benefits}

- Benefits of this study may include learning more about services.

$07 / 31 / 13 \quad$ Page 1 of 3 
THE LIVED EXPERIENCE OF HELP-SEEKING BEHAVIORS OF SOUTH AFRICAN WOMEN AFTER SEXUAL OFFENCE VICTIMIZATION

- The information you give may not help you directly, but it may help others.

\section{Compensation}

- You will be paid R100 in cash for each interview.

- If you do not want to answer some of the interview questions you will still be paid R100 for doing the interview.

- If you do not want to do an interview you will not be paid for that interview.

\section{Confidentiality}

- Complete privacy cannot be guaranteed.

- Your privacy will be protected as much as the law will allow.

- If the results of this study are published your name or location will not be used.

- It probably won't happen, but so you know the following may look at the study records:

- The University of Louisville Institutional Review Board/The Human Subjects Protection Program Office

- People who are responsible for research where the study is being done.

- Office of Human Research Protections (OHRP).

- Study information will be kept on the researchers password protected computer.

- Any other study information will be locked in a cabinet at the University of the Free State.

\section{Voluntary Participation}

- Being in this study is voluntary.

- You do not have to be in this study at all.

- If you decide to be in this study you can leave it at any time.

- If you decide not to be in this study or if you stop taking part at any time, you will not lose any benefits you may qualify for.

Research Subject's Rights, Questions, Concerns, and Complaints

If you have any concerns or complaints about the study or the study staff, you have 4 options.

1. You may call Dr. Sandra Ferreira $+27-51-401-2760$ (South Africa)

2. You may contact the principal investigator Dr. Celeste Shawler at 01 502-852-8391 (US)

3. To discuss your rights, questions, concerns or complaints, you may call the Human Subjects Protection Program Office (HSPPO) 01-502- 852-5188. At that number you may speak secretly with a member of the Institutional Review Board (the committee that reviewed this study).

4. To talk secretly to a person who does not work at the University of Louisville you may call 01-877-852-1167. You will be given the chance to talk about any questions, concerns or complaints in secret. This is a 24 hour hot line answered by people who do not work at the University of Louisville. 
THE LIVED EXPERIENCE OF HELP-SEEKING BEHAVIORS OF SOUTH AFRICAN WOMEN AFTER SEXUAL OFFENCE VICTIMIZATION

- When you sign your signature, it means that this study has been discussed with you, that your questions have been answered, and that you will take part in the study.

- This informed consent document is not a contract.

- You are not giving up any legal rights by signing this informed consent document.

- You will be given a signed copy of this paper to keep for your records.

Signature of Subject

Date Signed

Signature of Person Explaining the Consent Form

Date Signed

(if other than the Investigator)

Signature of Investigator

Date Signed

LIST OF INVESTIGATORS

PHONE NUMBERS

Dr. Sandra Ferreira

+27-51-401-2760 (South Africa)

Sheila Young Steinbrenner

Dr. Celeste Shawler

01-877-816-8773 (US)

01-502-852-8391 (US)

UNIVERSITY OF LOUISVILLE INSTITUTIONAL REVIEW BOARD Date Approved 8/05/2013 Valid Thru 5/21/2014 


\section{Appendix D}

\section{Demographic Data Collection Form}

Are you: (check all that are appropriate)

- Student

- Employed

- Not currently working

- Retired

- If you are employed what is you job?

Approximately how much money do you make each week?

\section{Relationship Status:}

- Single

- Married

- Divorced

- Widowed

- In a relationship

\section{Do you live in a:}

- Home

- Apartment

- Hostel

- Other (describe)

Household:

How many people live in your household? Female Male

Do children live in your household?

- Yes

$\circ$ No

If yes, how many children live in your household?

Weekly Income

Estimate how much your weekly total household income is

$08 / 03 / 13$ 
Date of Interview:

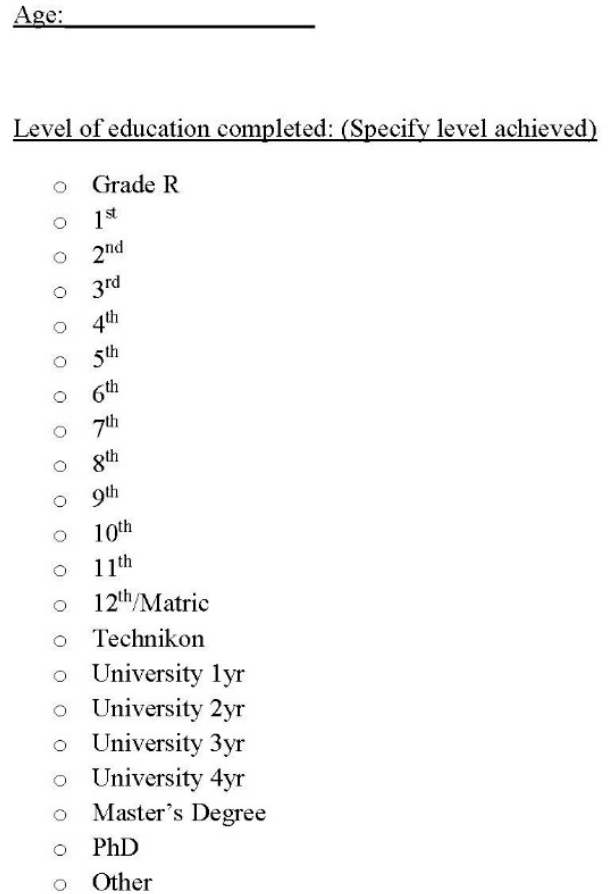

$08 / 03 / 13$ 
Appendix E

Interview Guide

\section{First Interview:}

1. What made you decide to seek help?

a. Tell me about the person/s you talked to about your experience?

b. Did you discuss your experience with someone in your family, a friend, or did you talk to your partner?

c. Tell me about your culture's viewpoint on a seeking help in situations like this?

d. What are your thoughts on seeking help?

2. How did you decide where you wanted to go for help?

a. Did you have a choice of where you could go for help?

b. Tell me more about what made you decide on where you wanted to go for help.

3. Once you decided to seek help, what did you do?

a. Did you immediately go for help, or did you wait to seek help?

i. If you went immediately, what made you decide you wanted to go immediately?

ii. If you waited what made you decide to wait?

1. How long did you wait?

\section{Second/Third Interviews}

1. We are going to continue to discuss your help-seeking experience. My first question is where did you go for help?

a. Tell me about the distance you had to travel to seek help?

b. If you traveled far describe your travel experience.

i. How did you get to the place you went for help, what kind of transportation did you use?

ii. Did you have to pay for you transportation?

2. If you found help locally (or close to your home) what kind of help was available in your community?

a. How did you get there?

b. Tell me more about getting to where you were going for help?

3. Tell me more about the place you went for help?

a. Describe the place?

i. Was it a clinic, a hospital, what kind of place was it?

ii. Tell me about the actual building where you went for help.

b. How safe did you feel where you went? 
c. Did they have a place for you to wait?

i. Was it a private space or were there a lot of people around you?

d. Tell me more about the place you went for help.

e. Who were the people there who helped you?

i. How many people helped you?

ii. Tell me more about the people who helped you.

4. How long did you have to wait before someone helped you?

a. Tell me about the time while you were waiting?

b. What were you thinking about?

c. Did you feel safe while you waited?

d. Did someone wait with you?

e. Tell me more about waiting for help?

\section{Describe how the people helped you.}

a. Did they do an exam?

b. Did they talk to you about post-exposure prophylaxis (PEP) for HIV?

c. Did they give an HIV test?

d. If you received an HIV test, did they counsel you about the results?

e. Were legal options discussed with you?

6. Once you were helped, where did you go next?

a. Did you go home, or to the place where you were staying at that time?

b. If you did not go home, or the place you were staying, where did you go?

7. How did you get home?

a. Did you walk, take a bus, car, and if in a car was your car or was it someone else's car?

b. If you were driven home in someone else's car, whose car was it?

c. How safe did you feel?

d. Tell me more about what you felt like in the 24 hours after leaving the place where you received help.

\section{Let's discuss the legal process you went through.}

a. Did you file a docket?

b. Where was your case heard?

c. Who represented you?

d. Was the court a regular court or a sexual offences court?

9. Details about court proceedings

a. How many times have you or did you go to court?

b. Has your case been closed?

c. What was the final outcome?

d. Did the perpetrators go to jail?

e. If so what was their sentence 
10. In regard to each situation you came into contact with while in your process of help-seeking what did you find most helpful?

a. Describe more about how they were helpful.

11. In regard to each professional you came into contact with while in your process of help-seeking who did you find most helpful?

a. Describe more about how they were helpful.

12. In regard to each situation or professional you came into contact with while in your process of help-seeking who did you find that was not at all helpful?

a. Describe more about how these people who were problematic

13. In regard to each situation what did you find that caused you problems?

a. Describe more about how your experiences where problematic.

14. What advice would you give to others regarding help-seeking?

15. From all that you have learned/experienced while help-seeking is there anything you continue to use?

16. What have you implemented to assist you as you move forward?

17. If more counseling was available would you want it?

18. What would you suggest regarding help-seeking services?
a. Medical?
b. Mental health?
c. Police?
d. The legal system/courts?

Tell me how your life is going now. 
Appendix F

Batho Pele Principles

Batho Pele Principles (White Paper on Transforming, 1997) are eight principles that guide public service delivery.

The principles are:

(1) Consultation, citizens should be consulted about the level and quality of services they receive and whenever possible, should be given a choice about the services they are offered;

(2) Service standards, citizens should be told what level and quality of public services they will receive so they know what to expect;

(3) Assess, all citizens should have equal access to the services to which they are entitled;

(4) Courtesy, citizens should be treated with courtesy and consideration;

(5) Information, citizens should be given full, accurate information about the public services they are entitled to receive;

(6) Openness and transparency, citizens should be told how national and provincial departments are run, how much they cost, and who is in charge;

(7) Redress, if the promised standard of service is not delivered, citizens should be offered an apology, a full explanation and a speedy and effective remedy, and when complaints are made citizens should receive a sympathetic, positive response;

(8) Value for money, public services should be provided economically and efficiently in order to give citizens the best possible value for the money. 


\section{CURRICULUM VITAE}

Sheila Young Steinbrenner, $\mathrm{PhD}$ Candidate, $\mathrm{RN}$ 238 Rosemont Garden Lexington, Kentucky, 40503

(502) 553-9842

systei01@louisville.edu

$\underline{\text { sheila.steinbrenner@gmail.com }}$

\section{Education}

7/2012 - Present $\quad$ PhD Doctoral Candidate, Nursing School of Nursing, University of Louisville Louisville, Kentucky

Dissertation Defense 5/28/2014

7/2009-7/2012 PhD Doctoral Student, Nursing

School of Nursing, University of Louisville

Louisville, Kentucky

$5 / 2007$

Bachelor of Science, Nursing

School of Nursing, University of Louisville

Louisville, Kentucky

$5 / 1985$

Diploma in Commercial Art

Central Academy of Commercial Art

Cincinnati, Ohio 


\title{
Other employment
}

\author{
1/2012 - 1/2014 Graduate Teaching Assistant \\ School of Nursing, University of Louisville \\ Louisville, Kentucky \\ 10/2009 - 12/2011 Graduate Research Assistant \\ School of Nursing Research Office, University of Louisville \\ Louisville, Kentucky \\ 1/2012 - 08/2013 Registered Nurse \\ Critical Care, Norton Clinical Agency \\ Louisville, Kentucky \\ 5/2007 - 09/2011 Registered Nurse \\ Critical Care Unit, Norton Suburban Hospital \\ Louisville, Kentucky \\ 9/2008 - 5/2009 Project Director \\ School of Nursing, University of Louisville \\ Project Director on study conducted by School of Nursing Faculty \\ Louisville, Kentucky \\ 5/2008 - 9/2008 Research Assistant \\ Research Assistant to School of Nursing Faculty \\ School of Nursing, University of Louisville \\ Louisville, Kentucky \\ 7/2006 - 4/2007 Certified Nursing Assistant \\ Telemetry Unit \\ Norton Suburban Hospital \\ Louisville, Kentucky \\ 7/2006 - 4/2007 Research Assistant \\ Research Assistant to School of Nursing Faculty \\ School of Nursing, University of Louisville \\ Louisville, Kentucky \\ 5/2006 - 7/2006 Nurse Extern \\ Paid Externship, Telemetry Unit
}


Norton Suburban Hospital

Louisville, Kentucky

5/2001 - 6/2002 Creative Services Manager/Interface Designer

Corvus Digital

Louisville, Kentucky

9/2000 - 5/2001 Information Architect

Corvus Digital

Louisville, Kentucky

11/1999 - 9/2000 New Media Creative Manager

Kinetic Corporation

Louisville, Kentucky

10/1998 - 10/1999 Director of New Media/Interactive Designer

The Health Network,

Nashville, Tennessee

1998

Interactive Media Specialist

Freelance

Lexington, Kentucky

1996 - 1998 Director of New Media/Interactive Creative Director

Hammond Communications Group

Lexington, Kentucky

$1995-1996 \quad$ Art Director

University of Kentucky, Department of Engineering

Lexington, Kentucky

1986 - $1992 \quad$ Art Director

Foote, Cone \& Belding Advertising Agency

Chicago, Illinois

National Board Certification and state RN Licensure
5/2007 - Present
Registered Nurse
1114771
Kentucky - Active
2006 - Present
Basic Life Saving Certified 
2008 - Present $\quad$ Advanced Cardiovascular Life Support Certified

\section{Professional Memberships and Activities}

$\begin{array}{ll}2010-\text { Present } & \text { Southern Nursing Research Society } \\ 2009-\text { Present } & \text { Midwest Nursing Research Society } \\ 2009-\text { Present } & \text { Sigma Theta Tau International } \\ 2009-2010 & \text { AcademyHealth } \\ 2005-2007 & \begin{array}{l}\text { National Student Nurses Association } \\ \text { University of Louisville } \\ \end{array} \\ & \text { Louisville, Kentucky }\end{array}$

Honors and Awards

$3 / 2014$

2014 MNRS Graduate Student Research Scholars’ Award Midwest Nursing Research Society Annual Conference

St. Louis, Missouri

1/2014 - 5/2014 Doctoral Dissertation Completion Award

University of Louisville

Louisville, Kentucky

2008 - Present $\quad$ Golden Key Honor Society

5/2007 First Place Research Poster

Senior Research Poster Competition

School of Nursing, University of Louisville

Louisville, Kentucky

1993

Oswald Award

Creativity

University of Kentucky

Lexington, Kentucky

Journal Editorial Boards, Advisory Councils, Peer Reviewer of Manuscripts

8/2010 - Present $\quad$ Student Peer Reviewer

Issues in Mental Health Nursing

\section{Invited Lecturer}


$10 / 2013$

Dissertation Research Project \& Qualitative Research Methods

GTN 708 Feminist Theories

Department of Gender Studies

University of the Free State, Bloemfontein, South Africa

$11 / 2011$

Sexual Assault Services and Services Providers Pilot Study Project Forensic Nursing

School of Nursing

University of the Free State, Bloemfontein, South Africa

\section{Poster Presentations: Regional}

$4 / 2014$

$2 / 2012$

$4 / 2011$

$4 / 2010$
$2 / 2012$

$2 / 2011$

$4 / 2010$

\section{Research Grants}

Steinbrenner, S. Y. The Lived Experience of the Help-Seeking Behaviors of South African Women after Sexual Offence Victimization. Midwest Nursing Research Society Annual Conference. St. Louis, Missouri

Steinbrenner, S. Y. Sexual Assault Services and Service Providers in the Free State Province, South Africa. Southern Nursing Research Society Annual Conference. New Orleans, Louisiana

Steinbrenner, S. Y. International Adolescent Mental Health Treatment: A Limited Systematic Review. Midwest Nursing Research Society Annual Conference. Columbus, Ohio

Steinbrenner, S. Y., Logsdon, M. \& Usui, W. Measurement of Exposure to Community Violence in Adolescent Mothers. Midwest Nursing Research Conference, Kansas City, Missouri
Ruth Craddock Research Grant $\$ 600.00$. Research Poster Presentation. Southern Nursing Research Society Annual Conference. New Orleans, Louisiana.

Ruth Craddock Research Grant \$600.00. Research Poster Presentation. Midwest Nursing Research Society Annual Conference. Columbus, Ohio.

Ruth Craddock Research Grant. \$600.00. Research Poster Presentation. Midwest Nursing Research Society Annual Conference. Kansas City, Missouri

\section{Program/Training Grants}



(Sexual Violence Research Initiative) Forum 2013. International Conference.

Bangkok, Thailand

$10 / 2011$

Ruth Craddock Mentored Conference Grant \$500.00. SVRI Forum 2011. International Conference.

Cape Town, South Africa

$4 / 2010$

Ruth Craddock Mentored Conference Grant. \$500.00.

AcademyHealth National Conference, Boston, Massachusetts.

\section{Peer Reviewed Publications}

$1 / 2010$

Steinbrenner, S. Y. (2010). Concept Analysis of Community Violence: Using Adolescent Exposure to Community Violence as an Exemplar. Issues in Mental Health Nursing, (31)1, 4-7. 